\title{
SEAFLOOR RIPPLES CREATED BY WAVES FROM HURRICANE IVAN ON THE WEST FLORIDA SHELF
}

\author{
by \\ Colleen Marie Bowers \\ B.S., United States Naval Academy, 2004 \\ Submitted in partial fulfillment of the requirements for the degree of \\ MASTER OF SCIENCE \\ at the \\ MASSACHUSETTS INSTITUTE OF TECHNOLOGY \\ and the \\ WOODS HOLE OCEANOGRAPHIC INSTITUTION
}

September 2006

(c) Colleen Marie Bowers, 2006. All rights reserved.

The author hereby grants to MIT, WHOI, and the United States Navy permission to reproduce and to distribute copies of this thesis documents in whole or in part.

Author

Joint Program in Applied Ocean Physics and Engineering

Massachusetts Institute of Technology and Woods Hole Oceanographic Institution

Certified by

Peter A. Traykovski

Associate Scientist, Woods Hole Oeeaplographic Institution

Thesis Supervisor

Accepted by

Henrik Schmidt

Chairman, Joint Committee for Appliederean Science and Engineering Massachusetts Institute of Technology and Woods Hole Oceanographic Institution

Accepted by

Lallit Anand

Chairman, Graduate Committee

Massachusetts Institute of Technology 


\title{
SEAFLOOR RIPPLES CREATED BY WAVES FROM HURRICANE IVAN ON THE WEST FLORIDA SHELF
}

\author{
by \\ COLLEEN MARIE BOWERS \\ Submitted in partial fulfillment of the requirements for the degree of \\ Master of Science \\ at the Massachusetts Institute of Technology \\ and the Woods Hole Oceanographic Institution
}

\begin{abstract}
Recent studies have shown that the presence of sand ripples on the seabed improves sonar detection of buried mines at sub-critical angles. Sidescan sonar data of ripples off on the west Florida shelf were collected as part of ONR's Ripples Departmental Research Initiative (DRI) September 26-29 ${ }^{\text {th }}$ and November 7-9 ${ }^{\text {th }}, 2004$. Hurricane Ivan, the strongest storm of the 2004 hurricane season, passed over the experiment site a week before the first data collection. This study focuses on the ripples created by Ivan. Average relict ripple wavelengths left after the storm were found to increase with water depth $(50 \mathrm{~cm}, 62 \mathrm{~cm}$, and $83 \mathrm{~cm}$ in 20,30 , and 50 meter water depths) despite the fact that orbital diameter decreases with water depth.

Ripple prediction requires information about surface gravity waves and sediment grain size. The most reliable offshore wave field available was created with Wavewatch III by Naval Postgraduate School scientists. These waves were inputted into Delft3D WAVE, incorporating the nearshore wave model SWAN to predict waves at the locations where ripples were measured. Orbital motions at the seabed and grain size were inputted into a time-dependent ripple model with varying dissipation parameters to estimate sand ripples created by Hurricane Ivan. Ripple wavelength was found to be more strongly dependent on grain size than wave dissipation.
\end{abstract}

Thesis Supervisor: Peter A. Traykovski

Title: Associate Scientist 


\section{Acknowledgements}

My thesis advisor, Peter Traykovski, has been patient and helpful every step of the way. I have learned so much from him despite my short time in the Joint Program. I wouldn't have made it through even the first step of this endeavor without his support, and I appreciate all the time he spent working with me.

The Navy has offered me an amazing amount of opportunities already. Participating in this program has been another invaluable and irreplaceable experience. It would not have been possible without funding from the Oceanographer of the Navy and the Rear Admiral Richard F. Pittenger, USN (Ret) Fellowship.

It was difficult to be away from the people I love. The one person who kept me sane from day to day was Katie Silverthorne. She was my source of wisdom (and humor) when I needed answers about academics or life. Regardless of where our paths take us now, Katie will always be my best friend.

I owe everything I have to my parents. They have encouraged me through the tough times and helped me every step of the way. Beyond even their usual generosity, they spent countless hours organizing and preparing for my wedding this year, so I could focus on thesis and class work. I can never thank them enough for all they have given me.

I most certainly wouldn't have been able to finish this thesis without the love and support from my wonderful husband, Dan. He was patient and helpful all the way to the end of this endeavor. It was his faith in me that motivated me each day. 


\section{Contents}

1. Introduction 11

1.1 Background...................................................................

1.2 Mine Detection......................................................12

1.3 Sand Ripple Formation....................................................

2. Experiment 16

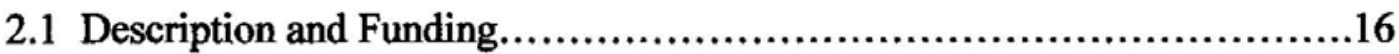

2.2 Data Collection Sites and Dates..........................................17

2.3 Instruments..............................................................

2.3.1 REMUS....................................................

2.3.2 Sidescan Sonar Description.................................23

$\begin{array}{ll}2.4 \text { Weather } & 24\end{array}$

2.4.1 Climatologic Data..........................................24

2.4 .2 Hurricane Ivan...............................................27

2.4.3 Wind Patterns Near Experiment Site...........................29

3. Sidescan Sonar Imagery of Ripples Analysis 34

3.1 Sidescan Sonar Resolution and Geometry..................................34

3.2 Ripples Analysis...............................................

3.2.1 Preliminary Analysis.......................................39

3.2.2 Spectral Analysis.............................................40

3.3 Ripple Analysis Results...........................................46

3.3.1 Ripple Wavelength.......................................48 


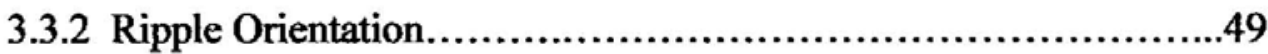

3.3.3 Comparison to USGS Ripple Analysis Results......................51

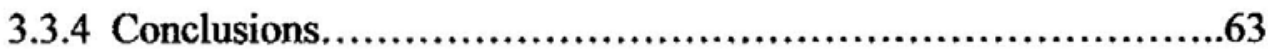

4. Wave Modeling and Analysis $\quad 64$

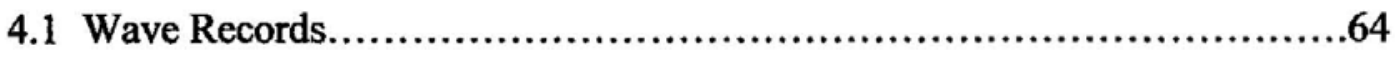

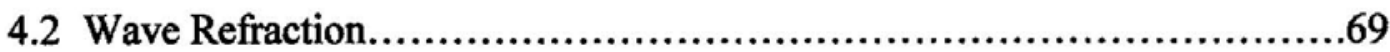

4.2.1 Wave Height Calculation from Statistics..........................70

4.2.2 Wave Height Calculation from Spectra...........................71

4.2.3 Comparison of Method Results...................................72

4.3 Wavewatch III Data.........................................................

4.3.1 Model Description................................................

4.3.2 Comparison of Model Output and Refraction Calculations.........75

4.3.3 Model Improvements..........................................

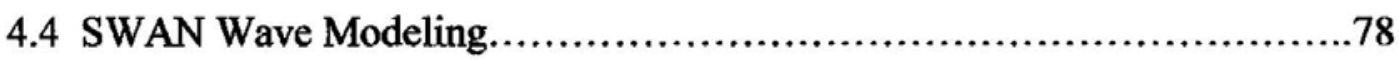

4.4.1 Model Description................................................

4.4.2 Comparison of Model Outputs....................................79

5. Synthesis of Wave and Ripple Analysis and Conclusions 83

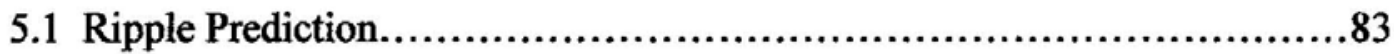

5.1.1 Orbital Properties Calculations......................................83

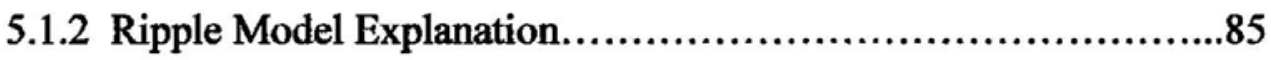

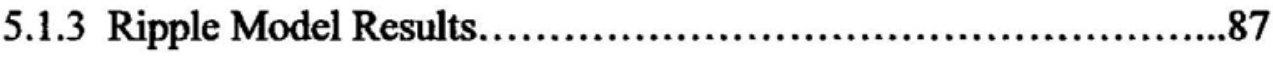

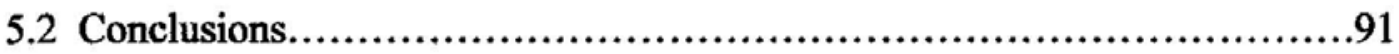




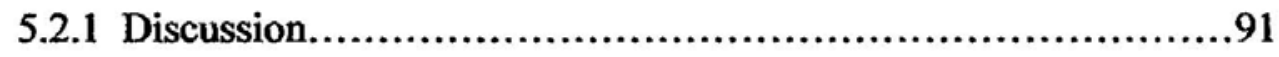

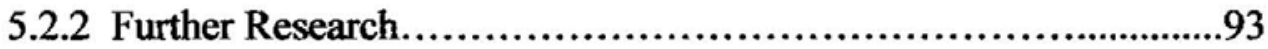




\section{List of Figures}

2-1 Locations of Site 7, Site 9, and REMUS deployments off the coast of Florida...18

2-2 REMUS vehicle with ADCP, sidescan sonar, and pencilbeam sonar............20

2-3 High resolution bathymetry with REMUS paths off the coast of Florida.........22

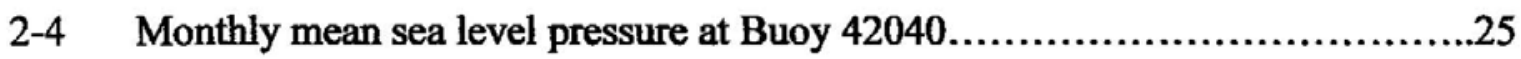

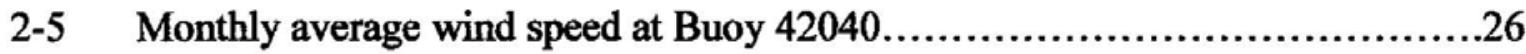

2-6 Hurricane Ivan tracking map...............................................

2-7 Pressure, wind speed, and wind direction at Buoy 42039 Sept-Nov............29

2-8 Pressure, wind speed, and wind direction at Buoy 42039 during Ivan...........30

2-9 Sea level pressure and wind at 1200 on September $15,2004 \ldots \ldots \ldots \ldots \ldots \ldots . .31$

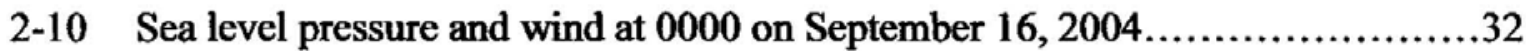

2-11 Sea level pressure and wind at 1200 on September $16,2004 \ldots \ldots \ldots \ldots \ldots \ldots \ldots . \ldots . \ldots . \ldots 33$

3-1 Diagram of sidescan sonar geometry.....................................35

3-2 Sidescan sonar image of a ripple field and mud.............................40

3-3 Typical sidescan sonar image with surface returns..........................42

3-4 Sidescan sonar image collected in $18 \mathrm{~m}$ water............................46

3-5 Sidescan sonar image collected in $33 \mathrm{~m}$ water..............................47

3-6 Sidescan sonar image collected in $50 \mathrm{~m}$ water............................47

3-7 Comparison of ripple wavelengths from manual and spectral methods..........48

3-8 Comparison of ripple orientations from manual and spectral methods...........50 
3-9 Matched USGS and WHOI September data collection sites.....................52

3-10 Matched USGS and WHOI November data collection sites.....................53

3-11 Enlarged view of matched nearshore collection sites in September................54

3-12 Enlarged view of matched nearshore collection sites in November...............55

3-13 Comparison of WHOI and USGS spectral calculations of ripple wavelength.....56

3-14 Linear comparison of USGS and WHOI ripple wavelength...................57

3-15 Comparison of WHOI and USGS spectral calculations of ripple orientation......59

3-16 Linear comparison of USGS and WHOI ripple orientation.....................60

3-17 Comparison of WHOI and USGS ripple orientations and sample sites...........61

3-18 Linear comparison of USGS and WHOI sites within $100 \mathrm{~km}$ of each other.......62

4-1 Locations of REMUS legs and NDBC Buoys 42003, 42039, and 42040 ........65

4-2 Wave heights during Hurricane Ivan at Site 7, and NDBC Buoys...............67

4-3 Matched Site 7 and NDBC Buoy 42039 wave heights............................68

4-4 Wave height and period during Hurricane Ivan at Site 7, and difference between statistical and spectral wave height calculations...............................73

4-5 Comparison of Wavewatch III and spectral refraction code calculations..........76

4-6 Comparison of Wavewatch III and Delft3D wave heights with a Collins

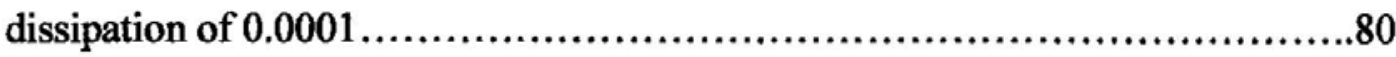

4-7 Comparison of Wavewatch III and Delf3D wave heights with a Collins

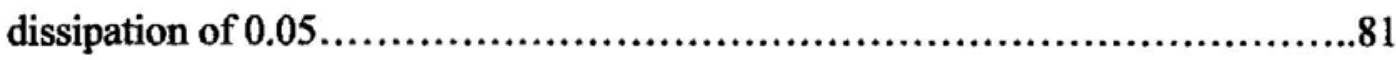

4-8 Comparison of Wavewatch III and Delft3D wave heights with a Collins

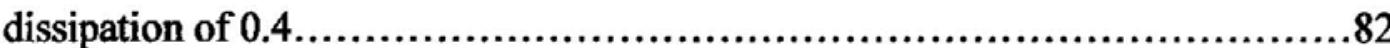


5-1 Orbital velocities and diameters predicted from a Collins dissipation of $0.05 \ldots . .85$

5-2 Model outputs of ripple wavelength according to grain size and dissipation

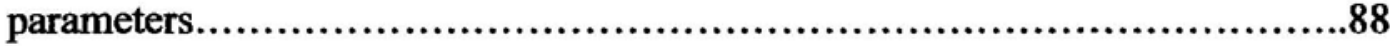

5-2 Difference in ripple wavelength according to grain size and dissipation parameters

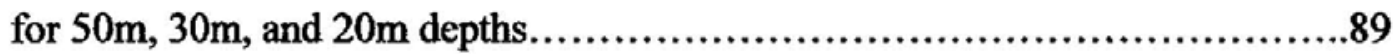

5-3 Measured and inferred grain sizes......................................90 


\section{Chapter 1}

\section{Introduction}

\subsection{Background}

Enemy sea mines have been responsible for 14 of the 19 Navy ships destroyed or damaged since 1950 . Therefore, improving sea mine detection is always a top priority for naval research. On March $10^{\text {th }}, 2005$, Rear Admiral Jay M. Cohen, Chief of Naval Research, addressed the Terrorism, Unconventional Threats and Capabilities Subcommittee of the House Armed Services Committee on Defense Science and Technology in support of the War on Terrorism, Transformation, and Beyond. RADM Cohen stated that,

"Because they are cheap, and able to seed the battle space with a menace far out of proportion to their numbers, mines have been and will continue to be deployed against us by terrorists and their state sponsors. We're working to give our forces an organic-that is to say, an inherent-and stand-off ability to detect, characterize, and neutralize mines wherever they may be encountered" 


\subsection{Mine Detection}

As U.S. Navy operations in the littoral increase, mine detection in shallow water becomes more and more important. However, current mine detection techniques have coverage limitations in shallow water. Therefore, many recent studies have been focused on examining using sonar with sub-critical incidence at the seabed (Schmidt, 1999). In the process of improving such techniques, it has been found that the presence of sand ripples on the seafloor enhances sonar penetration into the sediment at sub-critical acoustic angles (Chotiros, et al., 2002; Jackson, et al.,2002).

Specifically, ripple wavelength and orientation are critical parameters to reverberation frequency and insonification. Schmidt found in a recent study that "larger scale ripples encountered in deeper water will shift the reverberation "cut-off"' to a lower frequency, while shorter nearshore ripples will be associated with less low-frequency reverberation" (Schmidt, 1999). Schmidt also determined that "at low frequencies in particular, a dramatic, up to $60 \mathrm{~dB}$, reduction in reverberation power can be achieved by insonifying the seabed along the ripple direction." Therefore, predicting ripple properties is extremely important in detecting buried mines with sonar. If ripple properties can be reliably predicted, a sonar vehicle can take advantage of the seabed features by selecting the most favorable insonification direction. 


\subsection{Sand Ripple Formation}

Sand ripples on the ocean floor are ultimately caused by weather above the ocean's surface. Depending on the water depth and if the winds are strong enough, water particle movement due to waves can penetrate to the ocean floor. Water depth classifications depend on the ratio of water depth to the wavelength of surface gravity waves. For example, shallow water is defined as $\frac{H}{\lambda} \ll<1$, and deep water as $\frac{H}{\lambda} \gg>1$, where $H$ is water depth, and $\lambda$ is wavelength (Kundu and Cohen, 2004). While all water particles move in the same circular pattern at the surface of the water regardless of water depth, subsequent layers are affected differently. In deep water, the circular particle orbit decreases equally in all directions, resulting in the particle moving in smaller and smaller circles with depth. The orbital paths decrease exponentially until there is no turbulence in the water column from the surface waves. In shallow water however, particle orbital paths maintain their movement in the horizontal direction. Only the vertical component of the path is affected. Therefore, the orbits become more and more oval and elongated until flattening into horizontal linear paths. Particle motion in intermediate water is similar to both, with a larger decrease in vertical motion than horizontal diameter. The particle motion parallel to the ocean floor affects sand ripple formation the most. Horizontal orbital diameter at a single point in time can be solved for using:

$$
\xi=-a \frac{\cosh k\left(z_{0}+H\right)}{\sinh k H}
$$


where $a$ is amplitude, $k$ is wave number, and $z_{0}$ depth of the particle from the sea surface (Kundu and Cohen, 2004).

According to Wiberg and Harris, wave orbital motion will be present at the bed if the wavelength of a surface gravity wave is less than about half the water depth. The back and forth movement of particles creates sand buildup perpendicular to surface winds. For purely oscillatory flows, Wiberg describes the ripples as "symmetric in cross section, with broad troughs and narrow crests" (Wiberg and Harris, 1994). Ripples are often formed in shallow water, but on the continental shelf where the water is deeper, ripples are only formed during large wind events. Strong storms impart enough energy into surface waves that the resulting particle movement penetrates to the ocean floor. Past studies have shown that if mean wave direction is constant, ripple wavelengths increase as orbital diameter increases (Clifton and Dingler, 1984). The mean direction of orbital displacement can also be used to approximate ripple orientation (Traykovski 1999). These approximations can only be applied as the storm increases or maintains strength. Recent studies have shown that as the storm wanes and the orbital diameters diminish, ripple wavelengths and orientation are preserved (Arduin et al., 2002 and Traykovski 1999). These ripples are referred to as relic ripples and remain until another large wave event reorganizes the sediments or until biological processes or mean currents are sufficient to mobilize the sediment and degrade the wave formed ripples. The challenge arises in determining when a storm ceases to influence ripple formation.

This study will apply a model created by Traykovski (Traykovski, 2006) to predict ripple wavelength and orientation. These calculations are compared to ripple 
properties analyzed from sidescan sonar images of ripples collected on the west Florida shelf as part of the Office of Naval Research's Ripples DRI and SAX04 experiments. Because the model requires information about orbital movement at the seabed, a nearshore wave model was run to determine a time-varying wave field. 


\section{Chapter 2}

\section{Experiment}

\subsection{Description and Funding}

The over-reaching goal of the Office of Naval Research (ONR) is to fund scientific research that contributes to future naval power and the security of the nation. The ONR is divided into 7 main departments, one of which is the Ocean Battlespace Sensing Department. This includes the Coastal Geosciences program (Code 321), which focuses its research on nearshore seafloor characteristics. Ripples Departmental Research Initiative (DRI) is one of the Coastal Geosciences program's on-going projects. Ripples DRI is funded for 5 years, beginning in 2004 and ending in 2008. Its objective is to understand the genesis, evolution, and decay of small-scale sand ripple morphology on the continental shelf.

There are two main field experiments planned for Ripples DRI. The first was conducted in 2004 off the coast of Florida along with ONR's Sediment Acoustics Experiment (SAX04), and the second is planned for 2007 at the Martha's Vineyard Coastal Observatory. SAX04 is funded by the ONR's Ocean Acoustics program, and its objective is to study sub-critical acoustic penetration to improve the detection of buried objects such as mines. Ripples DRI and SAX04 are inextricably linked, as sand ripples 
have been found to enhance sound penetration at low grazing angles, which may augment detection techniques of buried mines.

The U.S. Geological Survey (USGS) Coastal and Marine Geology Program, University of Florida, the Naval Postgraduate School, and scientists from Woods Hole Oceanographic Institute (WHOI) are all collaborating on Ripples DRI. The University of Washington's Applied Physics Laboratory is leading the work on SAX04.

\subsection{Data Collection Sites and Dates}

The SAX04 experiment site was in the Gulf of Mexico, directly south of West Destin, FL. Figure 2-1 plots the location of REMUS deployments by the WHOI research group as well as NPS data collection sites 7 and 9. Sea spider tripods with bottom pressure recorders were deployed at Sites 7 and 9 with an additional Datawell Directional Waverider buoy at Site 9 . 


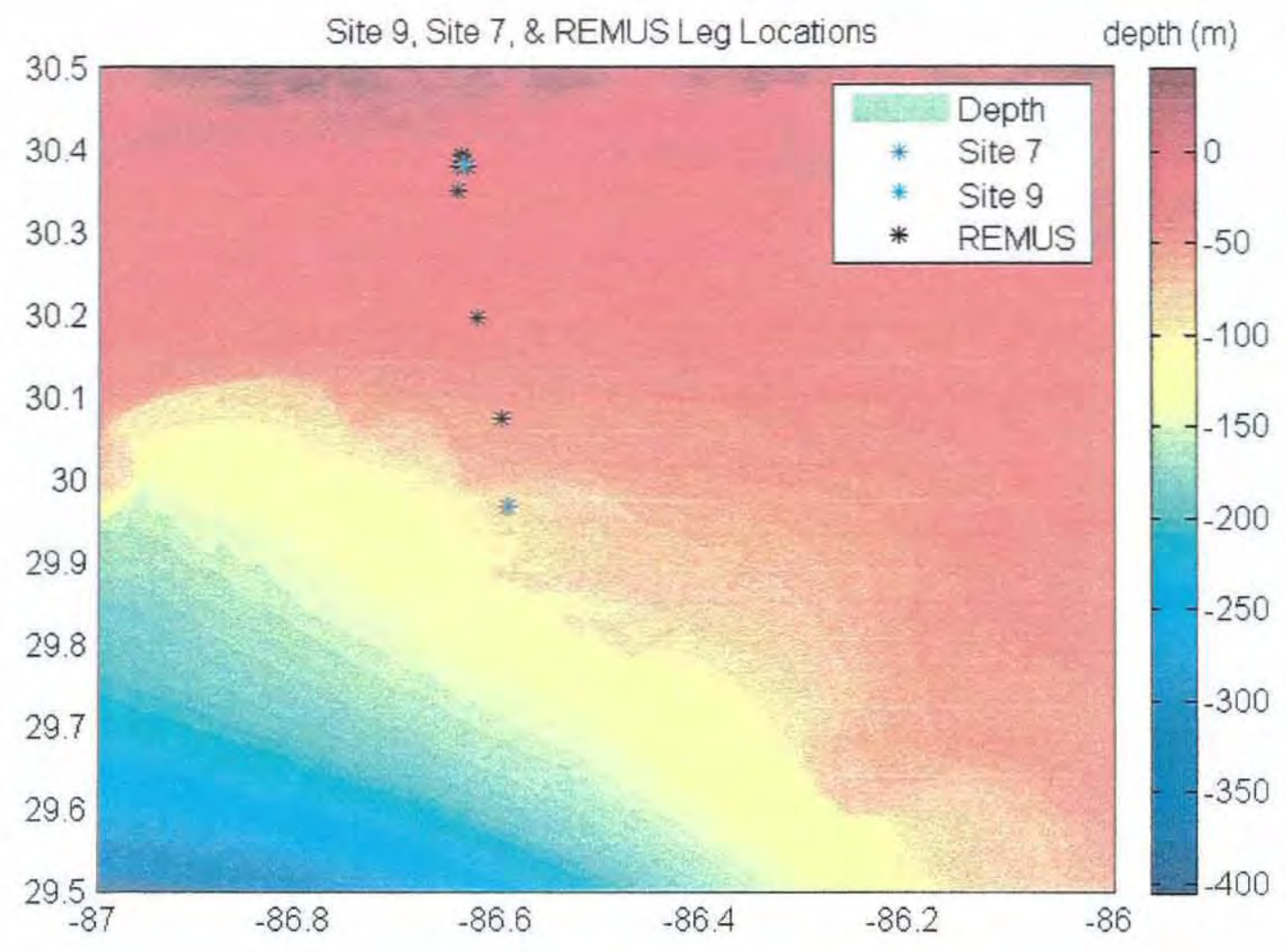

Figure 2-1: Locations of Site 7, Site 9, and REMUS deployments off the coast of Florida.

Although some of the instruments were deployed as early as May, most work was done September to November 2004. The USGS and WHOI research groups measured ripple properties from the $R V$ Pelican September $24-29^{\text {th }}$ and November $6-11^{\text {th }}$. The research vessel deployed a USGS tripod, which made measurements of ripple properties at single location for several minutes and then moved to a different location. The REMUS surveys were conducted from a small boat in the vicinity of the RV Pelican. Peter Traykovski led the WHOI effort in collecting ripple sidescan sonar data. 


\subsection{Instruments}

\subsubsection{REMUS}

The WHOI research group used a Remote Environmental Monitoring Unit (REMUS) in the Ripples DRI experiment to collect underwater data. These autonomous underwater vehicles were invented and developed at WHOI. Although there are many sizes and payloads for REMUS vehicles, the REMUS employed in Ripples DRI was 175 $\mathrm{cm}$ long, $15 \mathrm{~cm}$ in diameter, and weighed about $42 \mathrm{~kg}$. All REMUS vehicles are outfitted with a control computer, power supplies, and three motors that operate the propeller and two fins. For this experiment, a sidescan sonar system, ADCP, fathometer, inertial navigation system with GPS, and pencil-beam sonar were added as well. Figure 2-2 depicts the beams from the ADCP and two sonar systems on the REMUS. 


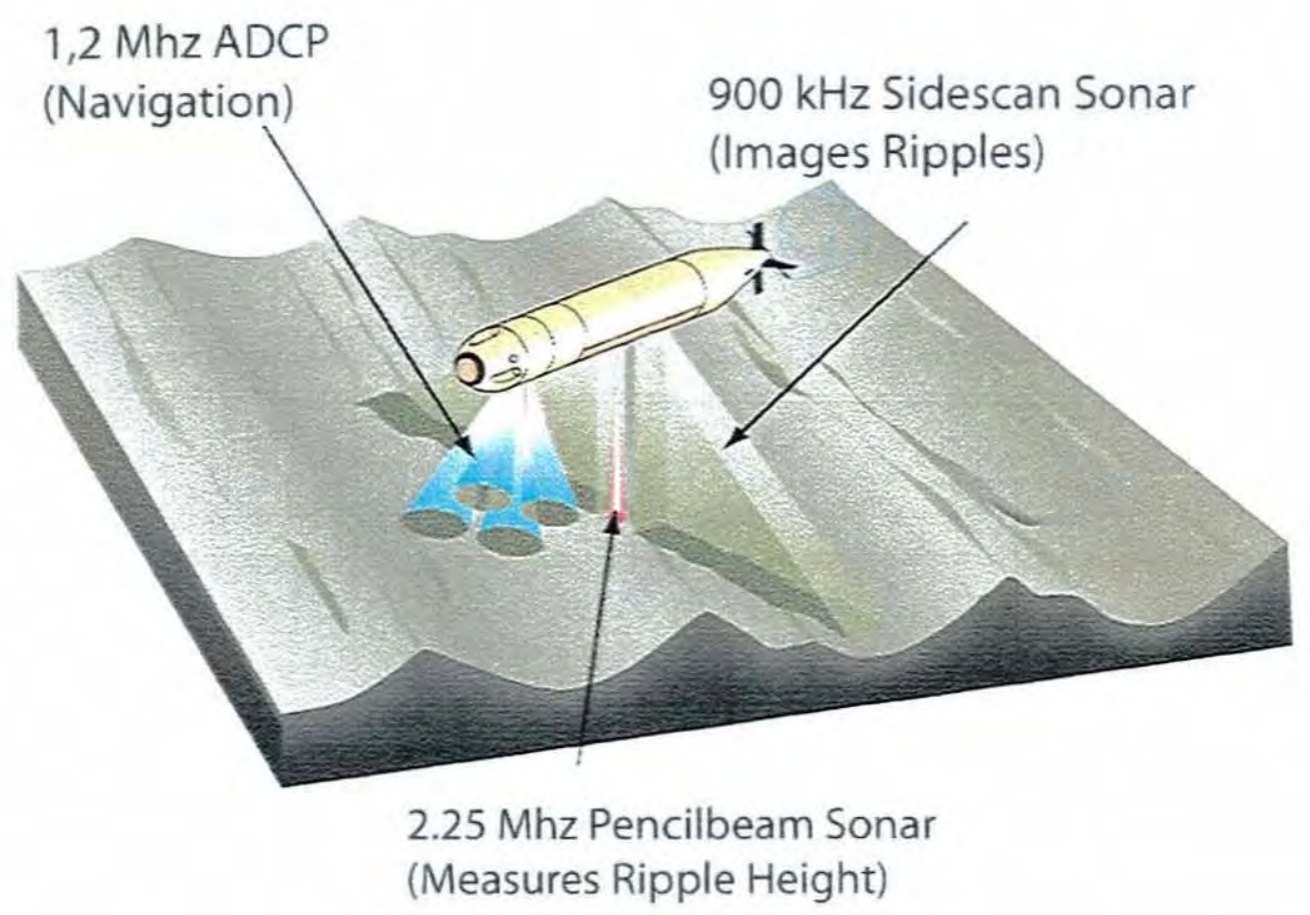

Figure 2-2: REMUS vehicle with ADCP, sidescan sonar, and pencilbeam sonar.

Figure courtesy of Woods Hole Oceanographic Institution Graphics Dept.

Figure 2-2: REMUS vehicle with ADCP, sidescan sonar, and pencilbeam sonar. Figure courtesy of Woods Hole Oceanographic Institution Graphics Dept.

When the REMUS was deployed to collect data, it traveled back and forth in a pattern referred to as "mowing the lawn." It was programmed to maintain a constant altitude from the ocean floor, although the height did vary during the deployment. The REMUS was programmed to travel parallel to the coast along predicted ripple crests in hopes of receiving strong sidescan sonar returns. The vehicle traveled $2 \mathrm{~km}$ along the coast, then turned around to sample a swath $2 \mathrm{~km}$ offset from the original track, eventually covering a rectangular area of the seafloor. In order to maximize coverage, the swaths did not overlap, as seen in Figure 2-3. The REMUS was deployed at $50 \mathrm{~m}$, $30 \mathrm{~m}, 20 \mathrm{~m}, 12 \mathrm{~m}, 8 \mathrm{~m}$, and $5 \mathrm{~m}$ depths to examine the presence of ripples in varying water depths. Although ripples are expected to be formed in shallower water, only large 
storms have enough energy to propagate to the ocean floor and create ripples in deeper waters $(\mathrm{eg} 50 \mathrm{~m})$. 


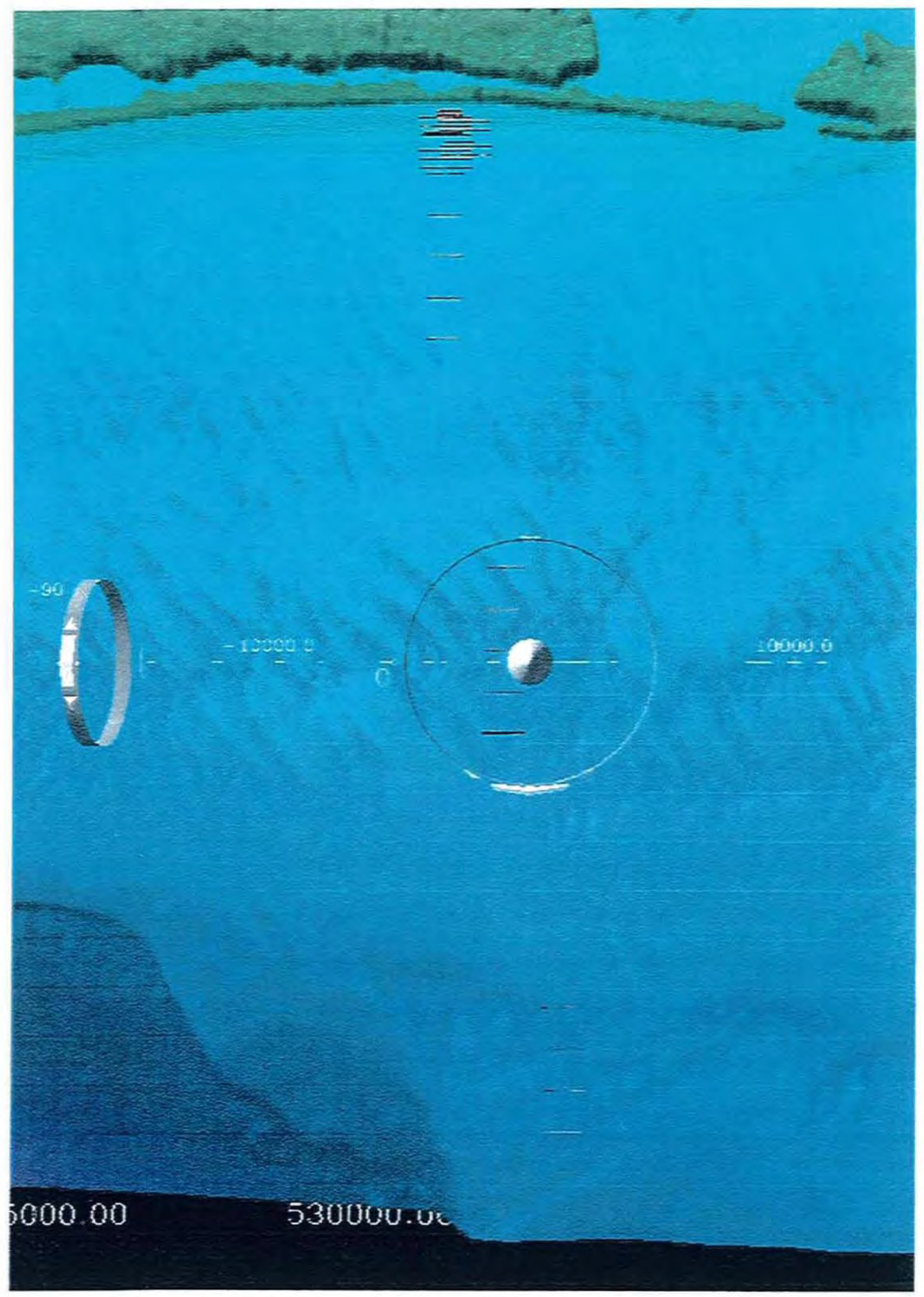

Figure 2-3: High resolution bathymetry with REMUS paths off the coast of Florida. 


\subsubsection{Sidescan Sonar Description}

The sidescan sonar systems on the REMUS have 2 side-looking transducers that send out sound-waves in a fan-like swath perpendicular to the vehicle's movement, as seen in Figure 2-2. The sound pulses are then reflected by the ocean floor and received by the transducers on the vehicle. The data is recorded for each pulse of sound, then pieced together and interpreted as an image.

The strength of the returning sound pulse depends on the acoustic reflectivity, and topography of the seabed. Scoured bottoms, exposed hard strata, floors and walls of submarine canyons, and flows containing coarse sand and rubble yield strong returns. Weak returns are often caused by mud, homogenous and soft sediments, and areas of active deposition. Therefore, features such as mud, smooth sand, rock, canyons, and specifically sand ripples on the ocean floor are easily recognizable in sidescan images.

In the Ripples DRI images, collected with vehicle altitude 2 to 3 meters above the seafloor, sand ripples are extremely prominent. They are especially defined in deeper water where the ripples are larger. Ripples produce distinct patterns in sidescan sonar images because of their wavy contours. If the ripples are oriented with their peaks perpendicular to the sidescan swath, the front slopes of the ripples reflect the sound waves back to the transducers. However, the leeward side of the ripple slopes away from the incoming sound wave and do not produce any strong reflections towards the vehicle. Therefore, the sidescan sonar system records an image of alternating strong and weak returns when ripples are present on the seafloor. 


\subsection{Weather}

As explained earlier, a large wind event is required to produce sand ripples on the seabed. Therefore, in order to predict the presence of sand ripples, it is important to examine weather patterns before and during the experiment. Climatologic data reveal meteorological monthly averages near the experiment site. Hourly buoy measurements can then be used to examine weather events in September and November more closely. Data collected during the passage of Hurricane Ivan are focused on in this study.

\subsubsection{Climatologic Data}

The National Data Buoy Center (NDBC) Buoy 42040 is located nearest to the experiment site. Its climatologic record of meteorological parameters can be examined to predict weather patterns during the experiment. The record has been compiled by NDBC from data collected in 1995 through 2001. The following two figures plot the results for monthly sea level pressure and wind speed respectively. 


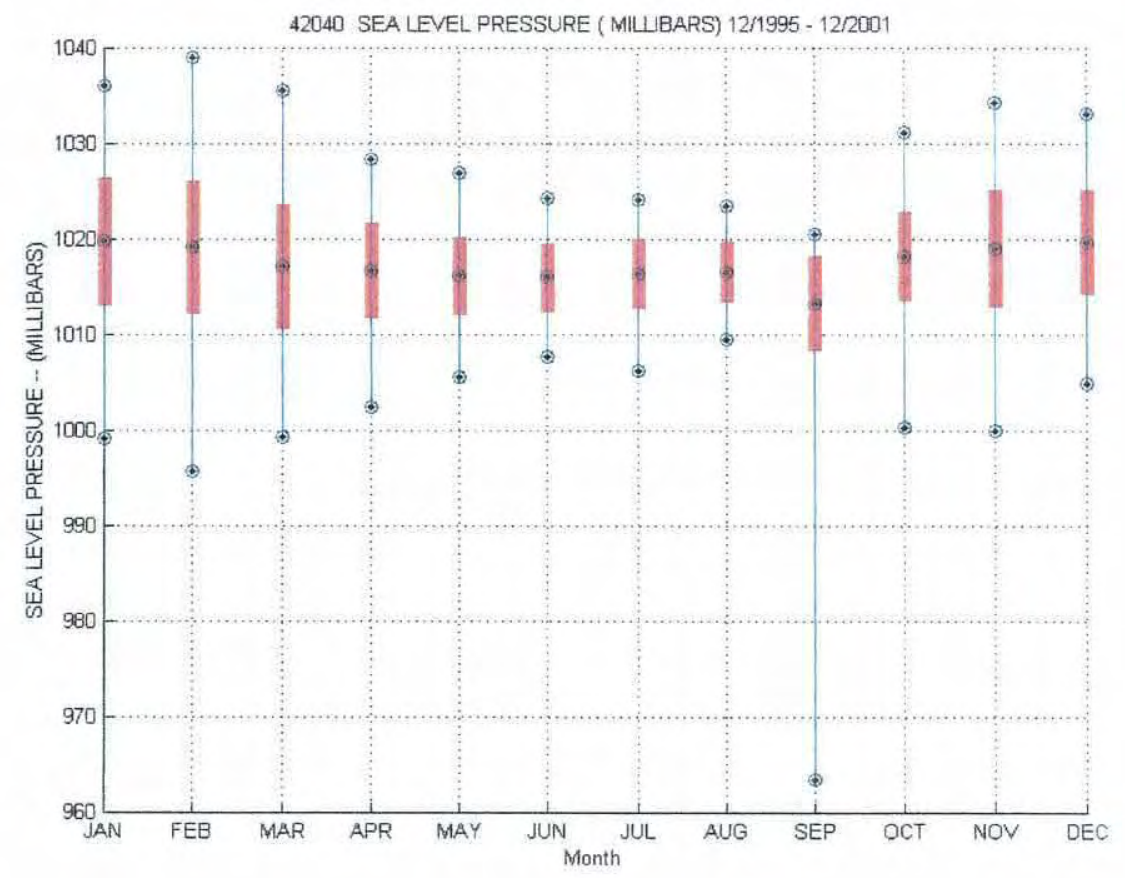

Figure 2-4: Sea level pressure at NDBC Buoy 42040 from NDBC Climatic Summary Plots. 


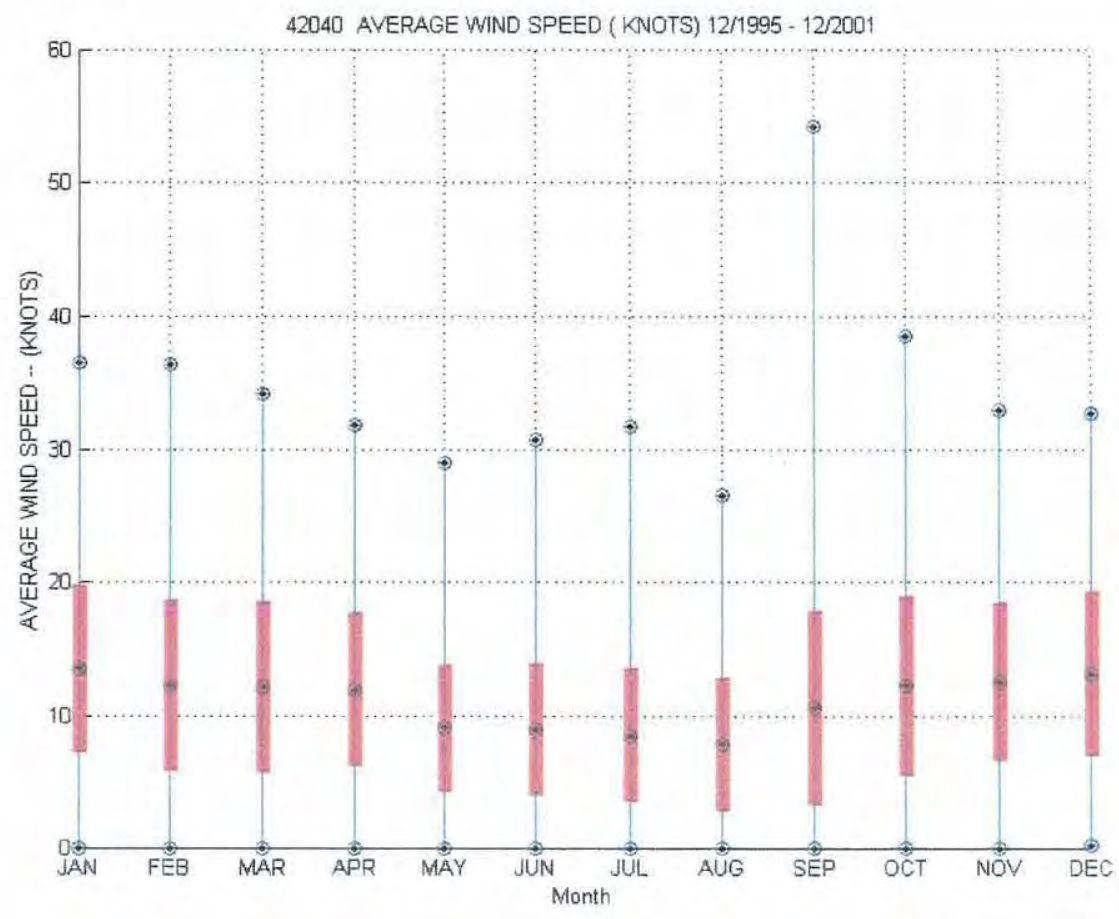

Figure 2-5: Average wind speed at NDBC Buoy 42040 from NDBC Climatic Summary Plots.

In both climatologic records, the month of September stands out due to its extreme values and variations. Mean sea level pressure is lowest in September, dropping to $1014 \mathrm{mb}$. Although this pressure is significantly below the means of other months, the most noticeable discrepancy is the extreme variability in September's pressure. Sea level pressure during the other months varies only by $25 \mathrm{mb}$, compared to the $50 \mathrm{mb}$ difference in September. September's monthly average can be as low as $963 \mathrm{mb}$. Such a low value of sea level pressure is indicative of strong storms, particularly tropical storms and hurricanes. In fact, according to NOAA, most hurricane activity occurs in midSeptember, although the Atlantic hurricane season is officially June $1^{\text {st }}$ to November $30^{\text {th }}$. 
Figure 2-5, plotting the monthly average wind speed, also supports the prevalence of hurricanes during this time. Although wind speed is typically large during the winter months, September again has the highest variability. The above plot shows that average monthly wind speeds can range up to $45 \mathrm{kts}$ from the climatologic mean in this month, produced by intense hurricane winds.

\subsubsection{Hurricane Ivan}

Strong wind events such as hurricanes typically produce well-defined sand ripples providing the water is shallow enough for the storm's energy to propagate to the ocean floor. Coincidently, a hurricane passed near the experiment site about a week before the WHOI sidescan sonar data was collected. This hurricane, Ivan, was considered the strongest storm of the 2004 Hurricane Season according to the National Hurricane Center. Ivan reached Category 5 status on the Saffir-Simpson Hurricane Scale (SSHS) three times, dropping to a minimum pressure of $910 \mathrm{mb}$. By the time Hurricane Ivan made landfall in the United States at about 0600 on September $16^{\text {th }}$, it was still a Category 3 hurricane.

Figure 2-6 is a map from NOAA depicting the path of Hurricane Ivan from September 11, 2004 to September $17^{\text {th }}, 2004$. Each hurricane symbol is labeled with its SSHS category. Although Ivan's eye passes slightly to the west of the experiment site, marked a box, the surrounding storm directly affects all sample sites. The subset in Figure 2-6 shows the extent of the storm at landfall. 


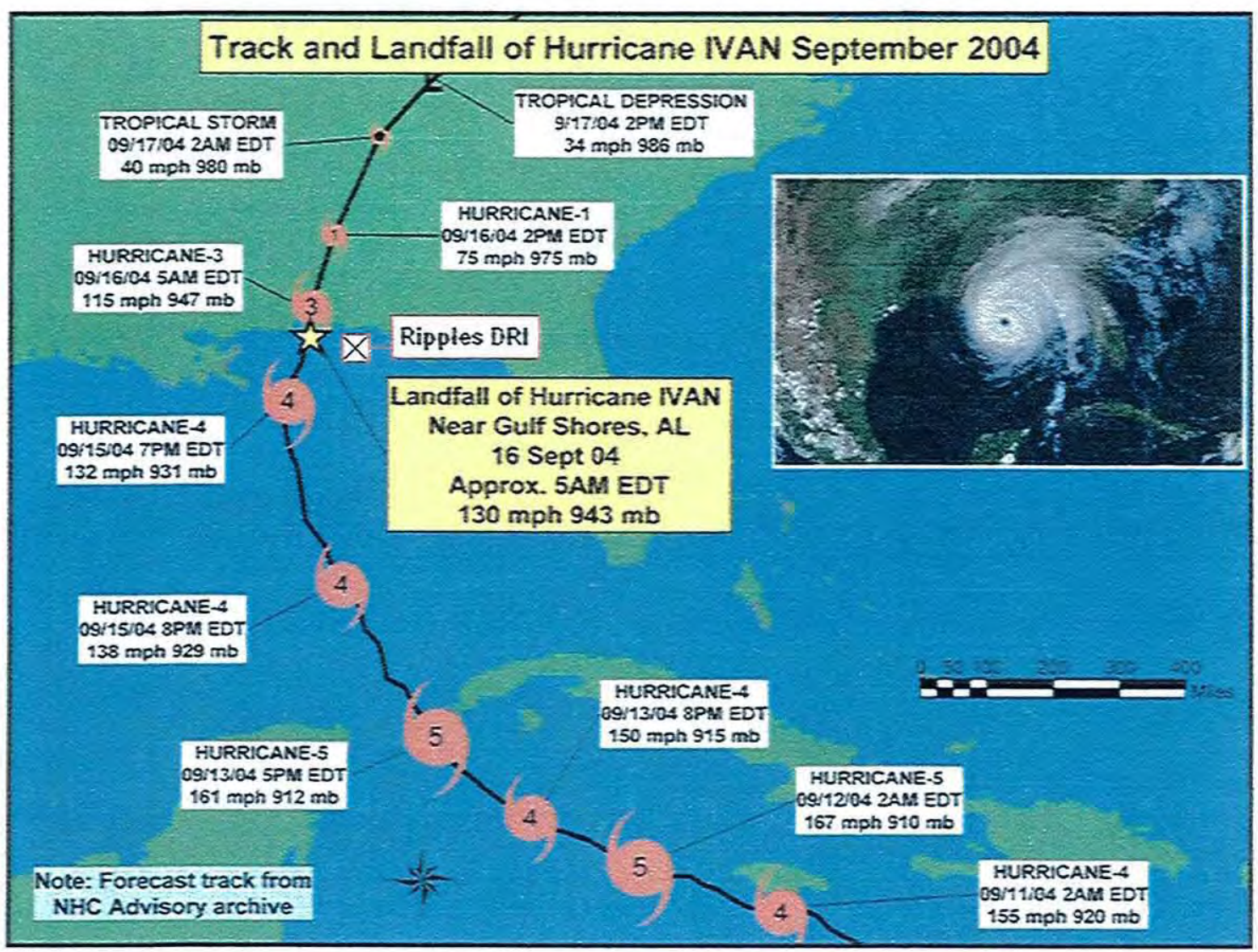

Figure 2-6. Hurricane Ivan tracking map from NOAA with Ripples DRI experiment site.

Figure 2-7 summarizes the barometric pressure, wind speed, and wind direction in September through November of 2004. These meteorological records are from NDBC Buoy 42039. Although Buoy 42040 is located closest to the experiment site, it cut out in mid-September due to the hurricane. Buoy 42039 is the next closest NDBC buoy, and has a complete data record. A large drop in pressure occurs in mid-September, along with an increase in wind speed. Both of these changes are much more extreme than any other variations in the three month period, and are indicative of a very strong storm. 

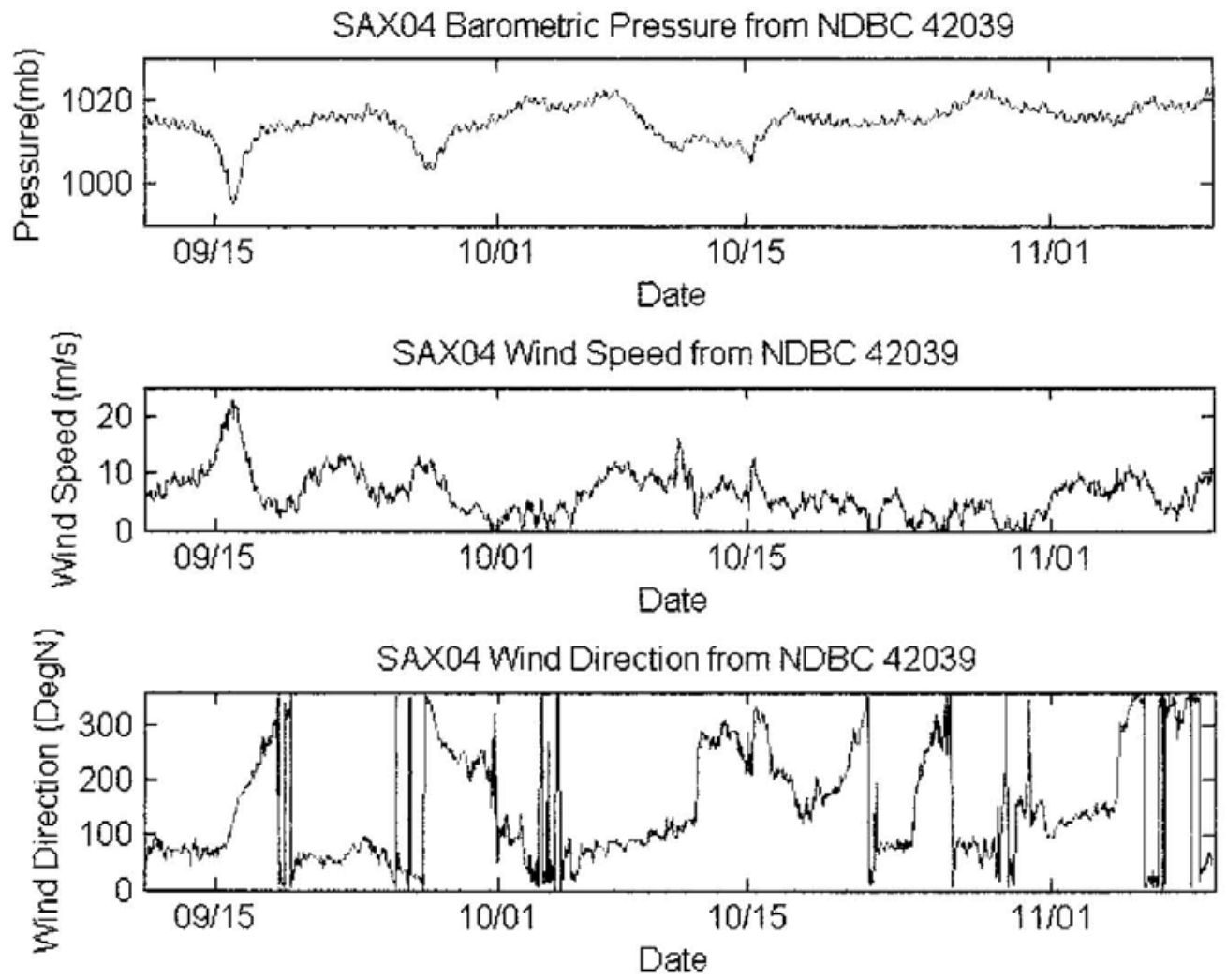

Figure 2-7: Pressure, wind speed, and wind direction at NDBC Buoy 42039 during experiment.

\subsubsection{Wind Patterns Near Experiment Site}

In order to examine the passage of Hurricane Ivan, meteorological records recorded by NDBC Buoy 42039 can be examined more closely. Figure 2-8 plots barometric pressure, wind speed, and wind direction recorded September $13^{\text {th }}$ through September $21^{\text {st }}$. The pressure drop and wind speed spike are extremely pronounced. 

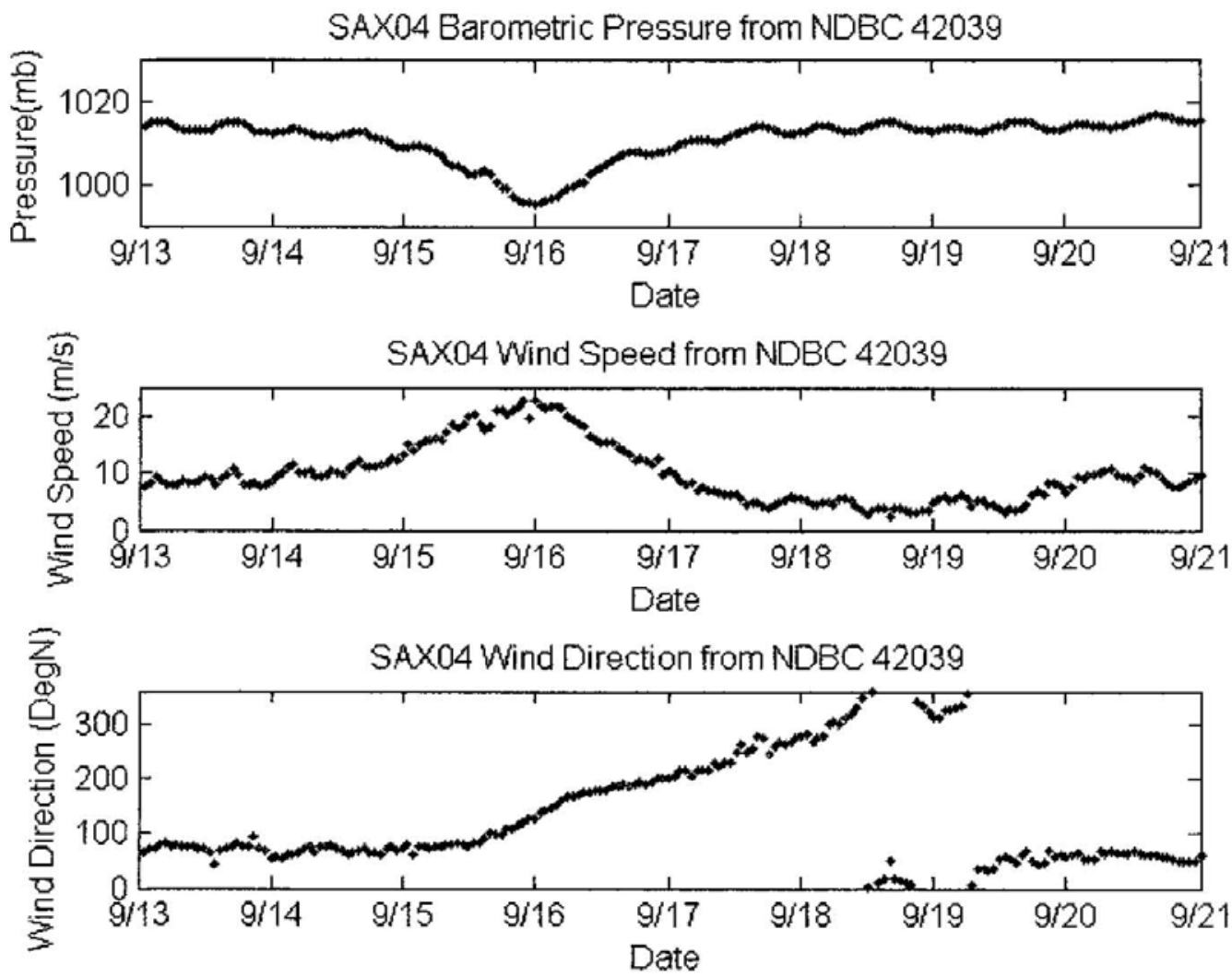

Figure 2-8: Pressure, wind speed, and wind direction at NDBC Buoy 42039 during Hurricane Ivan.

The pressure decreases to about $995 \mathrm{mb}$ on September $16^{\text {th }}$. At the same time, wind speed reaches about $23 \mathrm{mph}$. These extremes as well as the changes in wind direction correspond to the passage of Hurricane Ivan, seen in the figure of the hurricane track.

As shown below in Figures 2-9 to 2-11, Ivan approaches the experiment site from the south, with the eye of the hurricane passing slightly west. Red arrows represent wind directions at the experiment site. Figure 2-9 depicts the pressure and winds of the hurricane on September $15^{\text {th }}$, at 1200. 


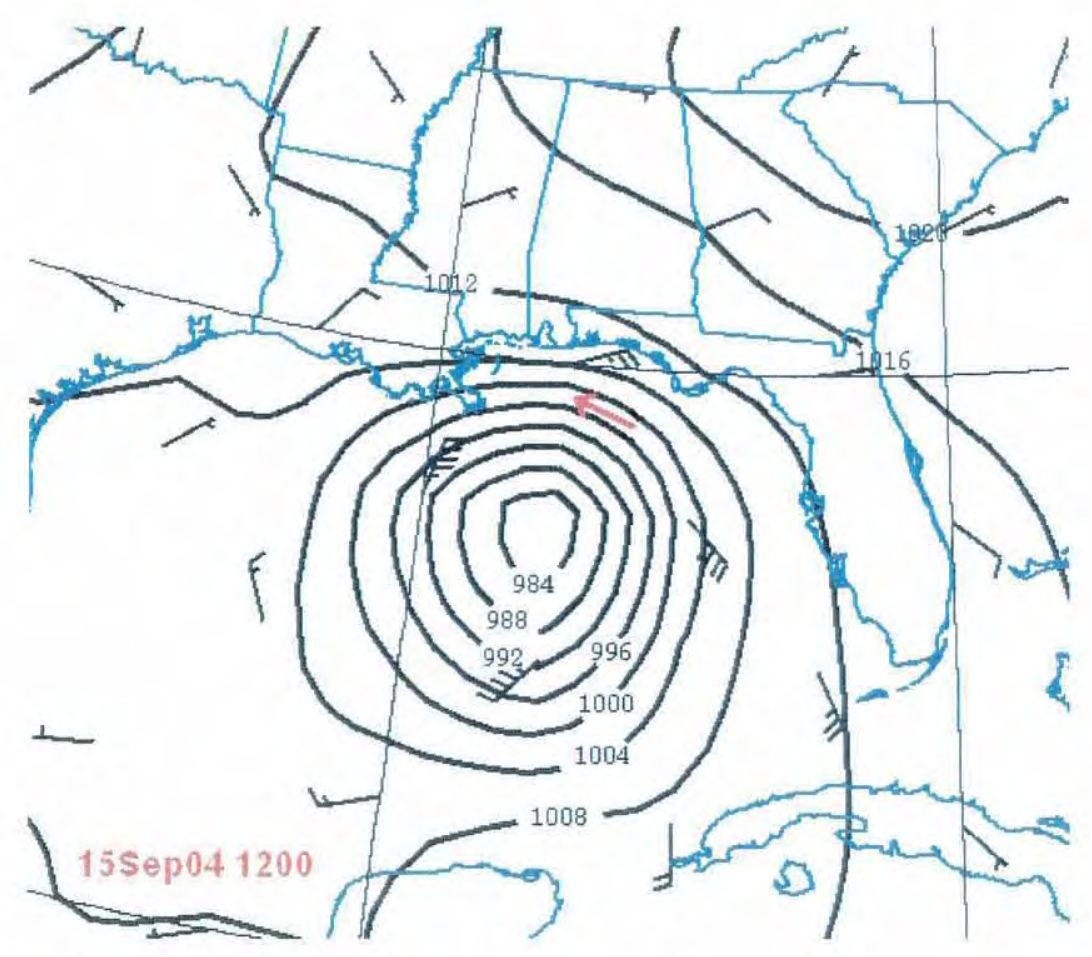

Figure 2-9: Sea level pressure and wind at 1200 on September 15, 2004 as Hurricane Ivan approaches experiment site.

\section{Created using the MIT PAOC Synoptic Laboratory.}

Although wind measurements are sparse, it can be seen that winds blow counterclockwise around the storm's center. Therefore, as the hurricane approaches, winds north-east of Ivan should blow from about $110^{\circ} \mathrm{N}$, marked with a red arrow. At the peak of the storm, on September $16^{\text {th }}, 0000$, the winds should blow from about $180^{\circ} \mathrm{N}$, as depicted in Figure 2-10. 


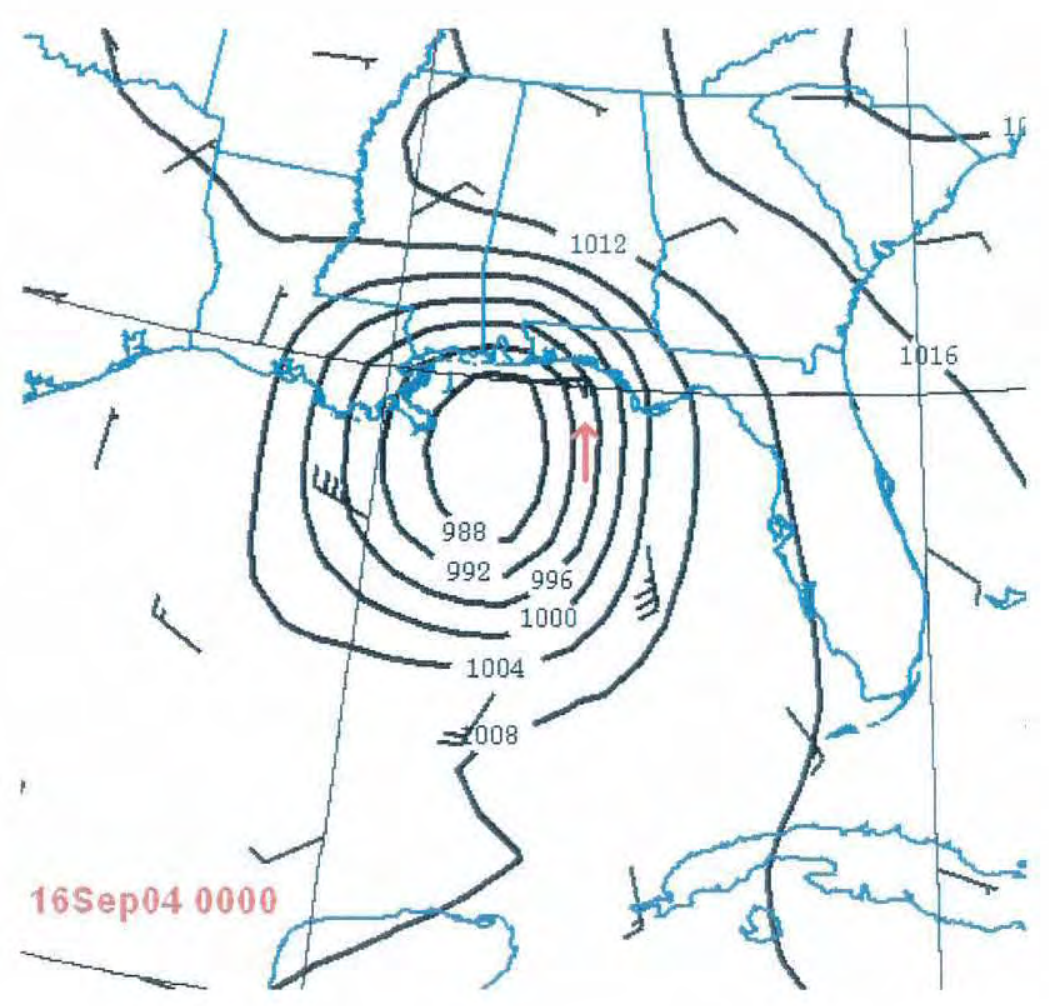

Figure 2-10: Sea level pressure and winds 12 hours later at 0000 on September $16^{\text {th }}, 2004$ as Ivan moves over experiment site.

Created using the MIT PAOC Synoptic Laboratory.

Then as the storm travels north past the experiment site, winds should rotate to blow from about $250^{\circ} \mathrm{N}$, as seen in Figure 2-11. These approximations correspond well with the winds recorded by NDBC Buoy 42039. 


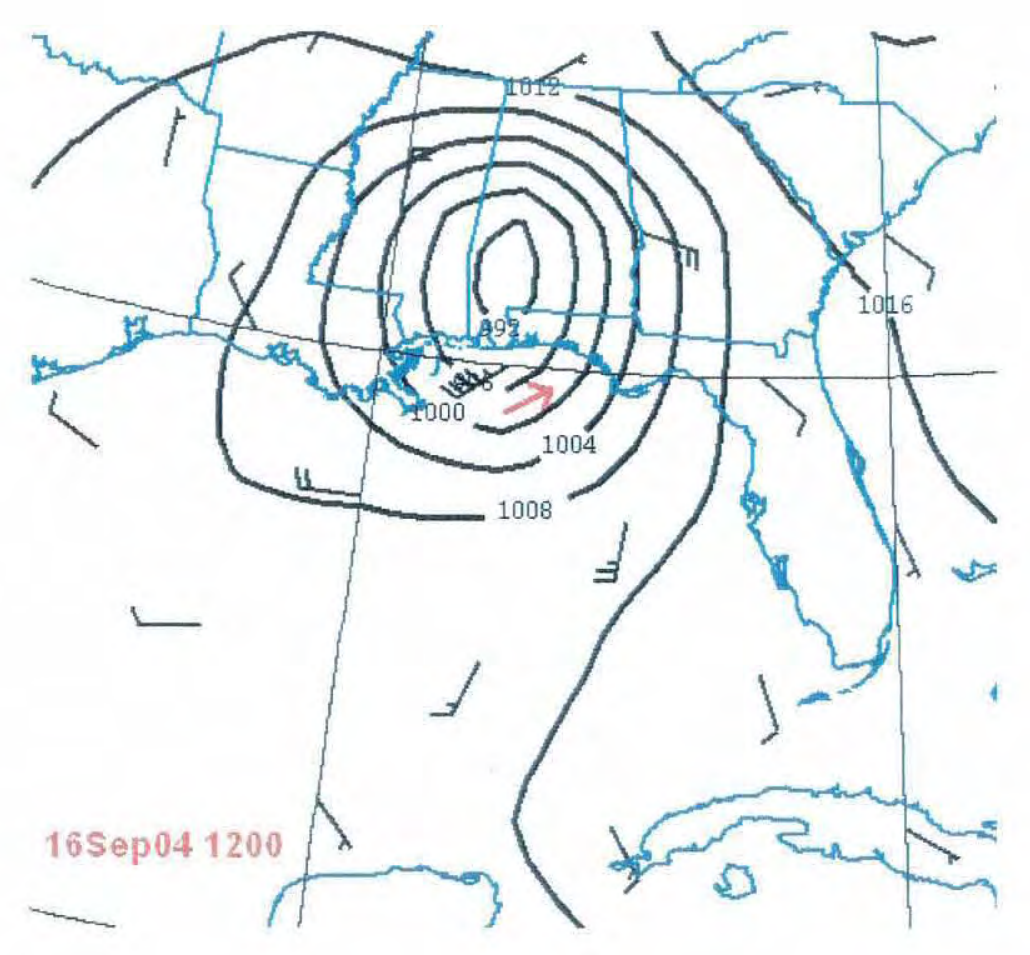

Figure 2-11: Sea level pressure and winds 12 hours later at 1200 on September $16^{\text {th }}, 2004$ as Ivan passes experiment site.

Created using the MIT PAOC Synoptic Laboratory. 


\section{Chapter 3}

\section{Sidescan Sonar Imagery of Ripples Analysis}

As discussed earlier, ripple crests generally run parallel to the coast (Traykovski, 1999). As sidescan sonar receives the strongest returns when it travels along ripple crests, the most useful data collected during the experiment is from the sections of each leg where the vehicle was traveling parallel to the shoreline. Therefore, only the data from these sections are analyzed in this study.

\subsection{Sidescan Sonar Resolution and Geometry}

When operating a sidescan sonar system, it is important to consider the effects of sound wave travel time, attenuation, and spreading on image resolution. Sound waves from the sidescan sonar must travel down to the bottom of the ocean before being reflected and traveling back to the transducers. The signals near the outside of the fan travel the greatest distance and therefore take longer to return as compared to the ones that are directed more immediately below the vehicle. If the sonar fan is too wide, the pulses will attenuate before reaching the seabed or before returning after reflection. In order to avoid this, the Ripples DRI REMUS was programmed to maintain an altitude of $3 \mathrm{~m}$ in deep water and $2 \mathrm{~m}$ in shallow water. Sonar range was limited to $30 \mathrm{~m}$ and $20 \mathrm{~m}$ in deep and shallow water respectively. Thus, two-way-time was decreased as much as 
possible, and beam spreading was minimized. Due to the short ranges desired, a sidescan sonar frequency of $900 \mathrm{kHz}$ was chosen, which allows for higher resolution images.

In order to interpret the data collected by the sidescan sonar, the geometry of the sonar beams in relation to the seabed and vehicle must be examined. Figure 3-1 depicts the REMUS and half of a sidescan sonar swath onto the sea floor. This section will explain the variables in the figure below.

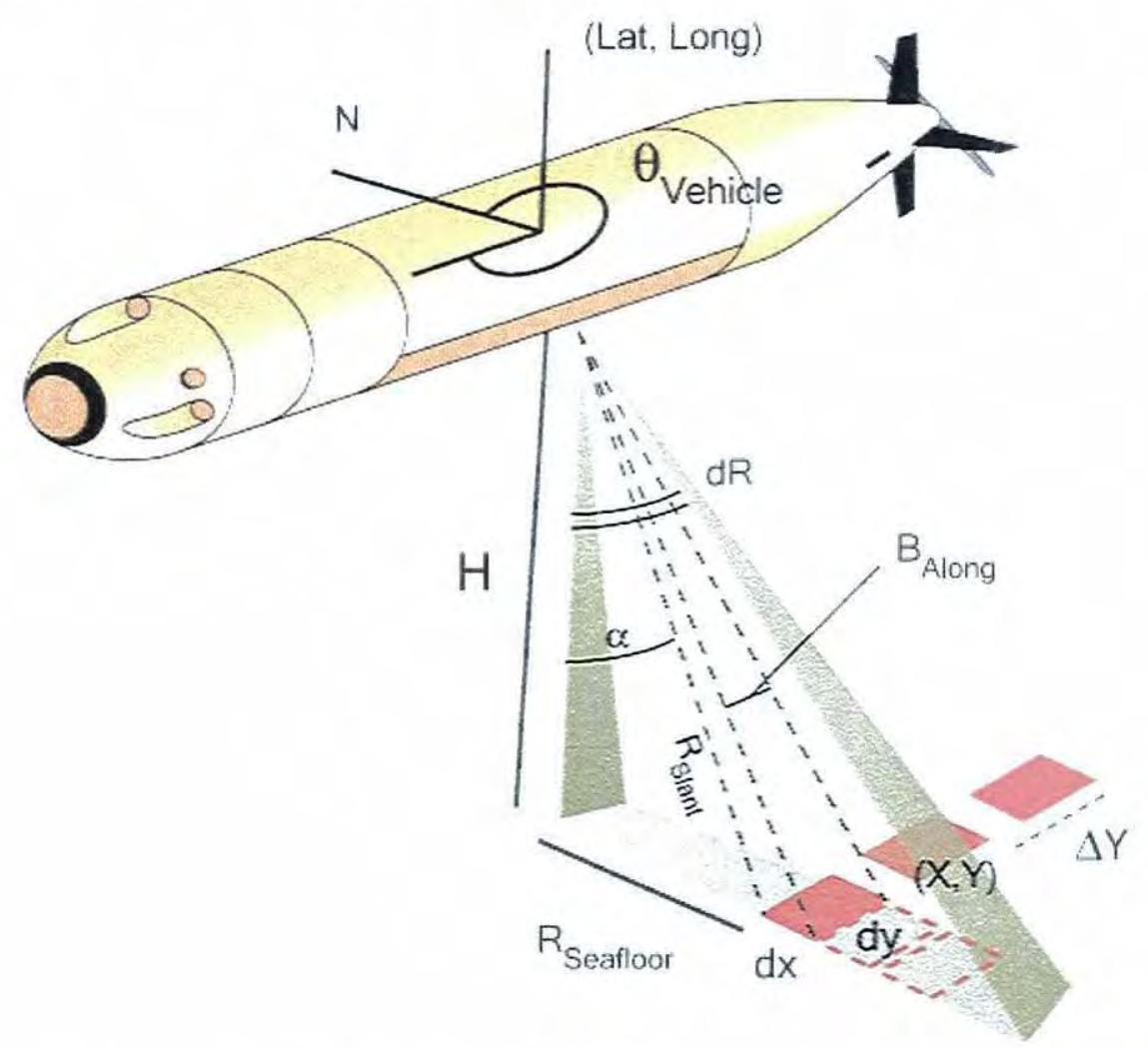

Figure 3-1: Diagram of sidescan sonar geometry.

Figure courtesy of Woods Hole Oceanographic Institution Graphics Dept.

First of all, in order to examine the data spatially, the relationship between geographic and vehicle coordinates must be defined. The GPS on the REMUS recorded 
the latitude and longitude of the vehicle at the surface of the water, and the ADCP and inertial navigation system estimated its position when the vehicle was underway. A compass recorded the heading, represented by $\theta_{\text {vehicle }}$ in Figure 3-1. The orientation of the sidescan sonar swaths is always $90^{\circ}$ from the heading: $\phi=\theta_{\text {Vehicle }}-90$. The $x$ and $y$ coordinates (in the local UTM coordinate system) of the swaths on the seabed can be solved according to:

$$
\begin{aligned}
& x=E_{U T M}+R_{\text {seafloor }} \sin \phi \\
& y=N_{U T M}+R_{\text {seafloor }} \cos \phi
\end{aligned}
$$

where $E_{U T M}$ and $N_{U T M}$ are the UTM Easting and Northing coordinate calculated from the vehicle position in latitude and longitude via utilities in the MATLAB ${ }^{\mathrm{tm}}$ mapping toolbox.

The three most basic dimensions of a sonar swath are the altitude of the vehicle $(\mathrm{H})$, slant range $\left(R_{\text {slant }}\right)$, and range on the seafloor $\left(R_{\text {seafloor }}\right)$. Vehicle altitude is measured by a fathometer on the REMUS and is typically $2 \mathrm{~m}$, although it was increased to $3 \mathrm{~m}$ in deeper water for greater spatial coverage. Sidescan data is collected as a function of twoway time and is organized into 512 range bins for each swath. The size of the range bins $(\mathrm{dR})$ is determined by the total range $\left(R_{\text {total }}\right)$ and number of bins:

$$
d R=\frac{R_{\text {total }}}{512} .
$$

Slant range can then be calculated by:

$$
R_{\text {slant }}=b i n \cdot d R \text {, }
$$


where bin is the range bin number between 1 and 512 . The $512^{\text {th }}$ bin is located furthest from the vehicle, where $R_{\text {slant }}$ equals the maximum sonar range. Range on the seafloor is also at a maximum at this point and can be solved for with simple geometry:

$$
R_{\text {seafloor }}=\sqrt{R_{\text {slamt }}^{2}-H^{2}} \text {. }
$$

Minimum values occur for bins directly under the vehicle where slant range is equal to vehicle height.

The red boxes in Figure 3-1 represent bins along the sonar swath. The variable $d x$ is the projection of $d R$ onto the seafloor

$$
d x=d R \frac{1}{\sin (\alpha)},
$$

where $\alpha$ is the angle between $H$ and $R_{\text {slant }}$. This angle can be calculated with:

$$
\alpha=\cos ^{-1}\left(\frac{H}{R_{\text {slant }}}\right) .
$$

As seen in Figure 3-1, $d x$ also represents the distance between the dotted red lines outlining locations of other boxes along the swath. For $R_{\text {seafoor }}$ values of 10,20 , and 30 meters, typical $d x$ lengths are $6.12,5.92$, and $5.89 \mathrm{~cm}$ respectively, for a maximum sonar range of $30 \mathrm{~m}$.

The second dimension of the red bin boxes is $d y$, which is dependent on slant range as well as the size and shape of the sidescan sonar's transducer. In this case, the transducer is 14 inches or about $35.56 \mathrm{~cm}$. For a rectangular transducer, the angle of the beam's width $\left(B_{\text {along }}\right)$ is related to the transducer length $\left(L_{t}\right)$ and sonar frequency $(f)$ : 


$$
B_{\text {along }}=\sin ^{-1}\left(\frac{c}{f L_{t}}\right) \text {. }
$$

From this angle, $d y$ can be calculated:

$$
d y=R_{\text {slant }} \sin \left(B_{\text {along }}\right)
$$

Typical $d y$ values are $4.89,9.48$, and $14.13 \mathrm{~cm}$ for the same 10,20 , and 30 meter $R_{\text {seafloor }}$ values.

The distance between the red boxes also represents the distance the vehicle travels between sonar swaths. Swaths must be spaced out because it takes time for the sound to travel to and from the seabed. A new ping can not be transmitted until the sound from the previous beam returns to the vehicle. During this time, the vehicle continues to move forward. The distance it travels $\left(\Delta_{y}\right)$ can be solved for by:

$$
\Delta_{y}=R_{\text {slant }} v_{\text {vehicle }} / c_{w},
$$

where $c_{w}$ is the speed of sound in water $(1500 \mathrm{~m} / \mathrm{s})$, and $v_{v e h i c l e}$ is the speed of the vehicle. The REMUS required a speed of at least $1.5 \mathrm{~m} / \mathrm{s}$ to maintain stability. For the maximum sonar range of $30 \mathrm{~m}$ and an average vehicle speed of $2 \mathrm{~m} / \mathrm{s}$, the distance between swaths is about $3 \mathrm{~cm}$. 


\subsection{Ripples Analysis}

\subsubsection{Preliminary Analysis}

The first approximations of sand ripple wavelengths and directions were solved from values returned from hand-clicking adjacent ripple peaks. Five well-formed ripple pairs were randomly selected from each image. The returned $x$ and $y$ position coordinates from each pair were used to calculate the distance between peaks using:

$$
\lambda=\sqrt{\Delta x^{2}+\Delta y^{2}} .
$$

Wave orientation was solved for from the same variables:

$$
\theta=\left(\frac{180}{\pi}\right) \tan ^{-1}\left(\frac{\Delta y}{\Delta x}\right)
$$

All wave orientation is referenced from $0^{\circ}$, or north. Therefore, a ripple orientation of $90^{\circ}$ indicates a ripple with its crest running directly east to west. The five resulting wavelengths and wave directions were averaged for each image. The preliminary results for ripple wavelength and orientation are discussed in the next chapter. 


\subsubsection{Spectral Analysis}

In order to create a more robust and more quantitatively accurate summary of the observed ripple properties, it is necessary to analyze a larger portion of the data than in the preliminary approximations. However, images containing mud patches must be discarded. Mud patches are characterized by extremely weak sonar returns, where the sidescan sonar sound waves are absorbed by the fine sediment on the ocean floor. The following figure is an example of an image with a large mud patch in a ripple field.

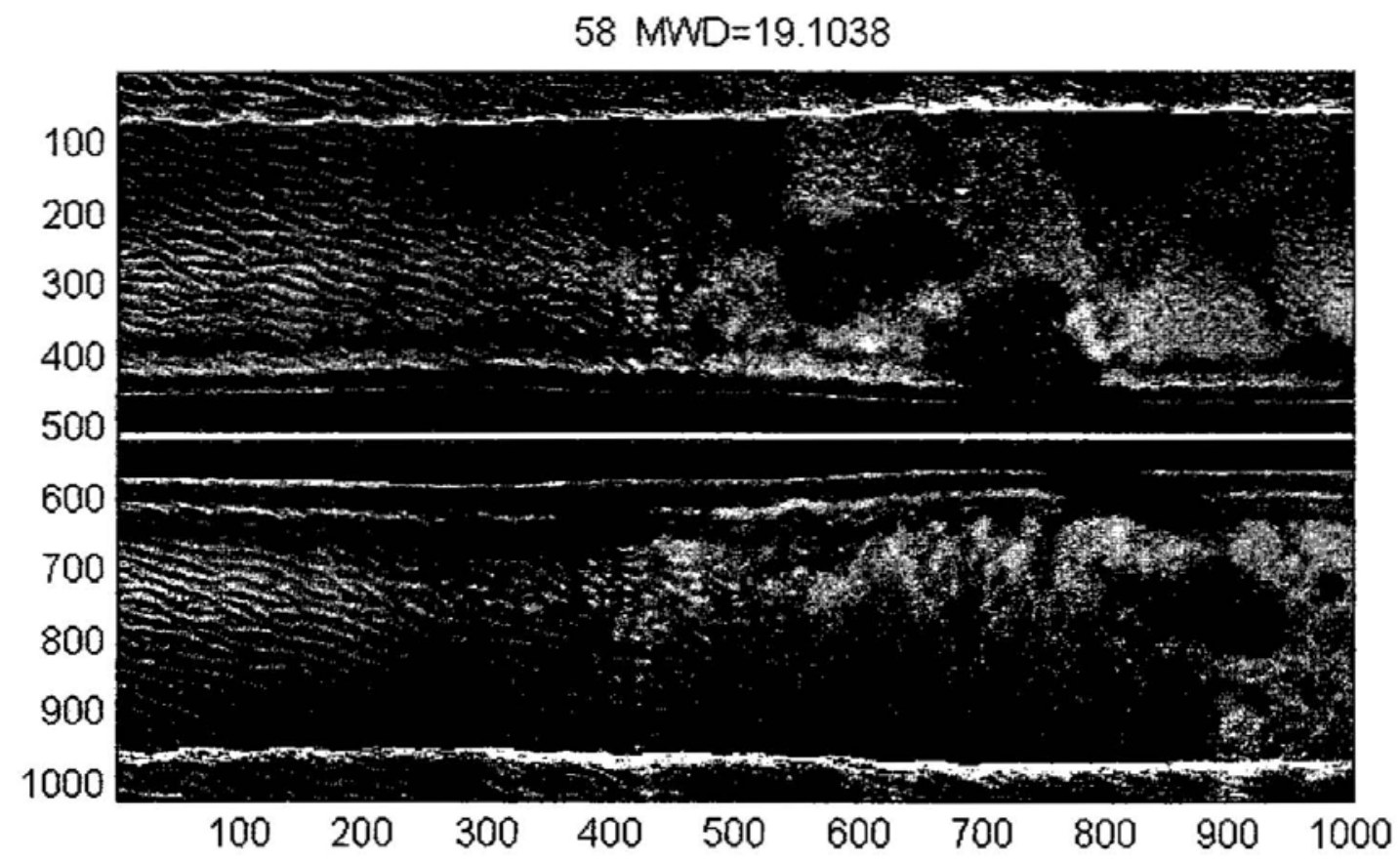

Figure 3-2: Sidescan sonar image of a ripple field (left) and mud (right). 
If mud covered $30 \%$ or more of an image, the image was discarded from the data set. This assessment was done by manually examining each image and estimating the amount of mud visible compared to ripples present.

\section{Irregularities}

In examining each sidescan sonar image, three main irregularities must be avoided. First, as seen in Figures 3-2 and 3-3, the sonar returns near the center of the images are extremely dark in the middle, with alternating dark and light bands on either side. Some of these returns, particularly the darkest, may be remnants of sound scattering in the water column underneath the vehicle. Most of the water column returns were removed according to estimated depth measurements before the images were plotted. However, if the height of the water column was slightly underestimated, some water column returns may still be visible in the center of the image. The alternating bands are caused by rapid variations in intensity under the REMUS due to the geometry of the sonar beam pattern. These returns will not be included in the spectral analysis. The irregular outer edges of some images, caused by movement of the vehicle, were also discarded. To do so, the images were reduced to rectangles instead of odd shapes. The most challenging obstacle to avoid in each image was the location of the surface return. A surface return occurs when the sound wave is reflected off the surface of the water back down to the vehicle. This return is often significantly stronger than bottom returns and therefore must be avoided in the spectral analysis of ripples. Figure 3-3 is an 
example of a typical sidescan sonar image with a strong surface return. This image has already been cropped to a regular rectangular shape.

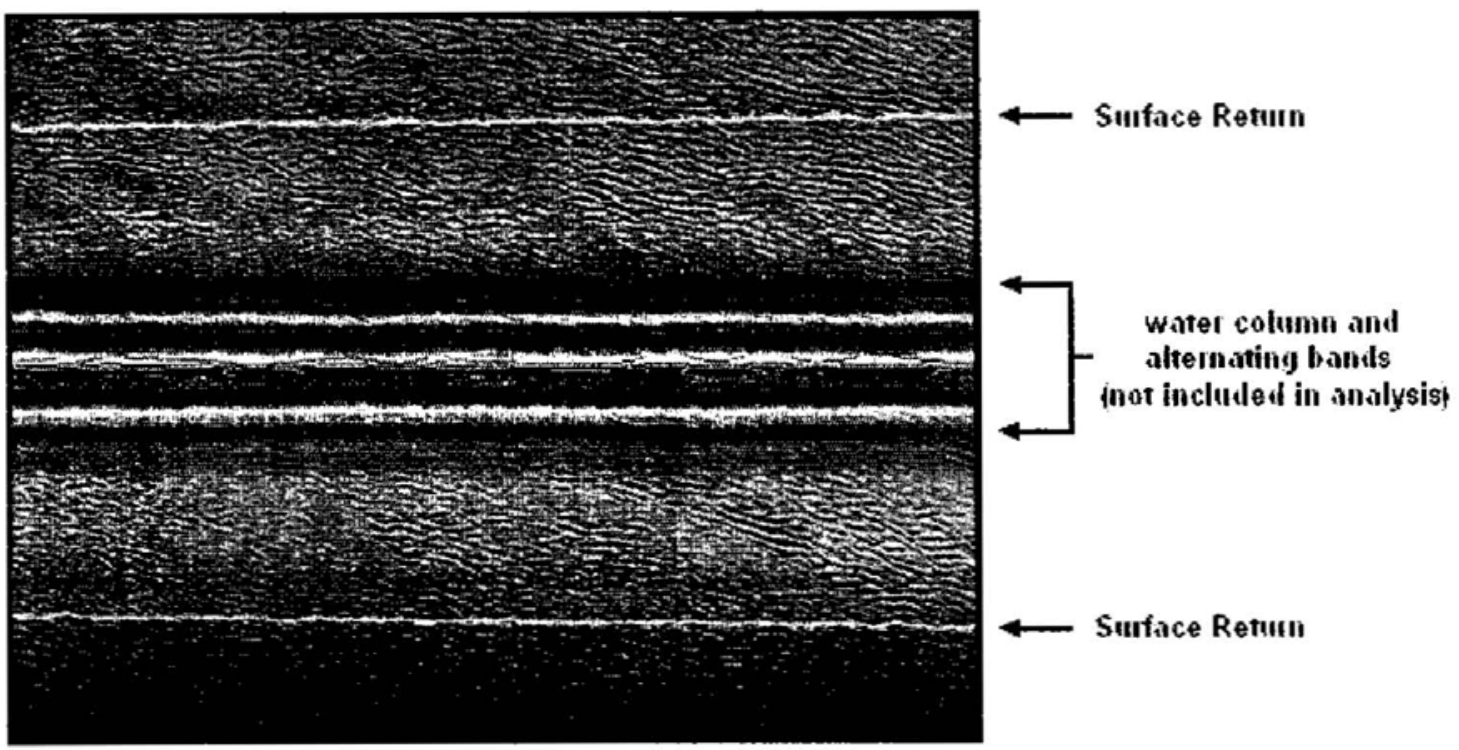

Figure 3-3: Typical sidescan sonar image with surface returns.

Surface returns are visible most often in shallow water, where vehicle depth is equal or less than the range of the sonar. To produce a surface return, sound waves must travel from the vehicle to the surface and back before all the sound waves return from the seabed. If the two-way travel time and therefore slant range of the surface return is less than the sonar's total range, then the surface return must be avoided in the analysis. $R_{\text {seaffor }}$ can be calculated for the surface return to determine its location on a sidescan sonar image in relation to seabed returns. 


\section{Processing}

In order to obtain average ripple properties from the images, a large amount of data must be analyzed. In this study, the average ripple wavelengths and alignments for each image are calculated from mean values of smaller "boxes," or portions of the image. The goal was to fit as many rows of uniform overlapping boxes between the edges and center of the images while avoiding surface returns. In this discussion, only the top half of the image will be addressed, but the same situation occurs on the bottom half as well. The boxes are $140 \times 140$ pixels and overlap by $50 \%$. There are three main possibilities for the placement of these boxes. First of all, if the image is too irregular and no boxes fit in the image, the image is discarded from the data set. Second, if no surface return occurs in the image, a row of boxes is placed along the edge of the image. If the image is wide enough, another row is placed below the first, overlapping it by $50 \%$.

The third possibility of box formation, when a surface return occurs in the image, is the most complicated. The location of the surface return defines where the boxes may be created. For example, if the return is closer to the center of the image, a row of boxes might fit between the edge and the surface return. If the return is closer to the edge instead, the boxes might fit between the surface return and center. However, due to variable image widths, there are occasions where the $140 \times 140$ pixel boxes are too wide to fit in either place. When this occurs, two formations are possible. If $70 \times 140$ pixel boxes will fit on both sides of the surface return, then the two rows of boxes can be added together to form the standard row of boxes. If not, the widths of the 140 pixel boxes must 
be broken up unevenly and added together, similar to the above formation. If none of these formations fit around the surface return in the image, then the data is discarded.

In order to calculate the mean ripple properties in the each image, the previously described boxes are individually analyzed before being averaged together in rows. First, if the water depth is $17 \mathrm{~m}$ or greater, a 2D median filter is applied to the data. A median filter is a non-linear operation that reduces "salt and pepper" noise while preserving the sharpness of an image. It filters the data according to the median of neighboring pixels instead of the mean. Therefore, it is less sensitive to outliers and extreme values than an averaging filter. In deep water, this translates to cleaner images of large scale ripples. The filter is not applied in shallow water because it would filter out the small ripples that are present. The data was detrended and a hanning filter was used to taper the edges of the data before a two-dimensional Fast Fourier Transform (FFT) is applied to solve for the ripple wave spectral components. Spectra from each row are then averaged with any other rows directly above or below it. These means are then averaged again with the similar result opposite of the centerline to get the final mean spectral properties of the image, referred to as $I\left(k_{x}, k_{y}\right)$ in the following calculations.

\section{Calculations}

From the mean properties of the images, the most important variables defining the environment are average water depth, position, and time. The Fast Fourier Transform (FFT) outputs the magnitude of the spectral amplitudes at a range of wavenumbers. A representative wavenumber to calculate ripple wavelength can be evaluated multiple 
ways. In this study, the peak wavenumbers $\left(P k_{x}\right.$ and $\left.P k_{y}\right)$ are evaluated with the following equations:

$$
\begin{aligned}
& P k_{x}=\frac{\iint_{x} k_{x} \cdot I\left(k_{x}, k_{y}\right)>0.5 \max I\left(k_{x}, k_{y}\right)}{\iint_{y} I\left(k_{x}, k_{y}\right) d k_{x} d k} \\
& P k_{y}=\frac{\left.\iiint_{x}, k_{y}\right)>0.5 \max I\left(k_{x}, k_{y}\right)}{\left.\iint k_{x}, k_{y}\right) d k_{x} d k} \underset{I\left(k_{x}, k_{y}\right)>0.5 \max I\left(k_{x}, k_{y}\right)}{\left.\int k_{y}\right) d k_{x} d k}
\end{aligned}
$$

where $k_{x}$ and $k_{y}$ represent wavenumber components. The integrals are limited to values within $50 \%$ of the peak wavenumbers. The rest are set to zero. From the peak wavenumbers, it is straightforward to calculate the wavelength of the ripples:

$$
\lambda=\frac{2 \pi}{\sqrt{P k_{x}{ }^{2}+P k_{y}{ }^{2}}},
$$

as well as the direction:

$$
\theta=\left(\frac{\pi}{180}\right) \tan ^{-1}\left(\frac{P k_{y}}{P k_{x}}\right) .
$$




\subsection{Ripple Analysis Results}

The following three figures are examples of sidescan sonar images collected for $10 \mathrm{~m}, 20 \mathrm{~m}$, and $45 \mathrm{~m}$ water depths. It is apparent that ripple wavelength increases with increasing water depth. Mud patches are present in 10 and 20 meter water depths, but not $45 \mathrm{~m}$. The ripples are also much more regular and well-defined in the deeper water. Orientation is difficult to discern in Figure 3-4, but seems fairly constant in Figures 3-4 and 3-6.

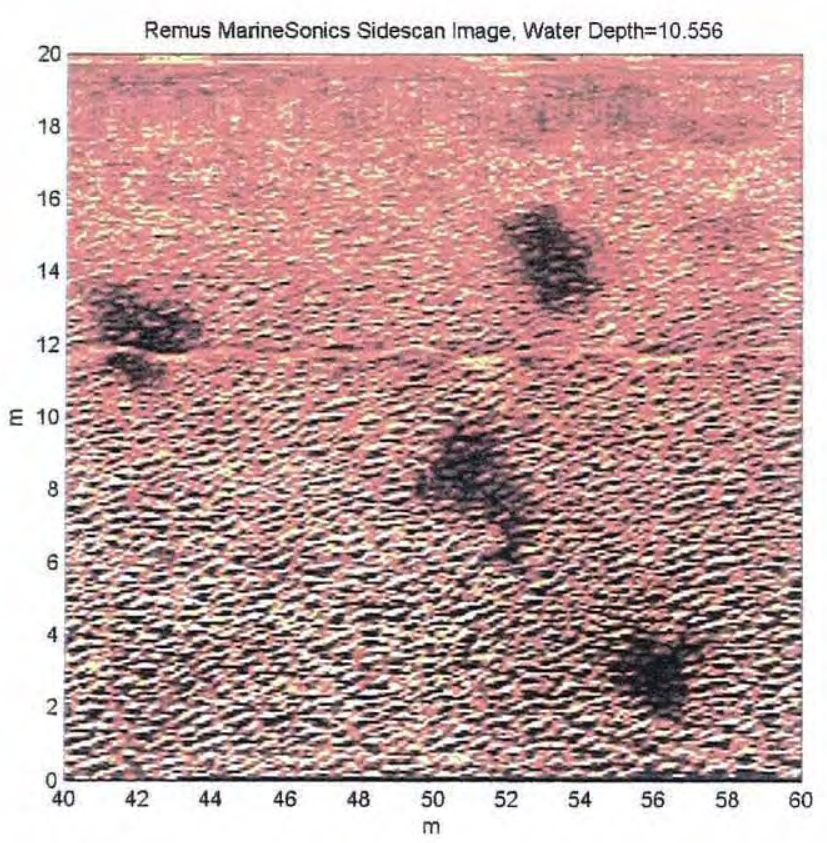

Figure 3-4: Sidescan sonar image collected in $10 \mathrm{~m}$ water depicting short ripple wavelengths and 2-4 m mud patches. 


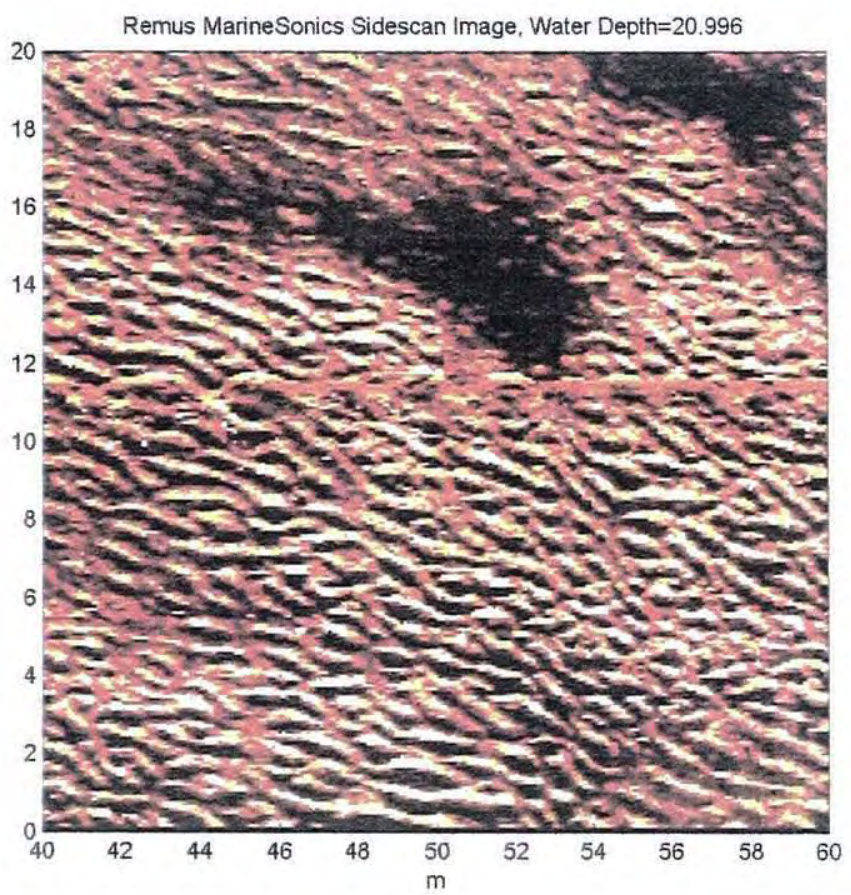

Figure 3-5: Ripples in 20 m water with larger wavelengths and mud patches (4-8 m).

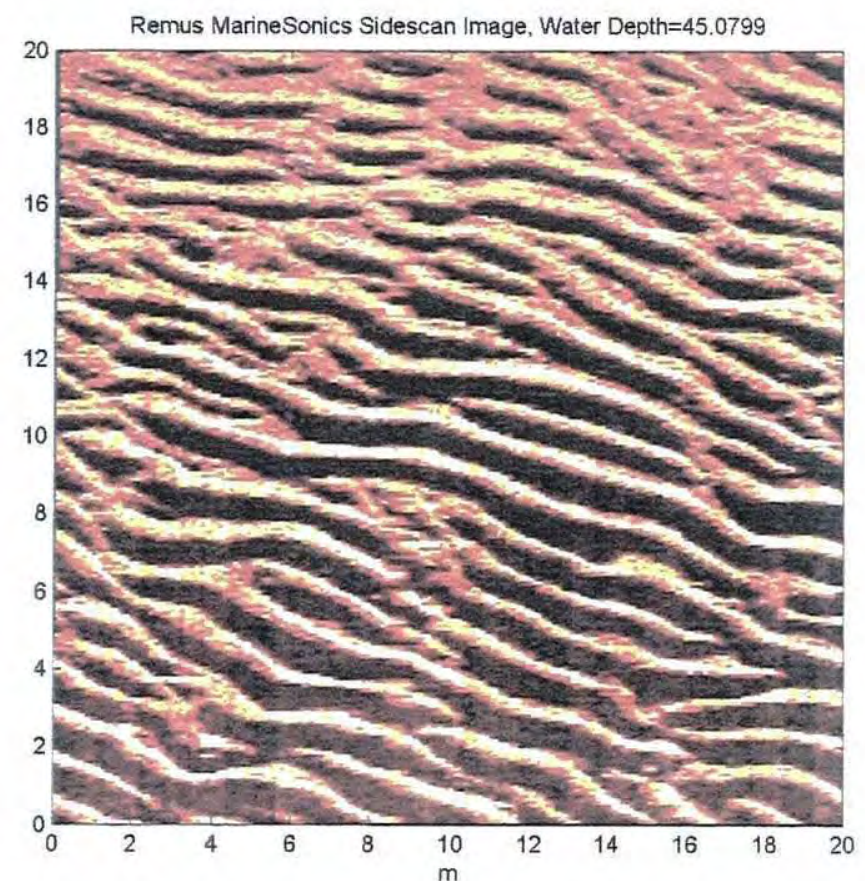

Figure 3-6: Well-defined, large ripples in 45 m water. 


\subsubsection{Ripple Wavelength}

The following figure first plots wavelengths calculated manually and then wavelengths calculated with FFT's, as described above.
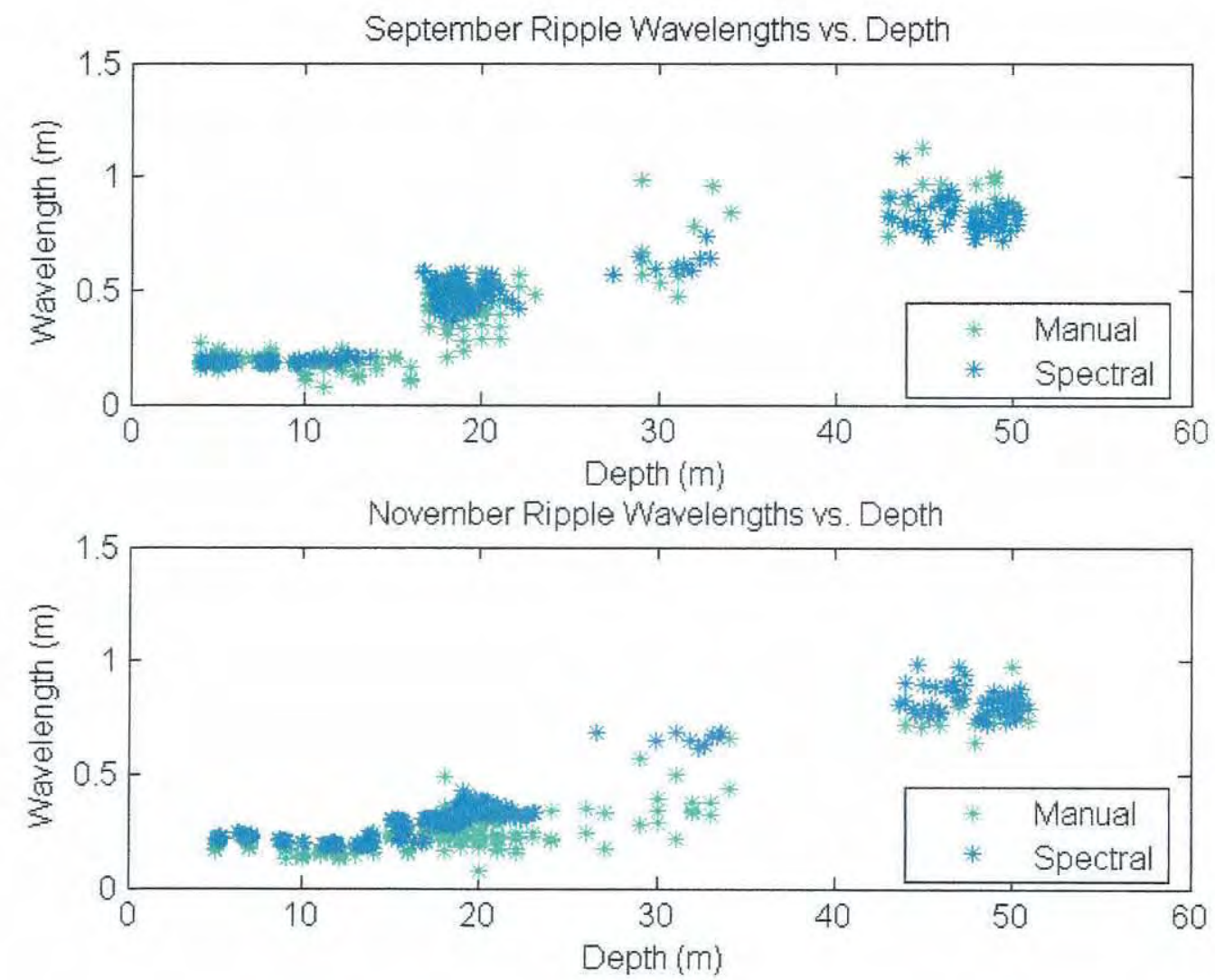

Figure 3-7: Comparison of ripple wavelengths from manual and spectral methods.

The results from both methods are fairly similar. The wavelengths increase linearly with water depth. However, the manually calculated wavelengths are slightly more scattered than those computed through spectral analysis. This is expected, as the manual measurement method is more vulnerable to human error and samples fewer 
ripples. On average, the wavelengths seem to be slightly underestimated with the manual calculation method. Significant trends in the data include a $0.2 \mathrm{~m}$ decrease in wavelength between the September and November at $20 \mathrm{~m}$ depth. The rest of the wavelengths remain relatively unchanged for both months.

\subsubsection{Ripple Orientation}

Like the wavelength plots, the ripple orientation plots for both methods are fairly similar, as seen in Figure 3-8. Again, the manually calculated values are much more scattered than those calculated spectrally. However, they are more spread out than the wavelength results. This is expected, and is a result of the manual measurement technique described in the earlier section. 

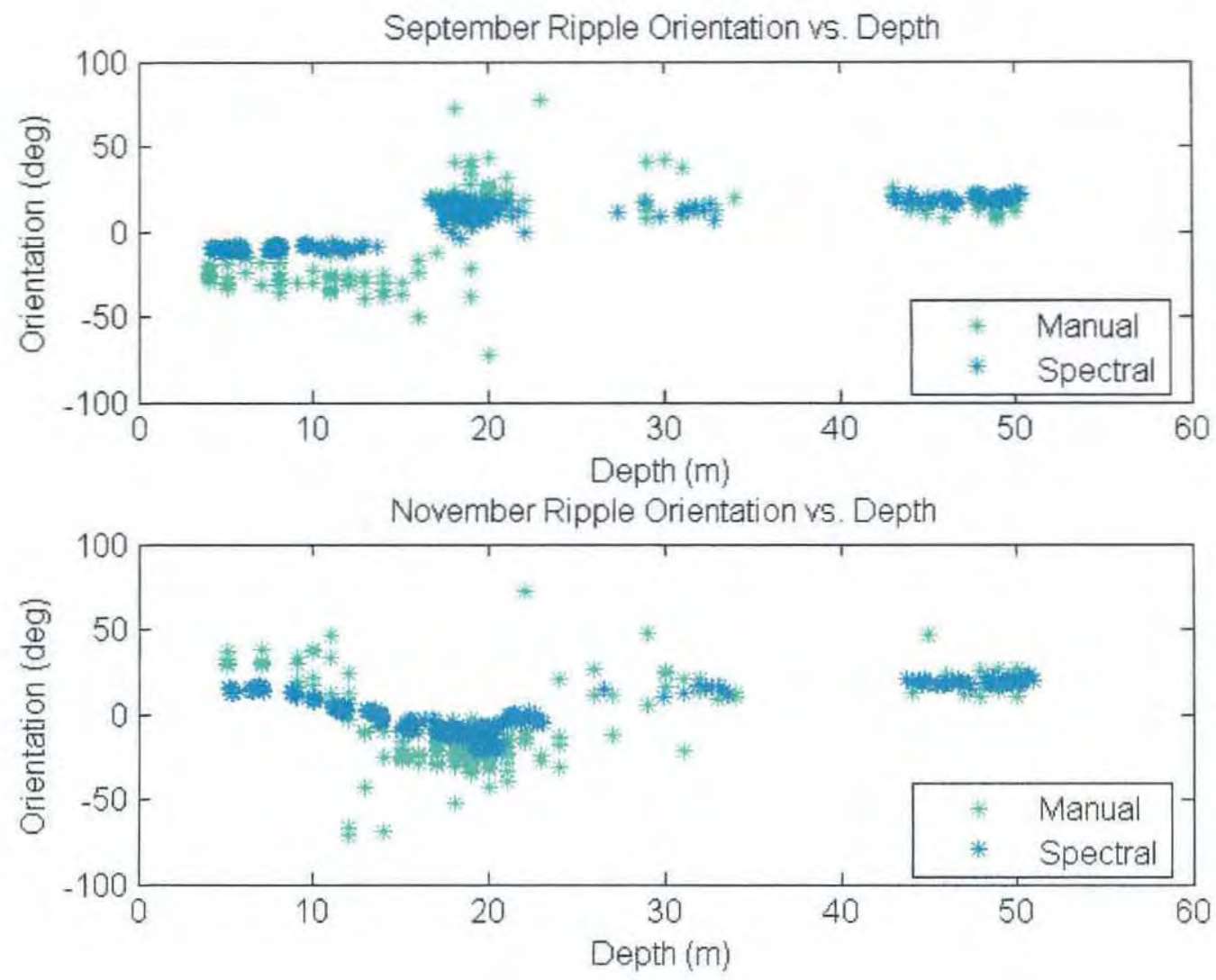

Figure 3-8: Comparison of ripple orientation from manual and spectral methods.

It is important to note that ripple orientations in $5 \mathrm{~m}$ to $23 \mathrm{~m}$ water shift up to $25^{\circ}$ between September and November. In shallower water, the ripples are $-10^{\circ} \mathrm{N}$ originally and shift to about $12^{\circ} \mathrm{N}$. The opposite change occurs in $17-23 \mathrm{~m}$ water, where the ripples begin at $15^{\circ} \mathrm{N}$ and shift to $-8^{\circ} \mathrm{N}$. The ripples in deeper water remain relatively unchanged for the two months.

Because the properties calculated spectrally are more precise due to the increased averaging, these will be used for further data analysis in this study instead of the manually calculated results. 


\subsubsection{Comparison to USGS Ripple Analysis Results}

The USGS research group collected sand ripple data independently of the WHOI group. They deployed an instrumentation system that applies both optical and acoustic techniques to collect ripple data. This system includes a multiple-transducer array (MTA), a sector scanning fan-beam sonar, a slide-projector camera system, and an ADCP.

The USGS data were not collected at the exact same locations as the WHOI sample sites. However, most of the USGS sites have at least one WHOI sample site nearby. In the following ripple wavelength and direction comparisons, each USGS sample point is compared to the results from the closest WHOI site. The following figures plot the matched sites for the September and November cruises. Figures 3-9 and 3-10 zoom in on Figure 2-1 and show all sample sites. 


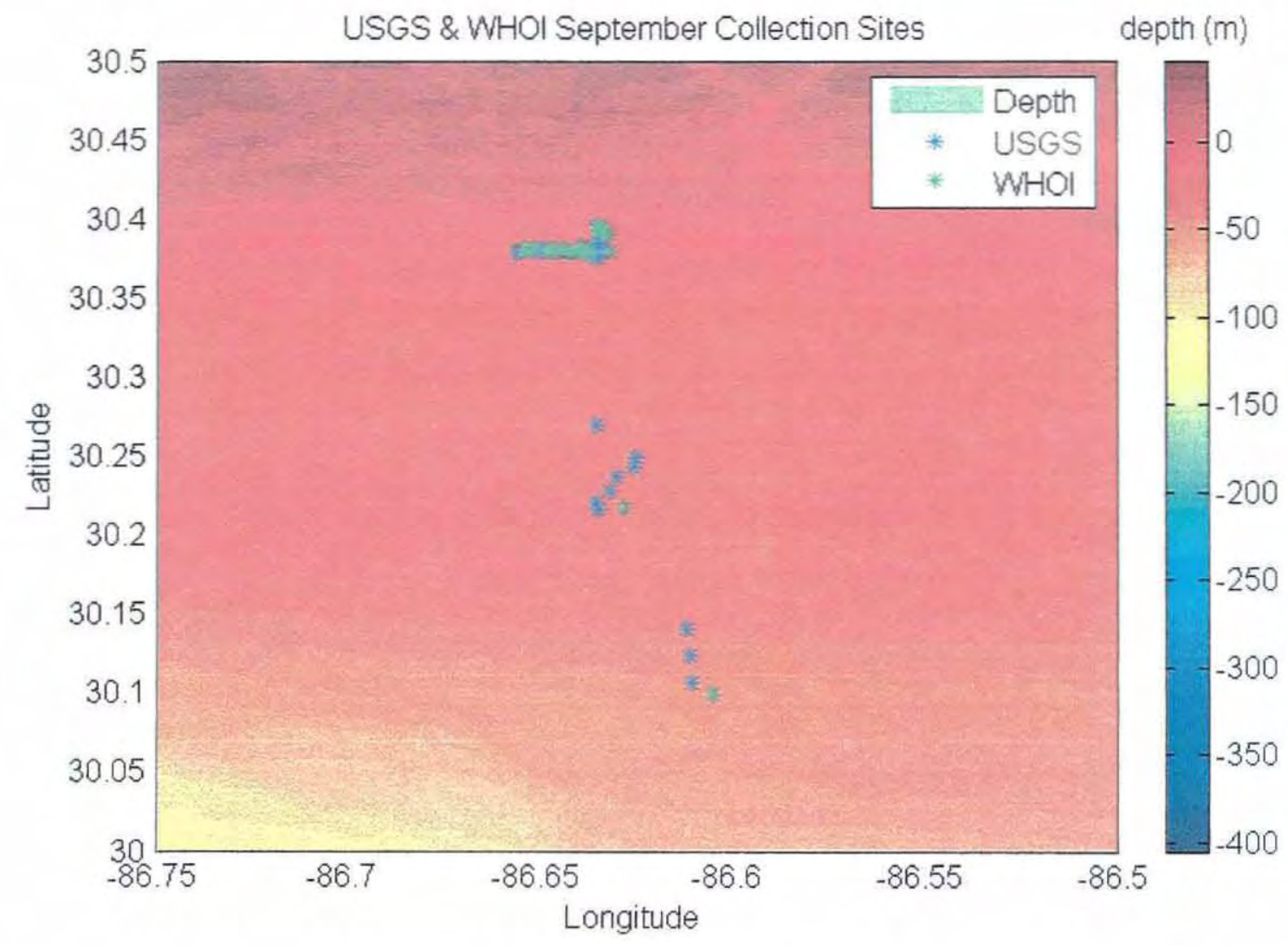

Figure 3-9: Matched USGS and WHOI September data collection sites according to water depth. 


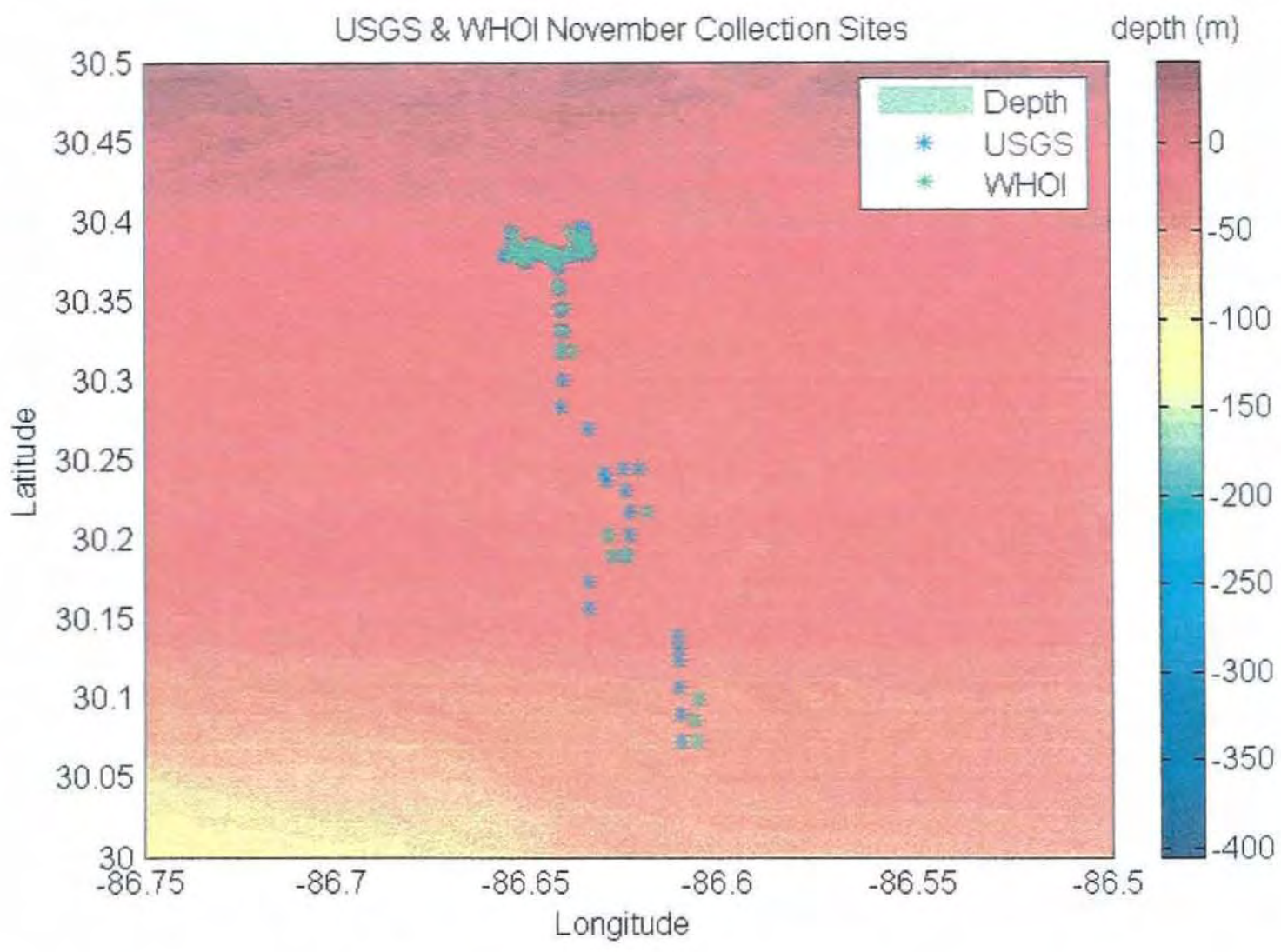

Figure 3-10: Matched USGS and WHOI November data collection sites according to water depth.

Most of the sites are located close to shore, and are difficult to differentiate at this resolution. Figures 3-11 and 3-12 zoom in on the shallow sites of both cruises. 


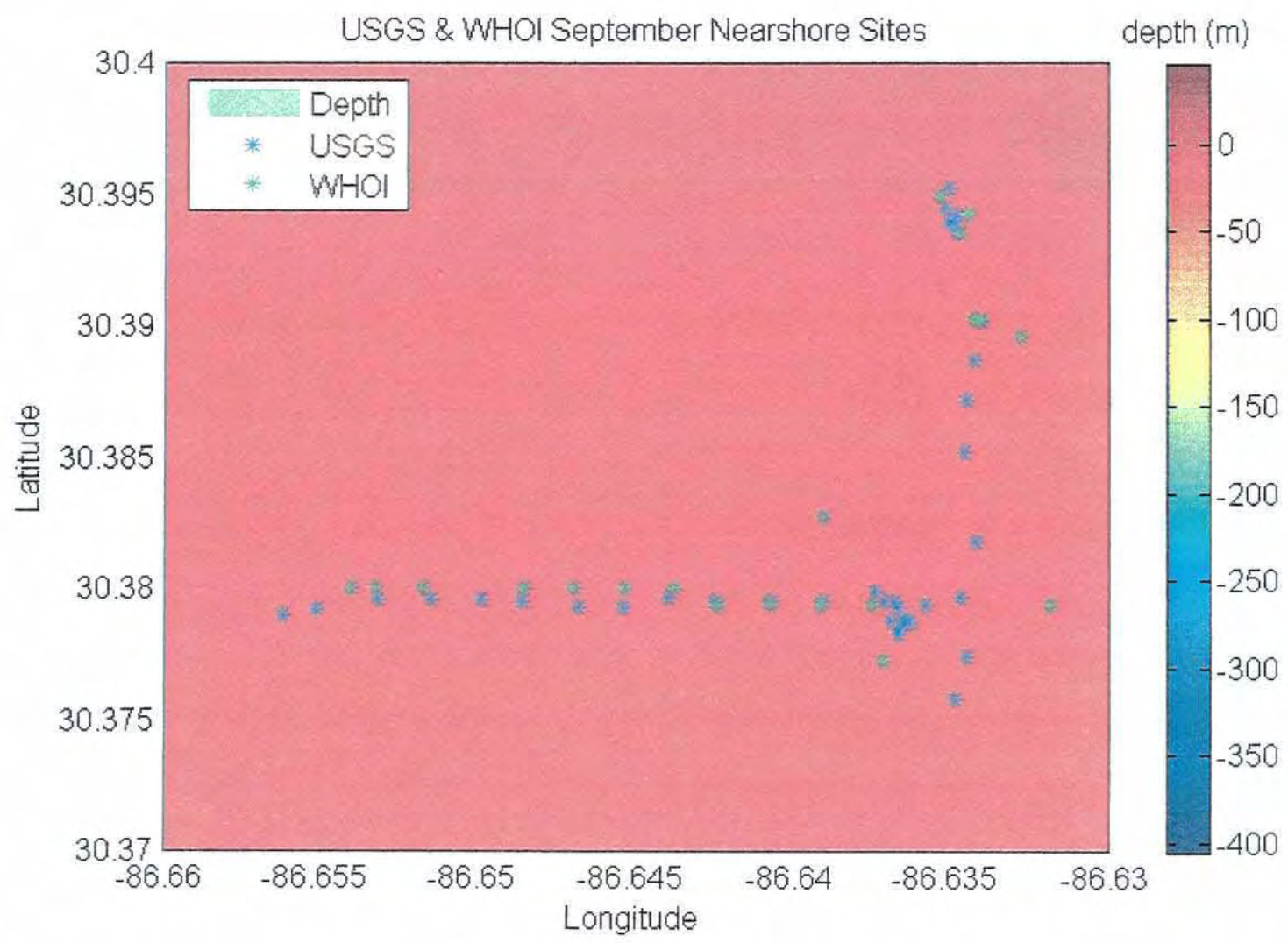

Figure 3-11: Enlarged view of matched USGS and WHOI nearshore collection sites in September. 


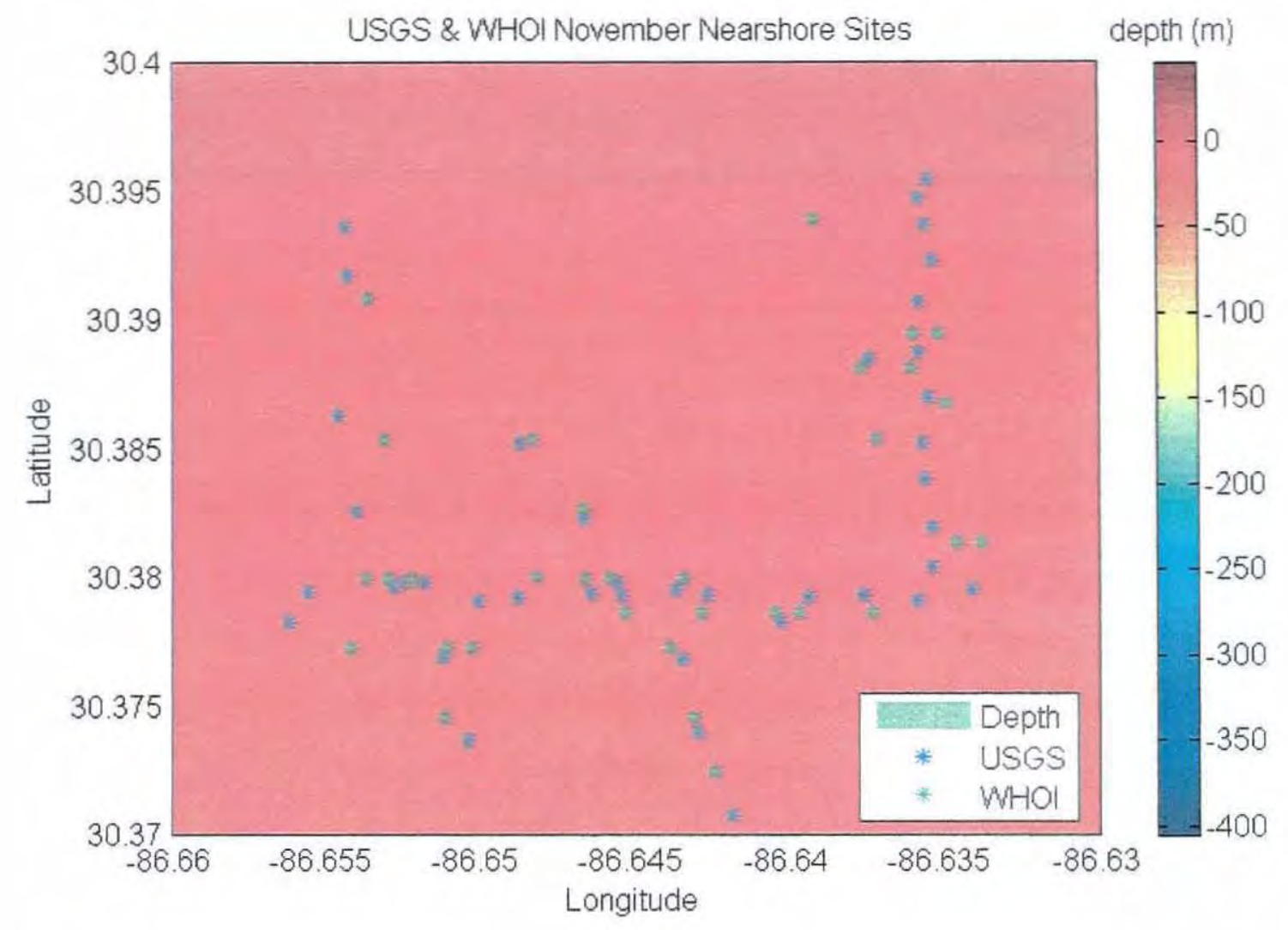

Figure 3-12: Enlarged view of matched USGS and WHOI nearshore collection sites in November.

Most of the matched sites are relatively close to each other, especially the shallow water sites. In deeper water however, some USGS sample locations do not match up well with WHOI sites. Often multiple USGS sites match up with the same WHOI site. This discrepancy is addressed in a later section.

\section{Ripple Wavelength Comparison}

Li Erikson analyzed the USGS sand ripple data. To measure wavelength, two different methods were used. First, 2D FFT's were applied to each sonar image from the 
rotary sidescan sonar, similar to the method described earlier. To verify the initial results, $\mathrm{Li}$ also used the slide projector and MTA to solve for ripple wavelength after correction for the position of the MTA across the ripple field. Although both methods produced similar results, few sites had both MTA and slide projector data available to analyze. Therefore, most sites rely solely on spectral results.

Figure 3-13 compares the USGS and WHOI calculated ripple wavelengths for the September and November research cruises. Although the USGS results have much fewer sample points, it is clear that the two correspond well at all depths.
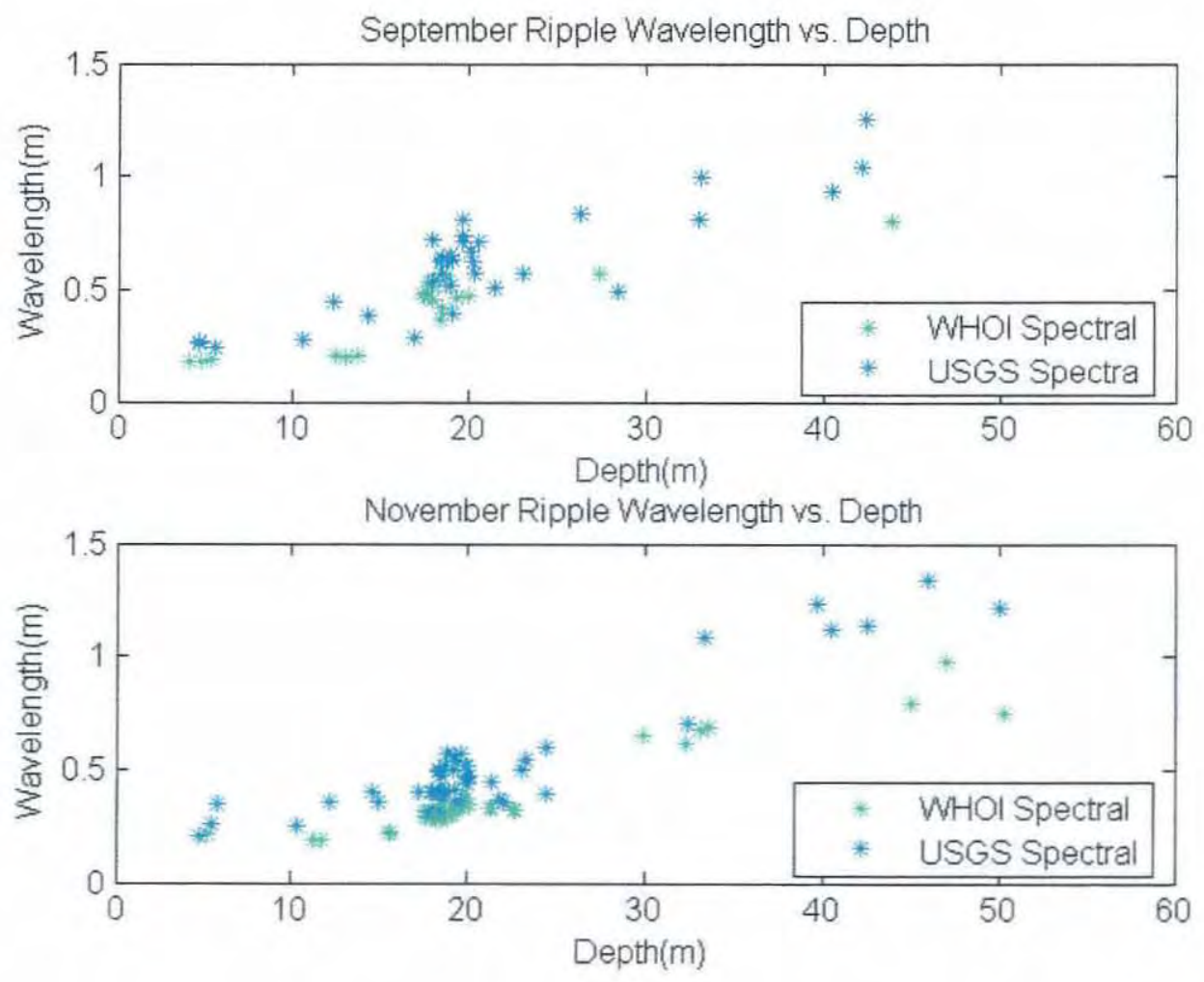

Figure 3-13: Comparison of WHOI and USGS spectral calculations of ripple wavelength. 
Figure 3-14 plots the USGS wavelength results versus the WHOI results for both research cruises, with the color of the plot markers representing mean water depth. The linear trend of the results confirms the similarity of the wavelengths measured by the two research groups. Most of the compared wavelengths differ by less than $0.2 \mathrm{~m}$, which is a relatively small amount of error. More of the outliers were collected by the November cruises, with the greatest discrepancy only about $0.4 \mathrm{~m}$.

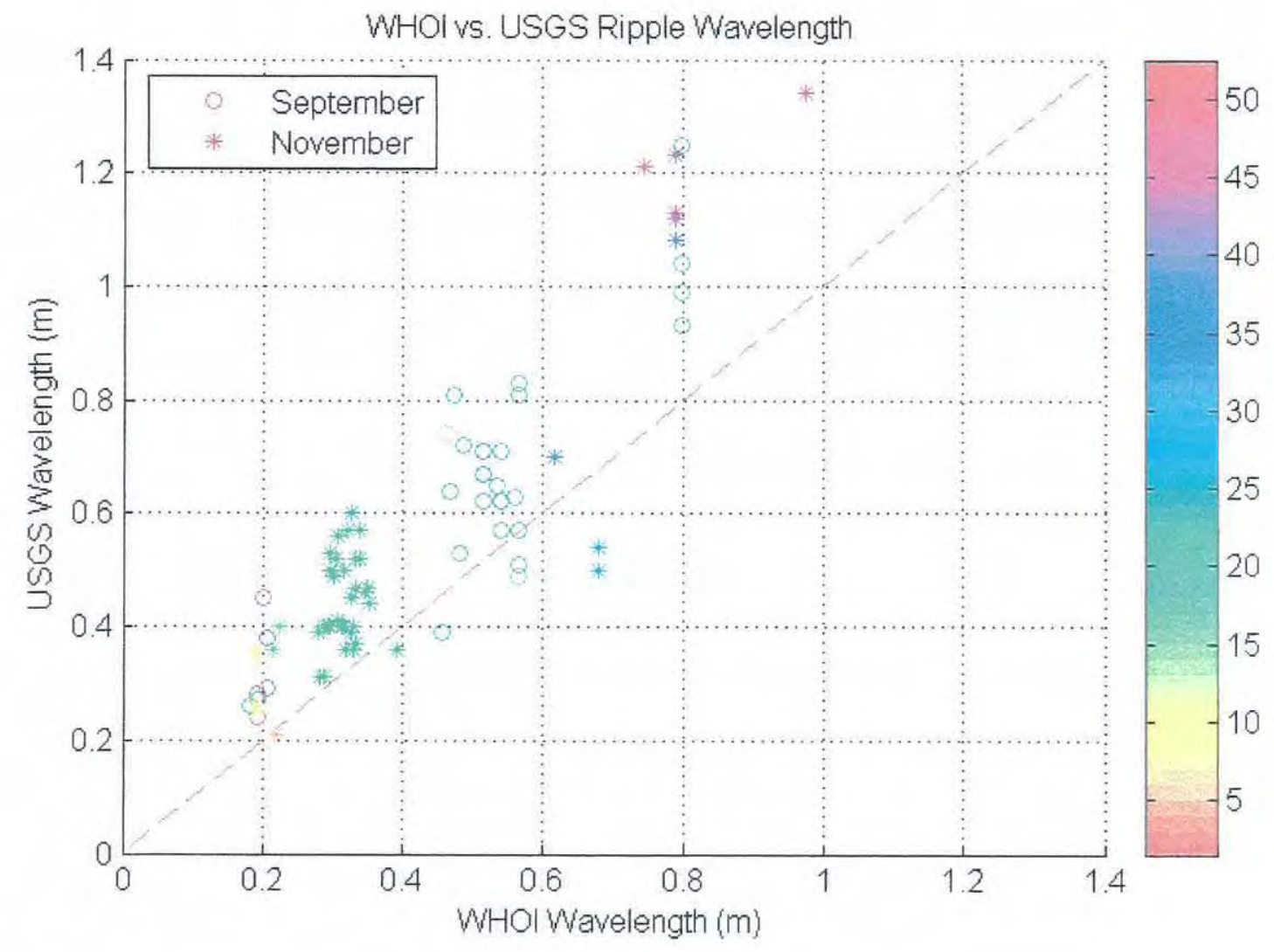

Figure 3-14: Linear comparison of USGS and WHOI ripple wavelength. 


\section{Ripple Orientation Comparison}

To solve for ripple orientation, the USGS group examined the areas least affected by the rotation of the sonar. Three different methods were used. The most robust approach was similar to the WHOI calculation method. A 2D FFT was applied to the images to obtain peak wave number spectral components which were then used to calculate ripple orientation using Equation 3.16. To verify these calculated results, the direction was also manually measured directly from the image with a protractor. As a final check, points on the image were digitized to calculate the orientation of the ripples. The following figures were produced from USGS ripple analysis results. Figure 3-15 plots the WHOI and USGS ripple orientations according to water depth for both cruises. Unlike the wavelength comparison, WHOI and USGS orientations differ from each other fairly significantly. 
September Ripple Orientation vs. Depth

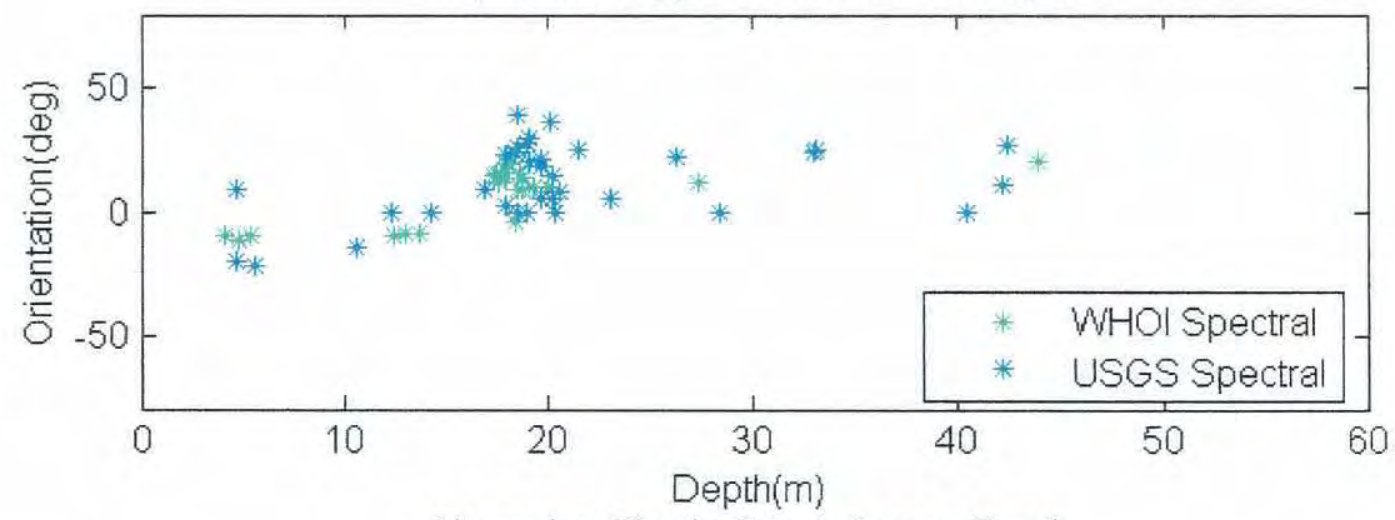

November Ripple Orientation vs. Depth

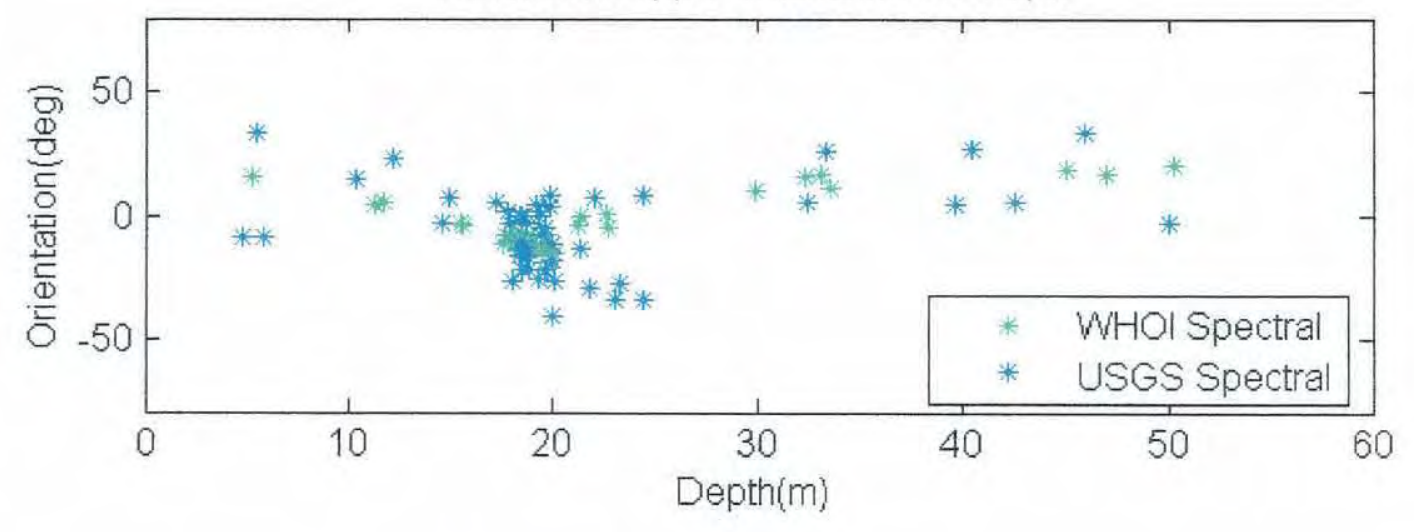

Figure 3-15: Comparison of WHOI and USGS spectral calculations of ripple orientation.

Again, the relationship between the results from each group can be examined more concisely when they are plotted against each other. Figure 3-16 reveals the large spread of values around the linear trend marked by a blue line. While most results only differ by $0^{\circ}$ to $20^{\circ}$, with an average difference of about $8^{\circ}$, the largest discrepancy reaches $45^{\circ}$. This disparity is too large to be ignored. 


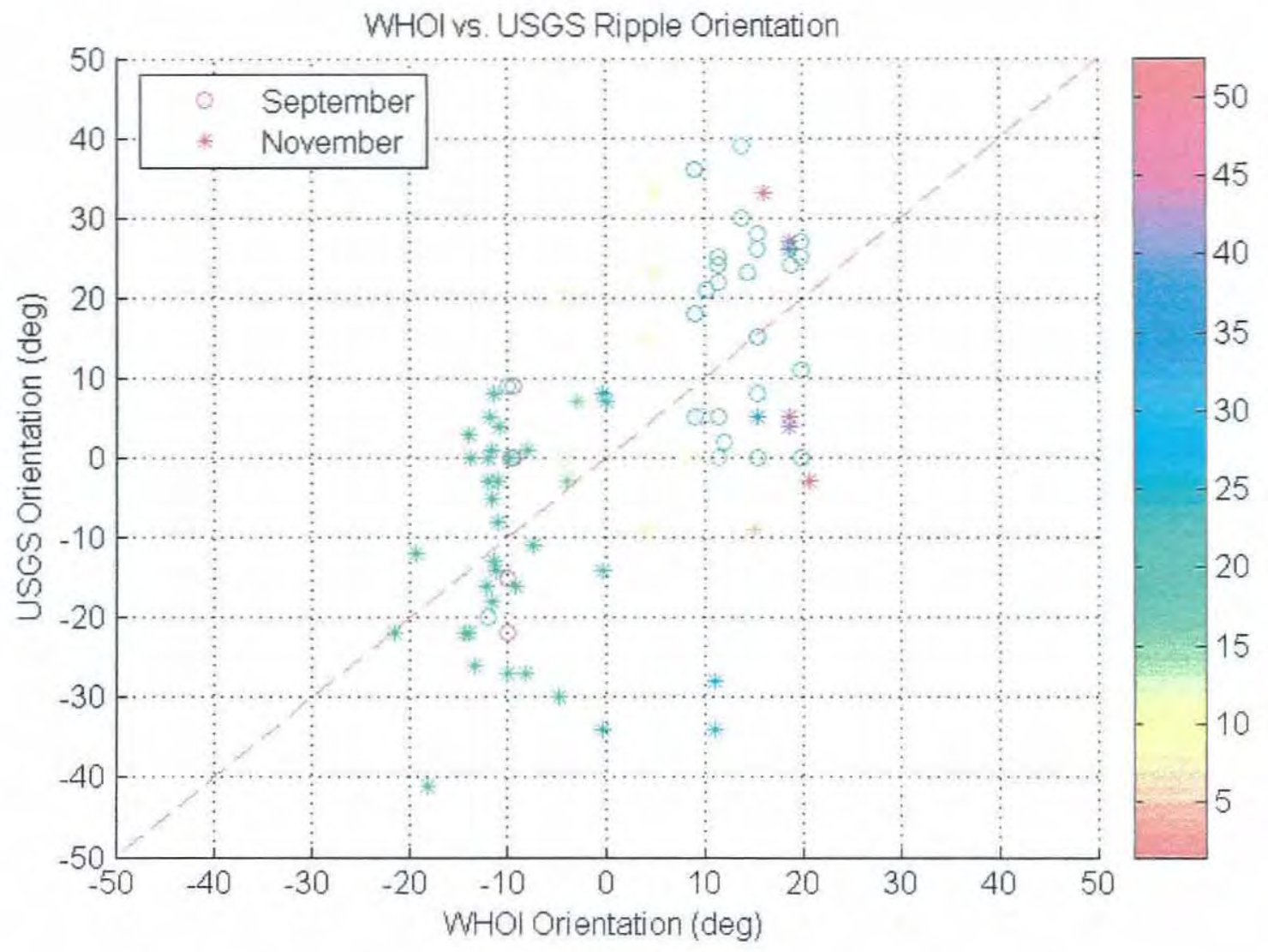

Figure 3-16: Linear comparison of USGS and WHOI ripple orientation.

There are two proposed explanations for the differences in USGS and WHOI calculated ripple orientations. First of all, as mentioned earlier, the sample locations for the two groups are not exactly the same. In fact, some matched data points are almost 6 $\mathrm{km}$ apart. The following figure plots the absolute difference between calculated ripple directions and the distance between the locations of the matched points. The maximum disagreement between sample points within $2 \mathrm{~km}$ is $27^{\circ}$. The three largest orientation discrepancies belong to points that are over $2.5 \mathrm{~km}$ apart. 


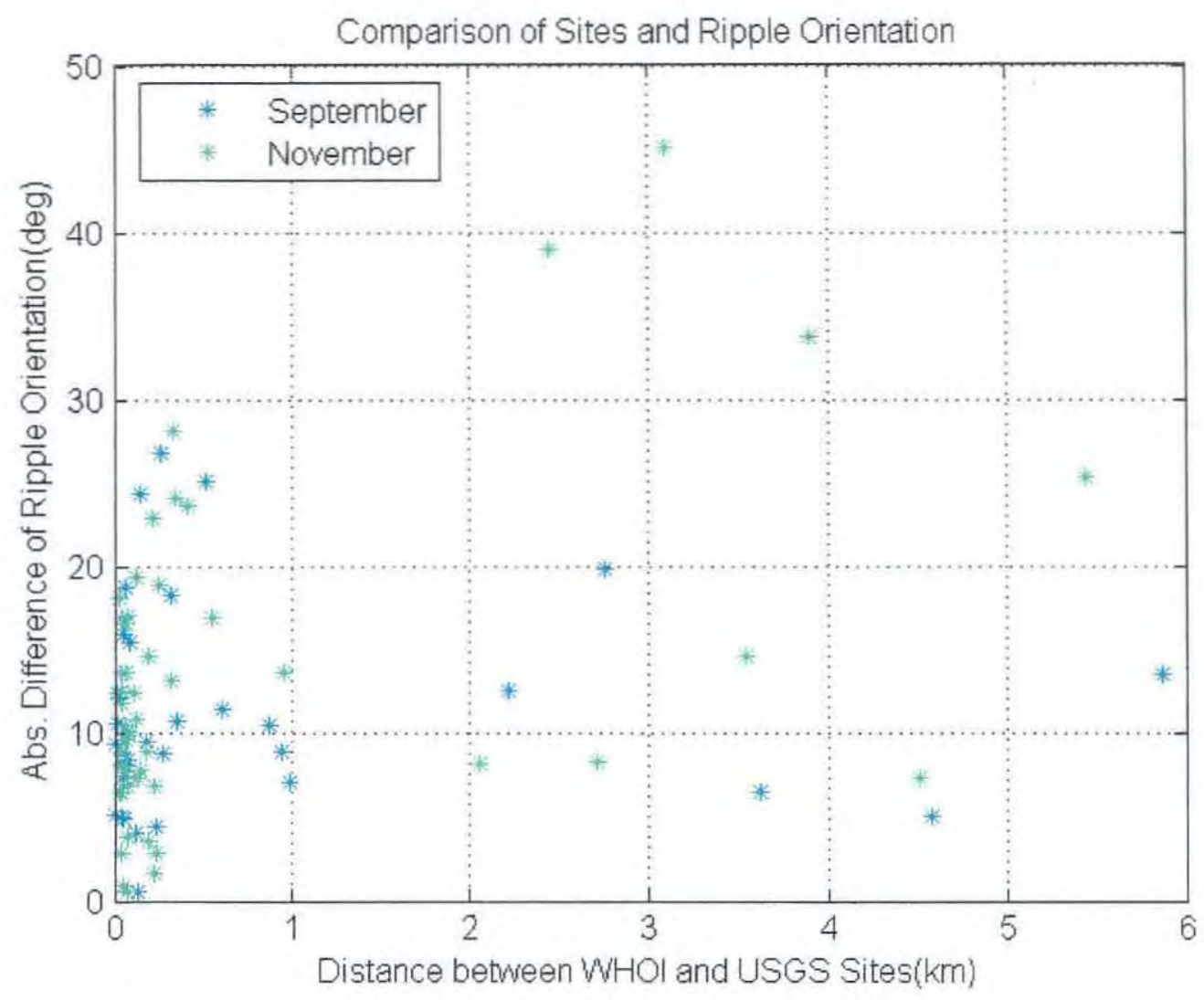

Figure 3-17. Comparison of the difference between WHOI and USGS ripple orientations and distance between WHOI and USGS sample sites.

To examine this more clearly, WHOI and USGS sites that are within $100 \mathrm{~m}$ of each other are plotted in Figure 3-18. Compared to Figure 3-16, the ripple orientations maintain a much more linear trend. On average, the orientations are within $10^{\circ}$ of each other. Most of the extreme outliers have been eliminated, with the largest discrepancy being only $25^{\circ}$. Therefore, the distance between the WHOI and USGS sample locations is extremely significant when comparing the calculated ripple orientation results from the two groups. 


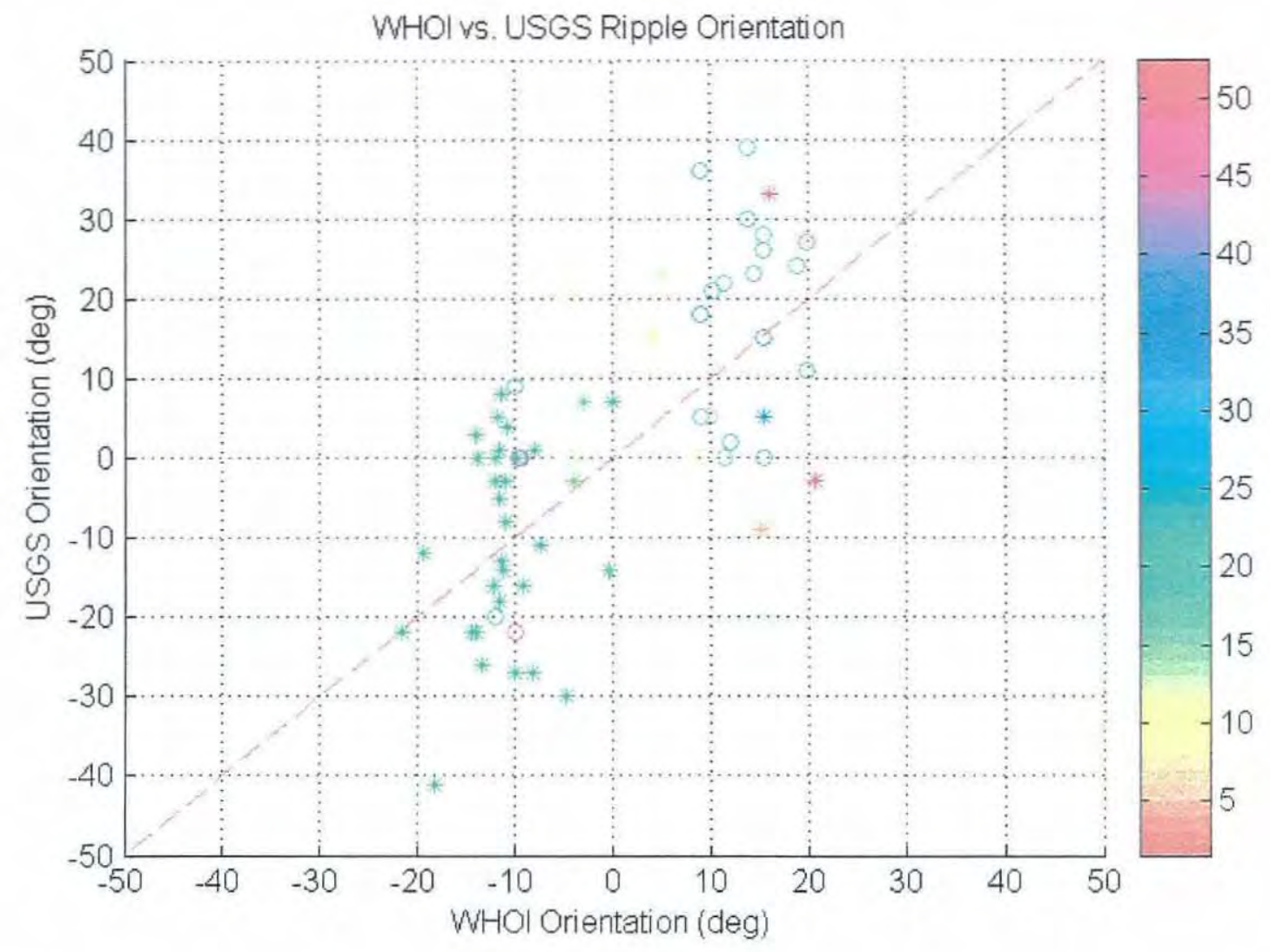

Figure 3-18: Linear comparison of USGS and WHOI sites within $100 \mathrm{~km}$ of each other.

Another explanation of the difference between the WHOI and USGS ripple orientation results is the sparseness and sampling techniques of the USGS data. The USGS group has fewer data collection sites than the WHOI group. From their limited sites, the sample areas are also smaller, sometimes only $2 \times 2 \mathrm{~m}$. Each WHOI sample site corresponds to a 40x1500 m sidescan sonar image, averaged according to the overlapping box method described in the earlier section. There are concerns with the reliability of the USGS compass as well, as the tripod swiveled on its axis while traveling to the ocean floor. Also, the rotation of the USGS digital imaging sonar causes the observed ripples to 
appear slightly concentric, which makes orientation difficult to calculate accurately. These discrepancies have been corrected for, but because the REMUS traveled in fairly well constrained east-west tracks along the ripple crests, WHOI measurements referenced from these orientations are more trustworthy.

Despite the discrepancies between the results from the two groups, the ripple orientation results are still comparable, considering the different sampling locations and techniques.

\subsubsection{Conclusions}

The USGS ripple wavelength and orientation measurements correspond well with the WHOI measurements calculated earlier in this section. The agreement of these measurements increases confidence that neither technique has major errors. Because WHOI measurements are calculated by a more reliable technique, these ripple wavelength and orientation results will be applied in the rest of the study. 


\section{Chapter 4}

\section{Wave Modeling and Analysis}

\subsection{Wave Records}

In order to predict ripples in shallow water near the sidescan sonar data collection sites, information about the surface wave field is required. Unfortunately, the Datawell buoy and bottom pressure recorder at NPS Site 9 were damaged during Hurricane Ivan. Therefore, the NPS bottom pressure recorder at Site 7 is the station closest to the sidescan sonar collection sites with available data. The following figure shows the location of NPS Site 7 in relation to the sidescan sonar sites as well as the location of nearby NDBC buoys with available wave data records. 


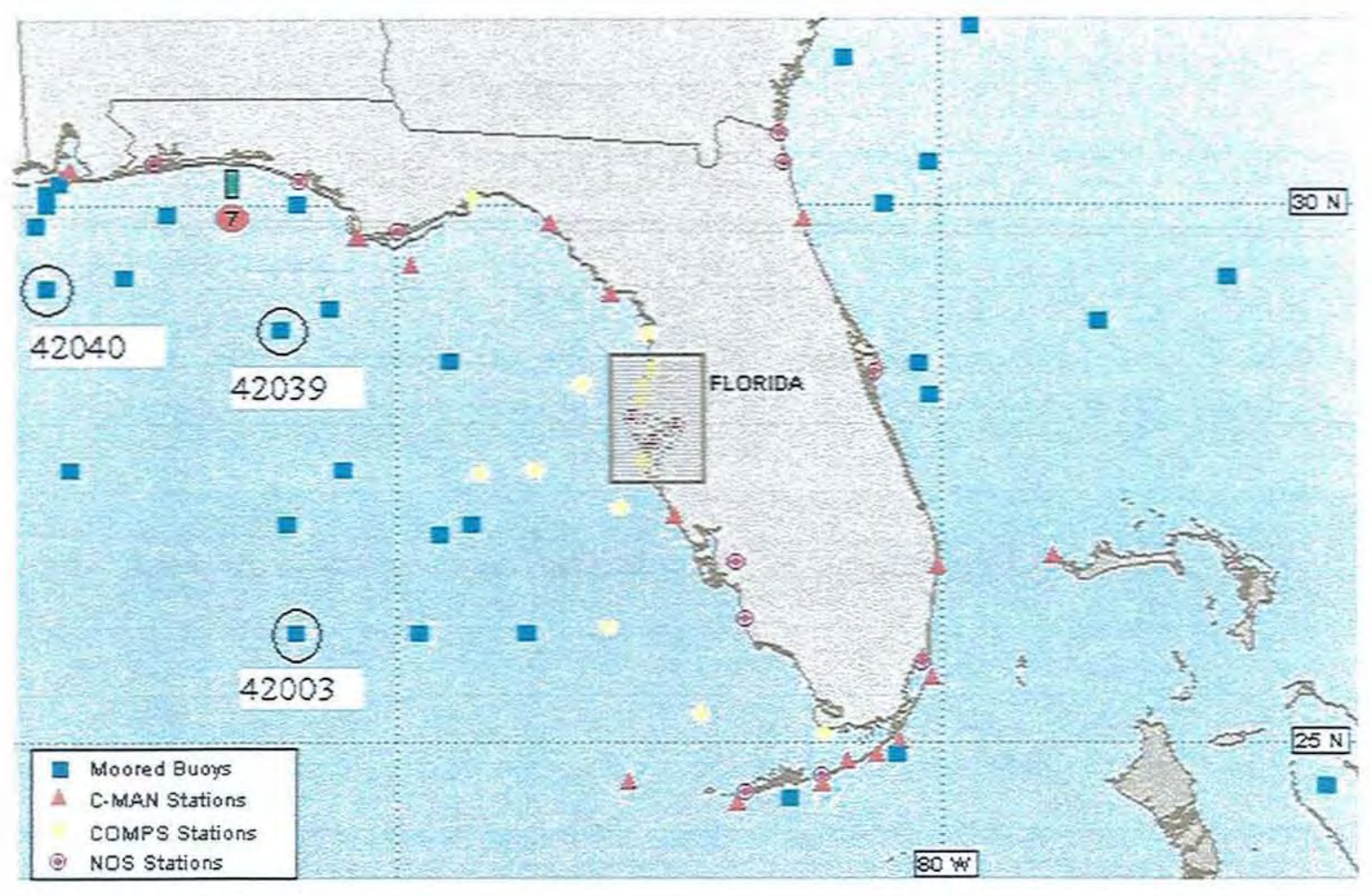

Figure 4-1: Locations of REMUS legs (marked by a green box with black border), Site 7 (marked with a red circle), and NDBC Buoys 42003, 42039, and 42040 (circled).

Map courtesy of NDBC.

Although the buoy at Site 7 collected data throughout the entire experiment, the data is non-directional. Wave height and wave energy density spectra were recorded with a seafloor mounted pressure sensor, but not wave direction. Because wave direction is extremely important in predicting the location and orientation of sand ripples, data from three nearby NDBC buoys must be examined. As seen in the figure above, the closest NDBC buoy to Site7 is Buoy 42040 . Unfortunately, this buoy also cut out during Hurricane Ivan and did not record data for almost two months after the storm passed. The next closest NDBC buoy is Buoy 42039. This buoy has a fairly reliable data set of 
wave height and energy density. Although Buoy 42039's directional data are not always physically realistic, as it indicated waves directly from the east during Hurricane Ivan when the winds were predominantly from the south, it was initially the only directional data available near the experiment site during the storm. Therefore, information from Site 7 and Buoy $\mathbf{4 2 0 3 9}$ was combined to create a preliminary representation of surface gravity waves during Hurricane Ivan.

Figure 4-2 plots the recorded wave heights at the UGGS sites and NDBC buoys during Hurricane Ivan. As mentioned above, the buoy at Site 9 and Buoy 42040 cut out at the peak of the storm. However, the wave records for Buoys 42040 and 42039 are extremely similar up to that point. Therefore, we will make the approximation that the wave field at Buoy 42039 is similar to the field at 42040 , which is closer to Site 7 . 


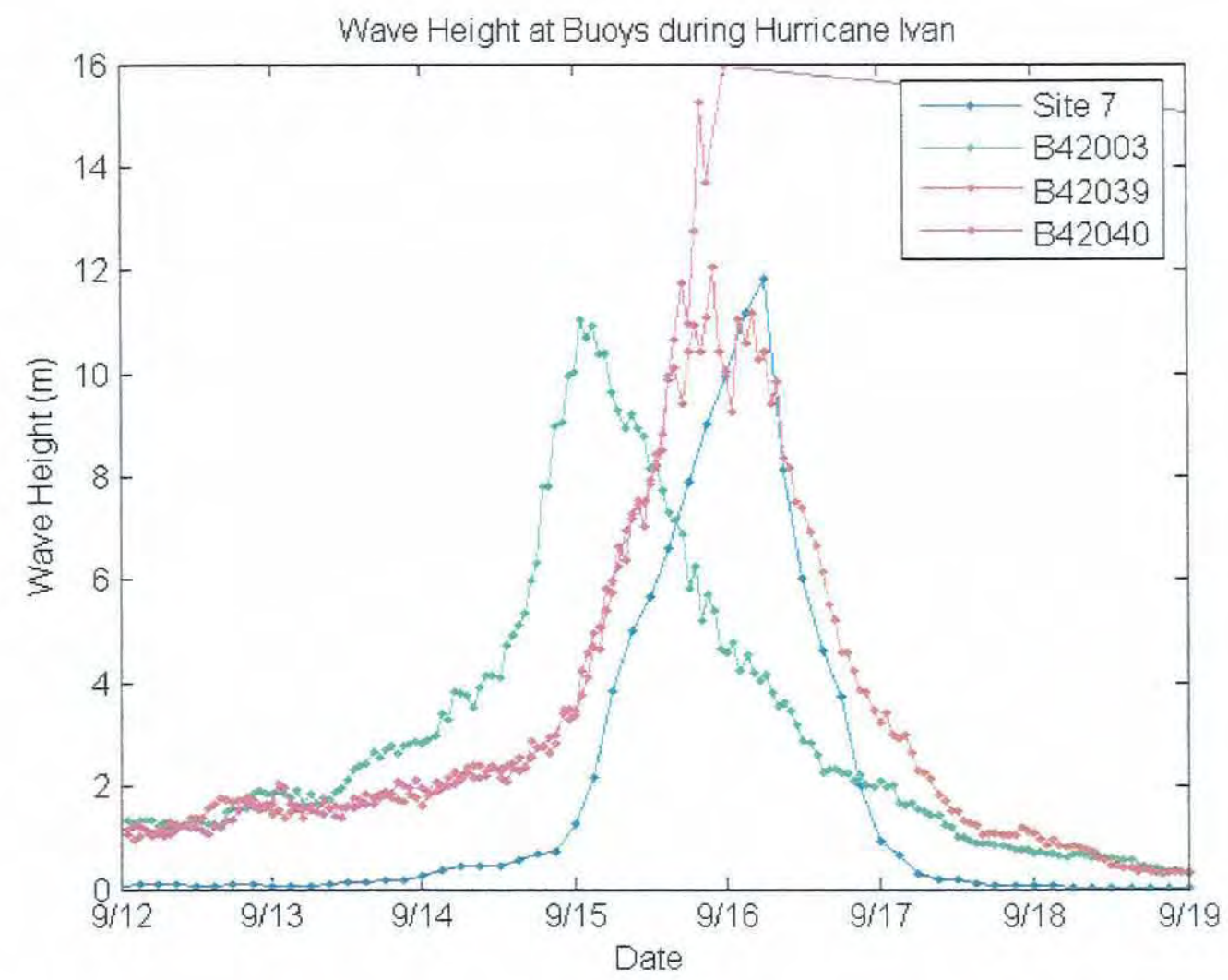

Figure 4-2: Wave heights during Hurricane Ivan at Site 7, and NDBC Buoys 42003, 42039, and 42040.

When examining the wave heights in Figure 4-2, it is evident that the peaks of the records at each location are shifted in time. These shifts can be easily explained after comparing the locations of the buoys. For example, Buoy 42003 is positioned the furthest south and reaches its maximum wave height first. This corresponds to Hurricane Ivan's approach from the south. The storm affects Buoy 42003 first, then influences Buoys 42039 and 42040 as it travels northward into more shallow water. Site 7 is the last to be influenced, reaching its maximum wave height about 29 hours after the first buoy. 
In order to relate Buoy 42039's wave directions to the wave heights and energy density spectra from Site 7, the effects of the time delay were removed. Also, Buoy 42039's sampling rate was decreased to every 3 hours to match Site 7's data record. Figure 4-3 plots the resulting wave height profiles for the two buoys.

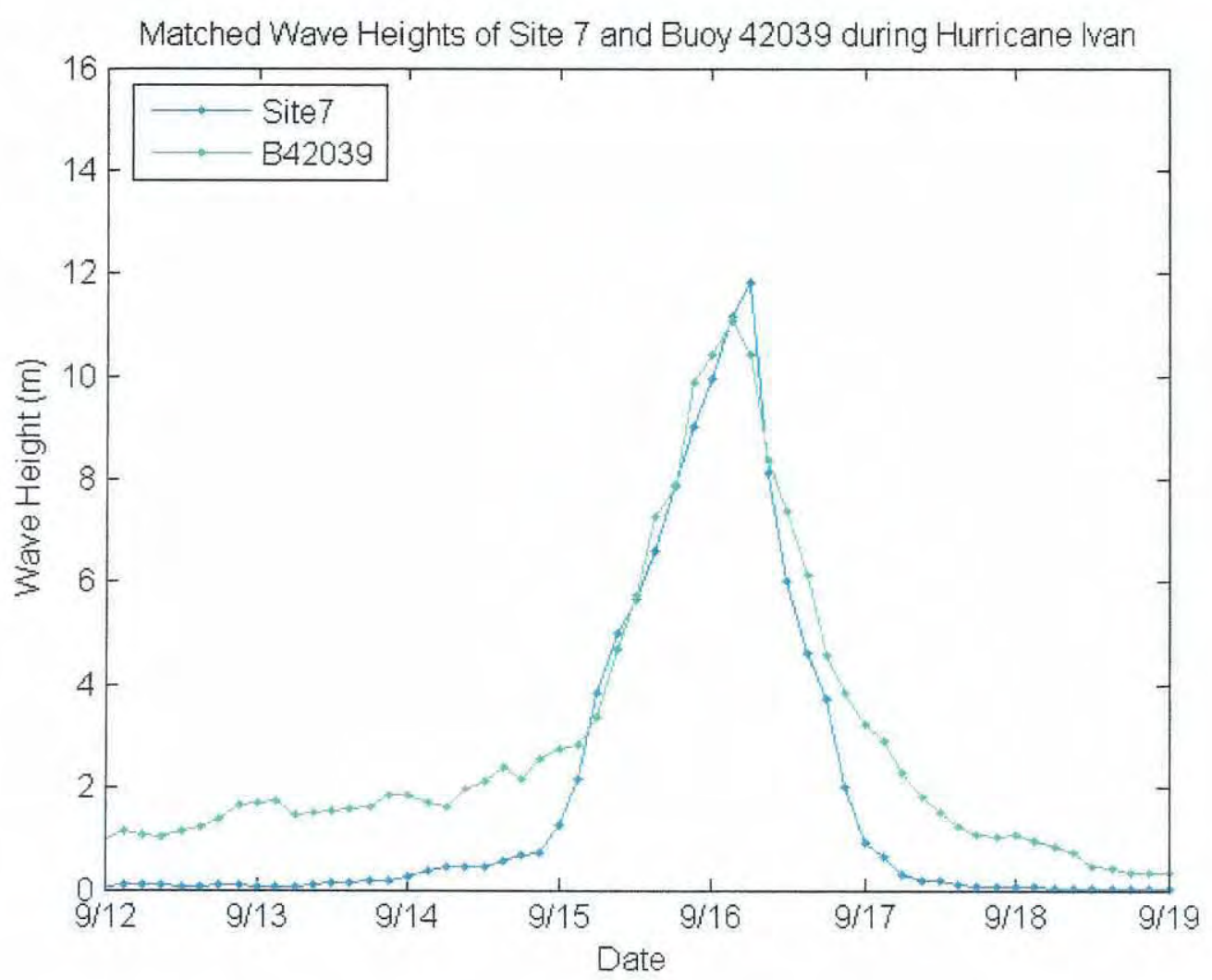

Figure 4-3: Manipulated wave heights matching Site 7 and NDBC Buoy 42039 wave conditions during Hurricane Ivan.

Buoy 42039's wave direction data from these times are then applied to Site 7's wave heights and energy density spectra. An important note is that Site 7's spectra are evaluated at different frequencies than Buoy 42039's spectra. For this study, Buoy 
42039's spectra have been interpolated to match the frequencies used at Site 7. All further calculations for Site 7 use this compiled data set.

\subsection{Wave Refraction}

Site 7 is not located near enough to the sidescan sonar collection sites to represent the wave conditions in those areas. However, it is possible to calculate shallow water wave heights and directions from data collected at deeper water locations. This section will explain the calculations required to compute wave heights and directions at the sidescan sonar collection sites.

To solve for wave heights and directions in increasingly shallow water in steady state, refraction and conservation of energy must be applied. Therefore, certain assumptions have been made. First of all, the offshore contours of the ocean floor are assumed to be straight and parallel. In this case, the bathymetry of the seafloor is approximated as a single linear depth profile. The profile ranges from a depth of $86 \mathrm{~m}$ at Site 7 to a shallow water depth of $10 \mathrm{~m}$, decreasing by $0.5 \mathrm{~m}$ in between. This condition is applied over the sample area. However, there is some error associated with this assumption, which will be evident when a more complete model is used to calculate the wave field.

Wave height can be calculated from statistical or spectral data. In the context of this paper, statistical data refers to significant wave heights, dominant periods, and average directions of the waves recorded at Site 7. In contrast, spectral data refers to 
energy densities and wave directions for varying frequencies. As this study is concerned with the waves propagating from Site 7 to shallow water, only data for incoming waves, $90^{\circ} \mathrm{N}<\theta<270^{\circ} \mathrm{N}$, will be considered in this study.

\subsubsection{Wave Height Calculations From Statistics}

In the statistical calculation, wave height at increasingly shallow locations will be solved for using:

$$
H_{2}=H_{1} K_{s} K_{r} \text {, }
$$

where $H_{I}$ is Site 7's incoming surface wave height, $K_{s}$ is the shoaling coefficient, and $K_{r}$ is the refraction coefficient. $K_{r}$ is defined as:

$$
K_{r}=\left(\frac{1-\sin ^{2} \theta_{1}}{1-\sin ^{2} \theta_{2}}\right)^{1 / 4},
$$

where $\theta_{1}$ is the incoming wave angle, and $\theta_{2}$ is the refracted wave angle. $K_{s}$ is defined as:

$$
K_{s}=\sqrt{\frac{C_{g_{1}}}{C_{g_{2}}}},
$$

where $C_{g_{1}}$ is the incoming wave group speed, and $C_{g^{2}}$ is the refracted wave group speed. However, to solve the above equations, refracted wave angle and incoming and refracted group speeds must be calculated.

To determine group speeds, wave number $k$ is calculated for each depth along the linear profile using the dispersion relation: 


$$
\sigma=\sqrt{(g k) \tanh (k h)},
$$

where $h$ is the assumed linear profile discussed above. In these calculations, $k_{l}$ is the wave number at Site 7 , and $k_{2}$ is the wave number at the shallower depth. Next, phase speed is determined from:

$$
C=\frac{2 \pi}{k} \tanh (k h) .
$$

Phase speed can then be used to solve for group speed:

$$
C_{8}=\frac{C}{2}\left(1+\frac{2 k h}{\sinh (2 k h)}\right)
$$

for incoming and refracted waves. As discussed in the earlier section, average wave direction for Site 7 is approximated by an adjusted data set from Buoy 42039. The incoming wave direction, $\theta_{1}$, is included in this data set, and $\theta_{2}$ can be easily calculated using Snell's Law:

$$
k_{2} \sin \theta_{2}=k_{1} \sin \theta_{1} .
$$

These variables make it possible to compute the refraction and shoaling coefficients (Equations 4.2 and 4.3 respectively) and therefore determine wave height in shallow water with Equation 4.1.

\subsubsection{Wave Height Calculations From Spectra}

Calculating wave height from spectral energy densities is a little more complicated than using statistical data. However, the results are often more reliable, 
especially for ripple calculations which require wave properties at the seafloor. With spectral energy densities, quantities can be translated down to the seafloor individually for each frequency. This is significant because exponential decay varies with frequency. Therefore, if spectral information is available, it is valuable to apply it to the analysis.

When solving for significant wave height in shallow water from spectral energy densities, the steps to calculate $\theta(f)_{2}, k(f)_{1}, k(f)_{2}, C(f), C(f)_{g}, K(f)_{r}$, and $K(f)_{s}$ remain the same. However, for every point in time, each sample frequency has a corresponding energy density and wave direction. Therefore, each variable must be solved for according to every frequency. Next, spectral densities for the refracted waves, $S(f)_{2}$, are calculated, using a similar equation to the one above:

$$
S(f)_{2}=S(f)_{1} K(f)_{s}{ }^{2} K(f)_{r}{ }^{2},
$$

where $S(f)_{1}$ represents the input spectral densities from Site 7. Significant wave height is easily solved for from the refracted spectral densities using:

$$
H_{2}=4 \sqrt{\sum\left(S(f)_{2} \cdot d f\right)},
$$

where $d f$ is the bandwidth of each frequency band. This step is crucial because it sums the energy densities over all frequencies to obtain the total energy at the location.

\subsubsection{Comparison of Wave Height Calculations}

Figure 4-4 compares the wave heights calculated from statistics with those calculated from energy density spectra during Hurricane Ivan. The top two plots 
summarize average wave heights and dominant wave periods at Site 7 for the examined time period. Very large period waves occur up to and at the peak of the storm, and are highlighted in red. These low frequency waves are significant when calculating wave heights by the methods described above. Therefore, the corresponding waves are marked in the bottom plot of the difference between the two calculation methods as well.
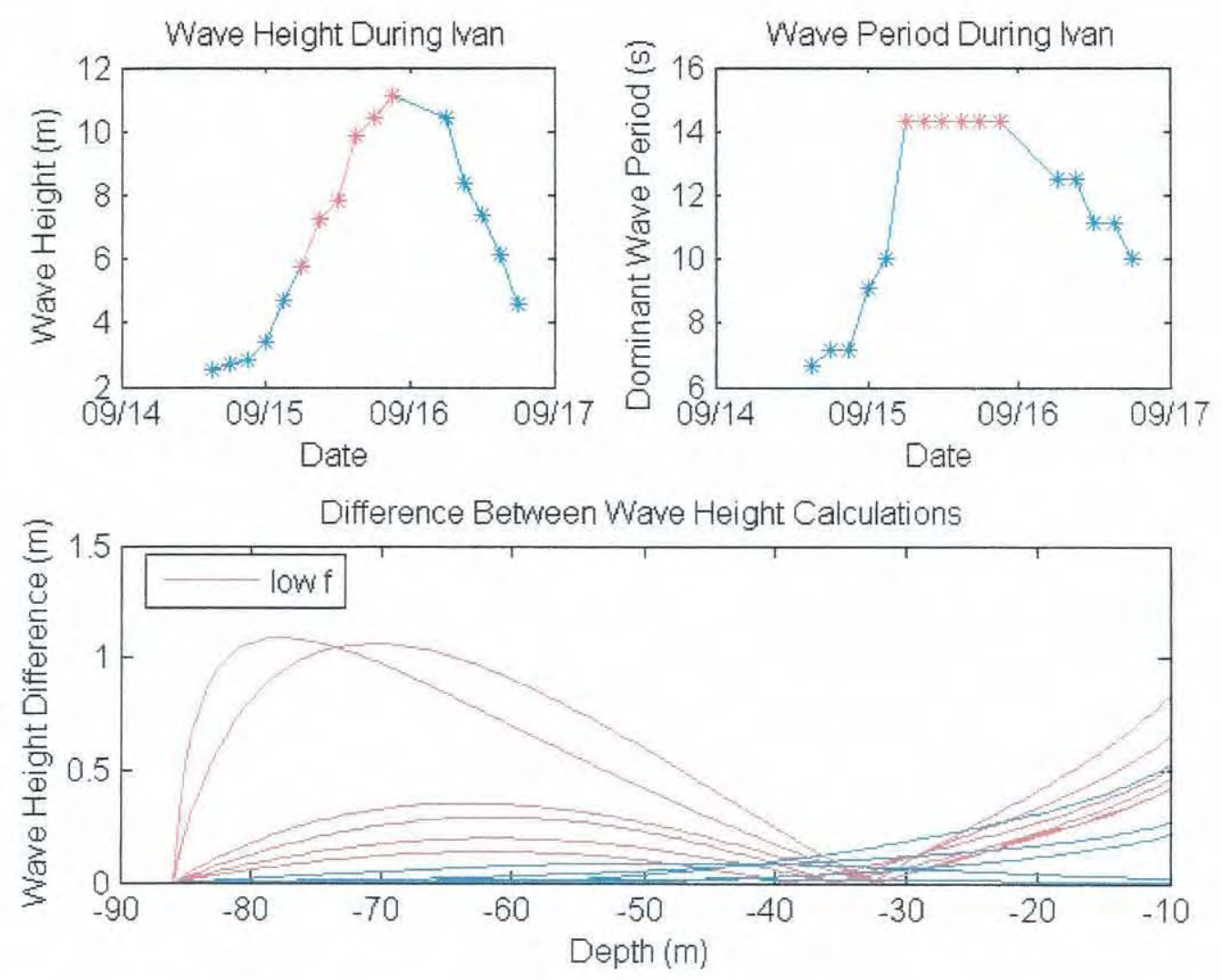

Figure 4-4: Wave height (left) and period (right) during Hurricane Ivan at Site 7 with low frequency waves marked in red. Bottom plot represents the difference between statistical and spectral wave height calculations during the same time period. 
As seen above, the differences are relatively small. In fact, most of the calculations are within $40 \mathrm{~cm}$ of each other. The largest differences occur during long period waves of around $14 \mathrm{~s}$ (marked in red) where the spectrally and statistically calculated wave heights differ by up to $1.1 \mathrm{~m}$. It is expected that the two methods would differ to some extent, as the wave heights calculated from statistics are solved for using a single dominant wave period. At the peak of the storm, the dominant period often underestimates the conditions, as it only accounts for one wave frequency. All frequencies are summed in the spectral calculation, so the resulting wave height is larger.

The calculated wave heights also differ more as the waves travel into shallow water. As depth decreases, high frequency wave components become more and more significant. These are accounted for by the multiple wave frequencies measured in the spectral approach. However, the statistical approach again underestimates the waves by using only one wave frequency to represent the wave field. For this reason, wave heights will be calculated from spectral data in the rest of the study.

\subsection{Wavewatch III Data}

The calculations described above are relatively basic and make certain assumptions that are not realistic. Most importantly, the effects of variable bathymetry and bottom friction are ignored, which are especially significant in shallow water. Also, the wave characteristics determined from combining NDBC Buoy 42039 and Site 7 data are not reliable. As these initialize the above calculations, error in wave predictions is 
unavoidable. Therefore, it is valuable to examine wave data produced by a wave model for the shelf alone, initialized with data from the larger scale WWWIII model.

\subsubsection{Model Description}

A source of deep water wave data is a Wavewatch III run completed by the Naval Post graduate school (NPS) research group. Fabrice Arduin ran a $0.025^{\circ}$ high resolution Wavewatch III run with a high resolution bathymetry grid created by Paul Jessen. The wind field inputted to the model was a gridded surface wind analysis from the NOAA Hurricane Research Division. This wind field defines wind within a square box centered at the eye of the hurricane. The box moves with the hurricane as it continues on its path. All winds outside of the square are set to zero. JONSWAP empirical bottom drag is applied in the model run.

\subsubsection{Comparison of Model Output and Refraction Calculations}

Wavewatch III outputs frequency-directional spectra. In order to compare this data with the significant wave heights calculated from buoy data in the previous section, the energy densities for each frequency and direction were summed using:

$$
H=4 \sqrt{\iint S(f, \theta) \cdot d \theta \cdot d f},
$$


where $d \theta$ is the difference between wave directions, and $d f$ is the bandwidth of each frequency band. The following figure compares these calculated wave heights to the summed frequency-directional spectra outputted by Wavewatch III for specific locations. The plotted wave heights represent wave conditions the morning of September $15^{\text {th }}$ (0000-1200), evaluated every three hours as Hurricane Ivan strengthens.

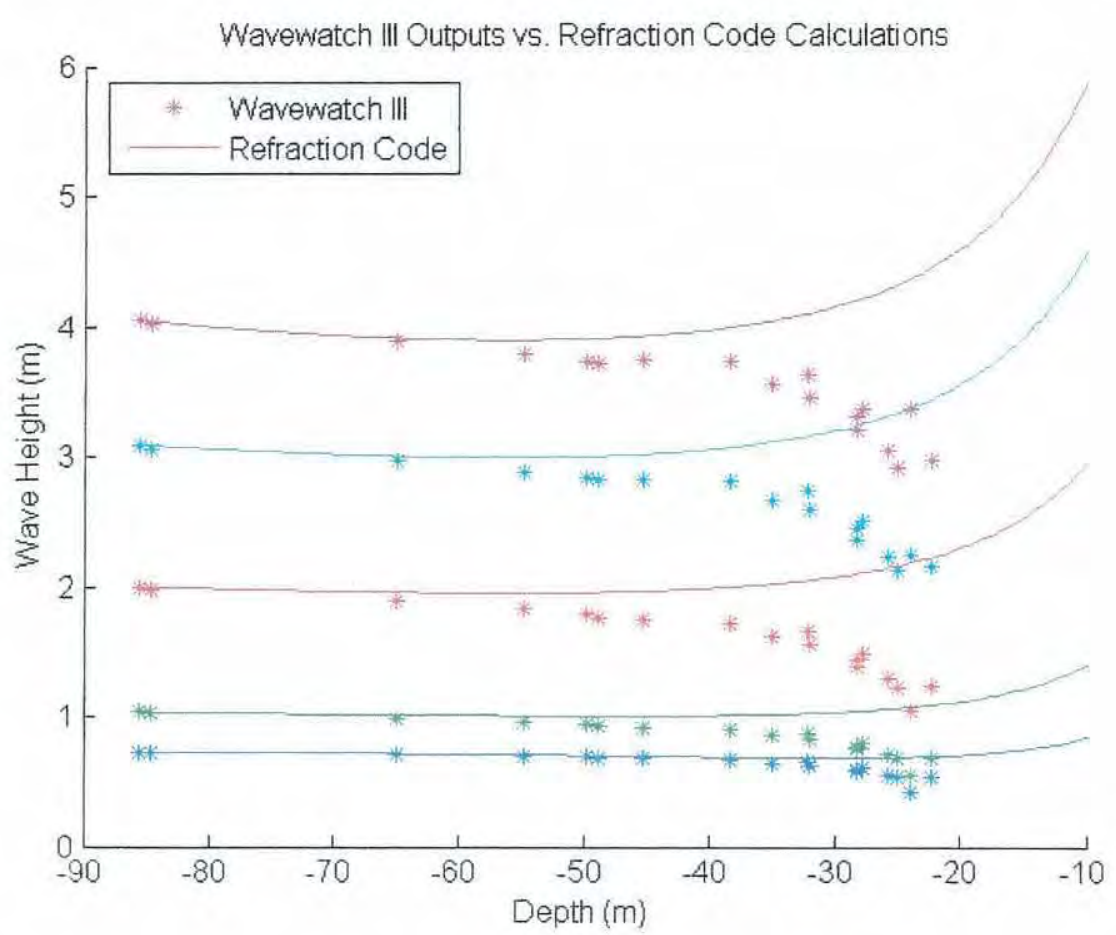

Figure 4-5: Comparison of Wavewatch III and spectral refraction code calculations of wave height during Hurricane Ivan.

Wave heights calculated from the refraction codes are similar to the Wavewatch III outputs in deep water, but the difference between the two increases significantly in shallow water. Wavewatch III heights decrease as water depth decreases, whereas wave heights calculated from the buoys increase rapidly. This is expected, as dictated by the 
shoaling coefficient defined in Equation 4.3. The decrease in water depth causes an unbalanced increase in wave height. The discrepancy between the two calculated wave heights is due to bottom friction being included in the Wavewatch III model. The difference is significant enough that dissipation must be considered when approximating wave propagation. Therefore, in shallow water the output from Wavewatch III is more realistic than the wave heights calculated from propagating the buoy conditions onshore using energy-conserving shoaling and linear wave theory.

\subsubsection{Model Improvements}

The NPS research group completed a second Wavewatch III computation with two significant improvements over the original computation described above. First of all, a new wind field was inputted by combining the $\mathrm{H}$-winds used in the original Wavewatch III computation with operational NCEP winds. Therefore, the wind field input is complete for all areas around the storm. Second, the model was run for an extra day longer to capture the waning stage of Hurricane Ivan. It is especially important for ripple modeling to have a reliable wave field during this time, as relic ripples are often formed during the waning stages of storms. Due to these improvements, the outputs from the second Wavewatch III computations will be used in all further calculations. 


\subsection{SWAN Wave Modeling}

Although the wave heights outputted by Wavewatch III are reasonable, the model is tailored to waves in deeper water. In order to approximate waves near the experiment site more accurately, the waves at USGS Site 7 outputted by Wavewatch III were propagated into shallow water by the SWAN WAVE module as implemented in Delft3D. By running the WAVE module separately, friction parameters could be varied on the shelf where friction is important. As a result, the sensitivity of the resulting ripple predictions to friction could be examined.

\subsubsection{Model Description}

In this study, the Delft3D-WAVE module, created by Delft Hydraulics Inc., is employed to simulate the propagation of short-crested waves from Site 7 to the sidescan sonar collection sites. Given bathymetry and offshore wind and waves, WAVE then solves for wave conditions at a specified location in shallower water. It runs the third generation spectral SWAN model, "Simulating Waves Nearshore," created by DTI. Although WAVE does not allow for non-stationary wave generation, SWAN can be run independently for time-varying 2D spectra.

WAVE was run for a rectangular grid $87.5 \mathrm{~km}$ wide by $125.3 \mathrm{~km}$ long. The bathymetry applied to the area was obtained from the National Geophysical Data Center 
(NGDC). The frequency-directional spectra outputted by Wavewatch III for Site 7 were applied to the southern boundary of the rectangular grid to define spatially uniform wave conditions offshore. These conditions were inputted every three hours from September $13^{\text {th }}$ through September $17^{\text {th }}, 2004$. Wind speed and direction were set to zero, as varying the wind had little effect on the outputted wave heights. Therefore, white-capping, quadruplets, and wind growth were deactivated. However, wave refraction and bottom friction were activated. Collins dissipation values were varied with each model run, ranging from 0.0001 to 0.4 . The model was set to output 2D spectra at 50,30, and 20 meter depths every three hours.

\subsubsection{Comparison of Model Outputs}

The following figures compare significant wave heights outputted by Delft3D to wave height outputs from Wavewatch III, calculated according to the previous chapter's specifications. The Wavewatch III wave heights are outputted at Site M, which is the output location closest to the experiment site (WW3 Site M). Figures 4-6 to 4-8 compare SWAN wave heights according to increasing Collins dissipation parameters of 0.0001 , $0.05,0.4$, respectively. It is important to note that wave heights decrease in shallower water, as expected. However, the magnitudes of these reductions depend on the dissipation parameter. Wave heights from Wavewatch III are always larger than the SWAN results, as the model is for deeper water where the waves are less subject to 
bottom friction. Figure 4-6 plots wave heights calculated by Delft3D with the smallest dissipation parameter.

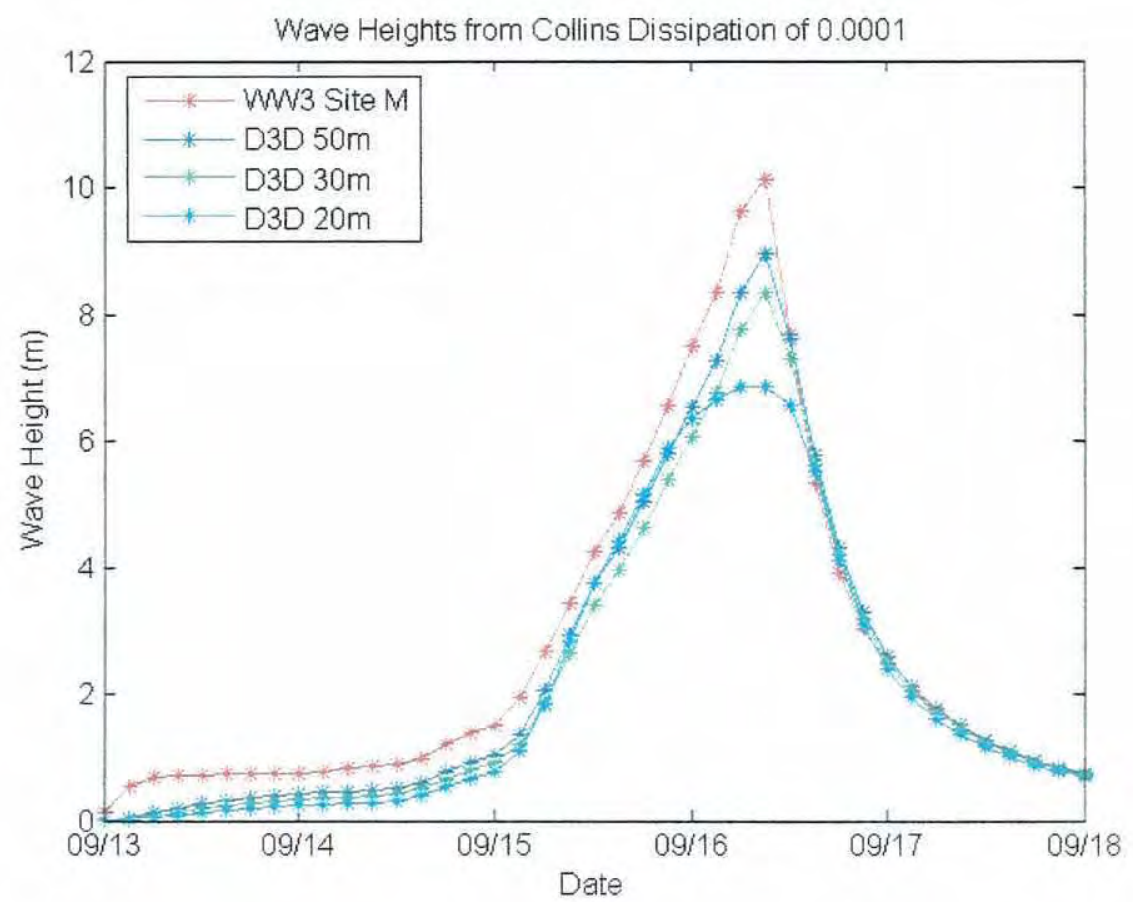

Figure 4-6: Comparison of Wavewatch III wave height output for Site $M$ and Delft3D outputs for $50 \mathrm{~m}, 30 \mathrm{~m}$, and $20 \mathrm{~m}$ depths during Hurricane Ivan using a Collins dissipation of 0.0001.

The wave heights are fairly similar until the peak of Hurricane Ivan, especially for the Delft3D outputs. This is expected, as the dissipation parameter is so small. In Figure 4-7, moderate dissipation reduces wave height significantly. Waves at $30 \mathrm{~m}$ and $20 \mathrm{~m}$ are especially affected by the increased bottom friction. 


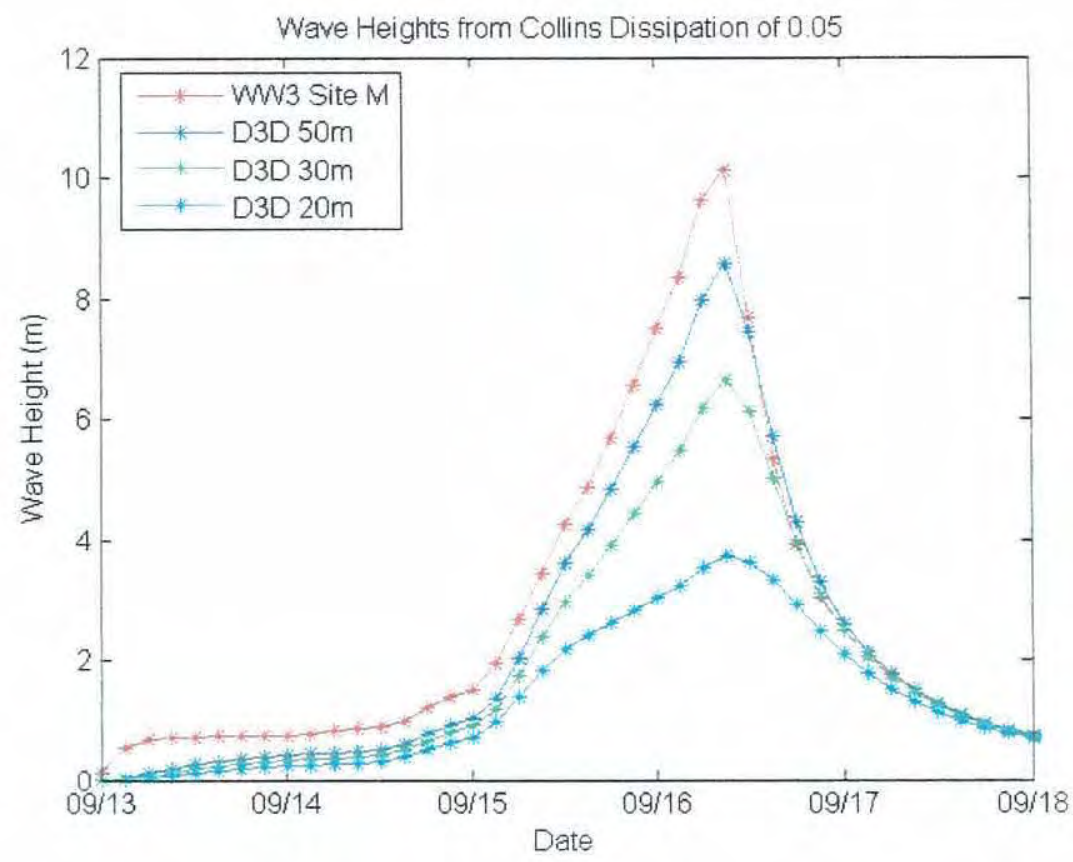

Figure 4-7: Comparison of Wavewatch III wave heights and Delft3D outputs using a Collins dissipation of $\mathbf{0 . 0 5}$.

Figure 4-8 depicts wave heights calculated with the highest Collins dissipation parameter of 0.4 . Wave heights at all three Deflt3D sites are extremely influenced by the strong bottom friction. In fact, the waves at $20 \mathrm{~m}$ barely increase during the hurricane compared to the $7 \mathrm{~m}$ waves when the lowest dissipation parameter is applied. 


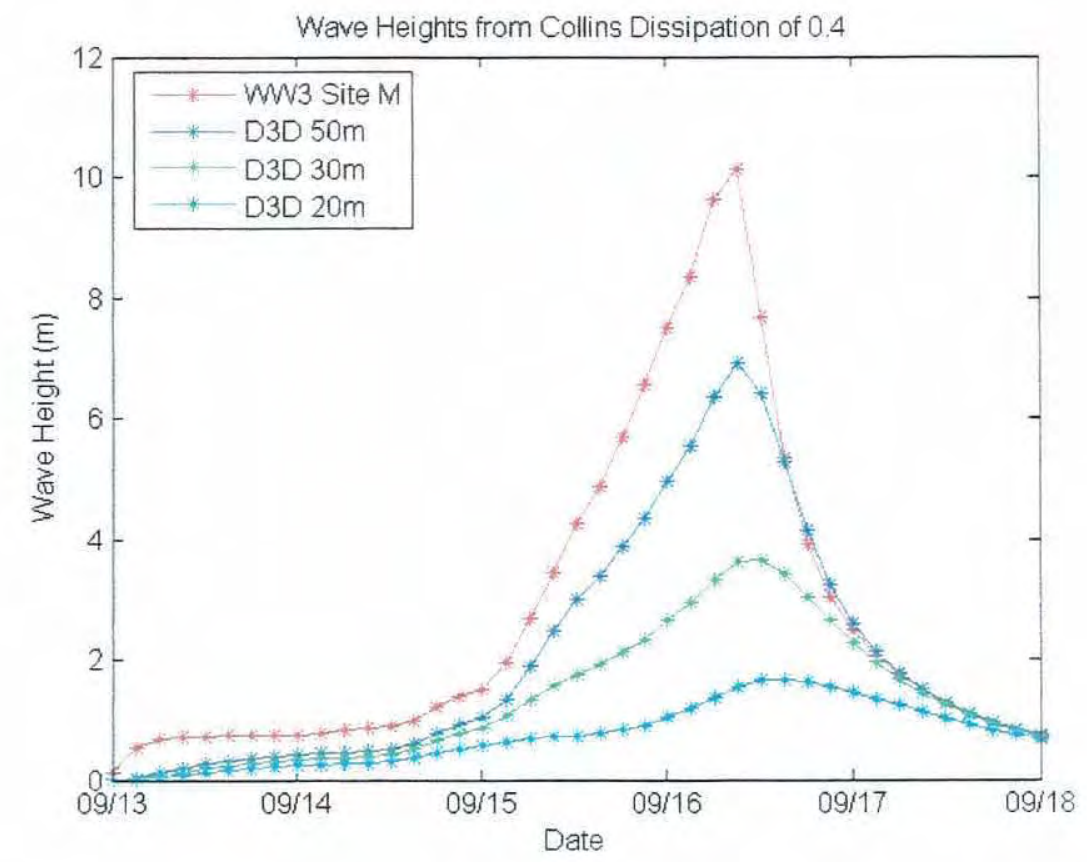

Figure 4-8: Comparison of Wavewatch III wave heights and Delft3D outputs using a Collins dissipation of 0.4 .

Dissipation parameter clearly is important to wave prediction. In order to examine how much dissipation affects ripple wavelength prediction, wave information must be inputted into a model incorporating wave motion at the seabed as well as grain size and dissipation. 


\section{Chapter 5}

\section{Synthesis of Wave and Ripple Analysis and Conclusions}

\subsection{Ripple Prediction}

\subsubsection{Orbital Properties Calculations}

Wave information calculated in the previous section can be used to solve for water motion at the ocean floor. Particle orbital information is extremely important as this motion causes ripples to be formed on the seabed. Orbital diameter, velocity, and period are the three most important inputs into ripple prediction models. To calculate these, the frequency-directional energy density spectra are integrated over all wave directions:

$$
S(f)=\int S(f, \theta) d \theta
$$

Then the dispersion relation is applied to translate the resulting frequency spectra to the seabed:

$$
S(f)_{b e d}=S(f)\left(\frac{1}{\sinh (k h)}\right)^{2}
$$

By integrating the spectra over frequency, orbital diameter can be calculated according to: 


$$
d_{0,1 / 3}=4 \sqrt{\int S(f)_{b e d} d f} .
$$

Orbital velocity can be similarly solved for:

$$
u_{w}=2 \sqrt{\int S(f)_{b e d}(2 \pi f)^{2} d f} .
$$

In order to determine orbital period $T_{0,1 / 3}=1 / f_{r}$, the energy-weighted mean frequency, or radian frequency, is calculated as well:

$$
f_{r}=\frac{\int S(f)_{b e d}(2 \pi f) d f}{\int S(f)_{b e d} d f} .
$$

These three parameters summarize the effects of the surface wave field on the seabed. Figure 5-1 plots the orbital velocities and diameters for a Collins dissipation of 0.05 . The plots are very similar, although with differing magnitudes, and correspond well with Figure 4-7 depicting calculated wave heights for the same dissipation. The values decrease in shallow water and reach their maximums together at the peak of the storm. 

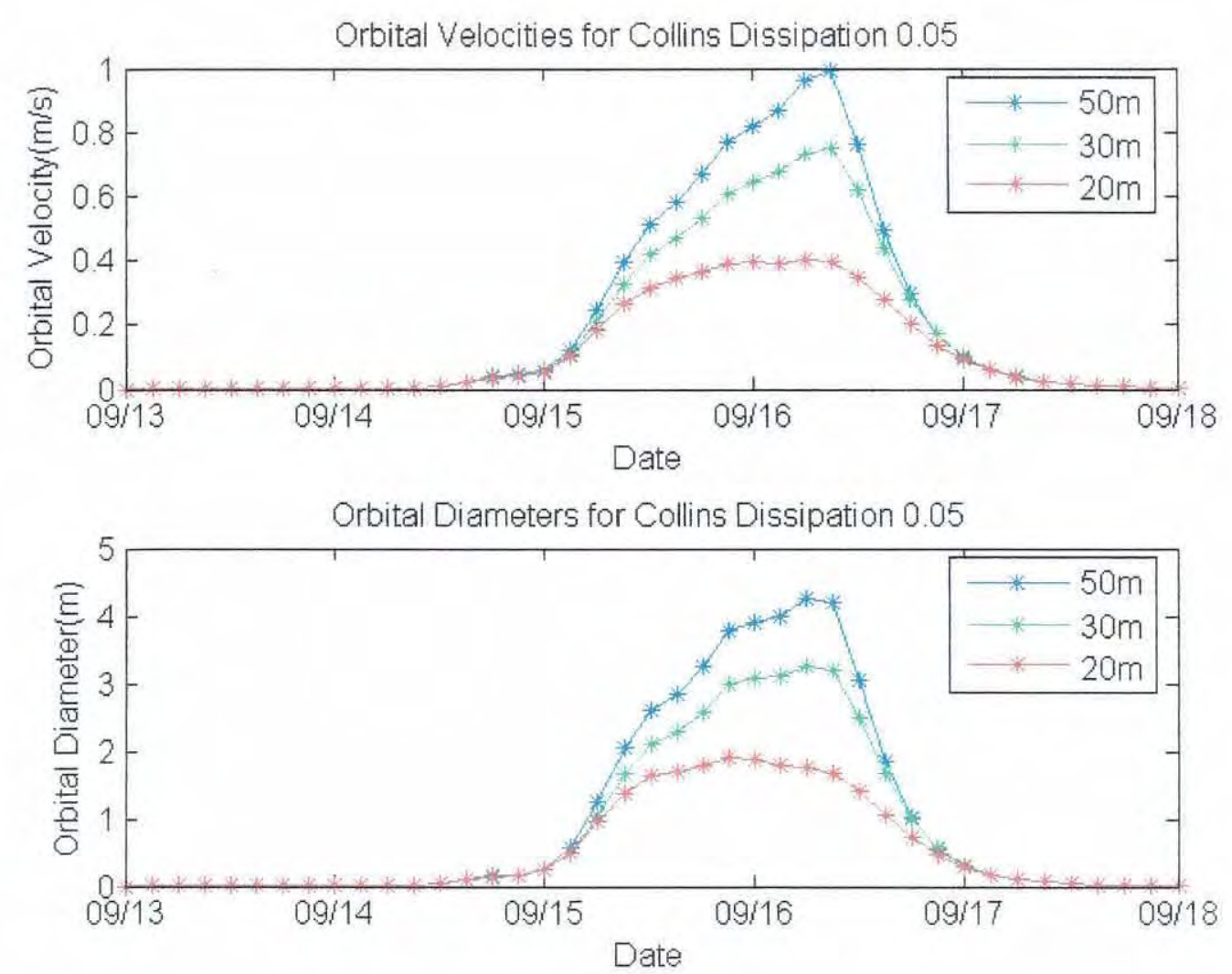

Figure 5-1: Orbital velocities and diameters predicted from a Collins dissipation of 0.05 .

\subsubsection{Ripple Model Explanation}

Traykovski's (Traykovski, 2006) time dependent ripple model was used to predict sand ripple properties from the orbital information calculated above. The model is based on the concept that ripple wavelengths will be proportional to wave orbital diameter until a certain suspension threshold is reached. This threshold is determined from wave velocity and grain size. The following equations summarize the foundation of Traykovski's model: 


$$
\begin{array}{cc}
\lambda_{e q}=0.75 d_{0,1 / 3}=1.5 u_{b, 1 / 3} / f_{r} & u_{b, 1 / 3} \leq 4.2 w_{s} \\
\lambda_{e q}=1.5\left(4.2 w_{s}\right) / f_{r} & u_{b, 1 / 3}>4.2 w_{s}
\end{array} .
$$

In these equations, $w_{s}$ is particle settling velocity, and $f_{r}$ is the radian wave frequency at the seafloor, again calculated from Equation 5.5. Significant wave velocity $\left(u_{\delta, 1 / 3}\right)$ is solved for according to $\left(u_{b, 1 / 3}=2 u_{w, m s}\right)$, where $u_{w, m s}$ is the r.m.s. of measured orbital velocities.

The ripple model applies the sediment continuity equation with a "departure from equilibrium" factor, assuming that the Shields parameter:

$$
\theta_{w}=\frac{\tau_{w, 1 / 3}}{\rho(s-1) g D_{50}}
$$

is calculated from wave stress alone. Wave stress is solved for by

$$
\tau_{w}=\frac{1}{2} \rho_{w} f_{w} u_{b r}^{2},
$$

where $f_{w}$ is the Swart friction factor (Swart, 1974), and roughness is $2.5 D_{50}$. The representative wave velocity $\left(u_{b r}\right)$ is calculated from $u_{b r}=\sqrt{2} u_{w, m s}$. The resulting sediment continuity equation is:

$$
\frac{d \eta(k)}{d t}=\frac{\eta_{e q}(k)-\eta(k)}{T(k)} .
$$

The $(\eta(k))$ terms represent ripple spectral components as a function of wavenumber.

The difference between the components is large when ripples are far from their equilibrium state, and zero when they are at equilibrium. $T(k)$ is the adjustment time scale for each wavenumber and can be solved for according to: 


$$
T(k)=\frac{(1-\phi) \eta_{s} \lambda_{s}}{2 Q}=\frac{(1-\phi) 0.16(2 \pi / k)^{2}}{2 Q}
$$

The term $(1-\phi)$ allows for the porosity of sand in the ripples and is set to 0.35 . The bed transport rate is represented by:

$$
Q=\begin{array}{cc}
\left(\theta-\theta_{\mathrm{c}}\right)^{1.5} / \rho(s-1) g D_{50} & \theta \geq \theta_{\mathrm{c}} \\
0 & \theta<\theta_{\mathrm{c}}
\end{array} .
$$

It is assumed that maximum flux occurs at the crest of the ripple and no flux in the trough.

\subsubsection{Ripple Model Results}

The orbital properties from the SWAN model output, representing the surface wave field, were inputted into the time dependent ripple model to solve for ripple wavelength with varying grain size and dissipation values. Figure 5-2 summarizes the results, with the color-bars representing ripple wavelength. Each subplot represents a different water depth of $50 \mathrm{~m}, 30 \mathrm{~m}$, and $20 \mathrm{~m}$. Dissipation parameter is plotted on the $\mathrm{y}$ axis and grain size on the $\mathrm{x}$-axis. 

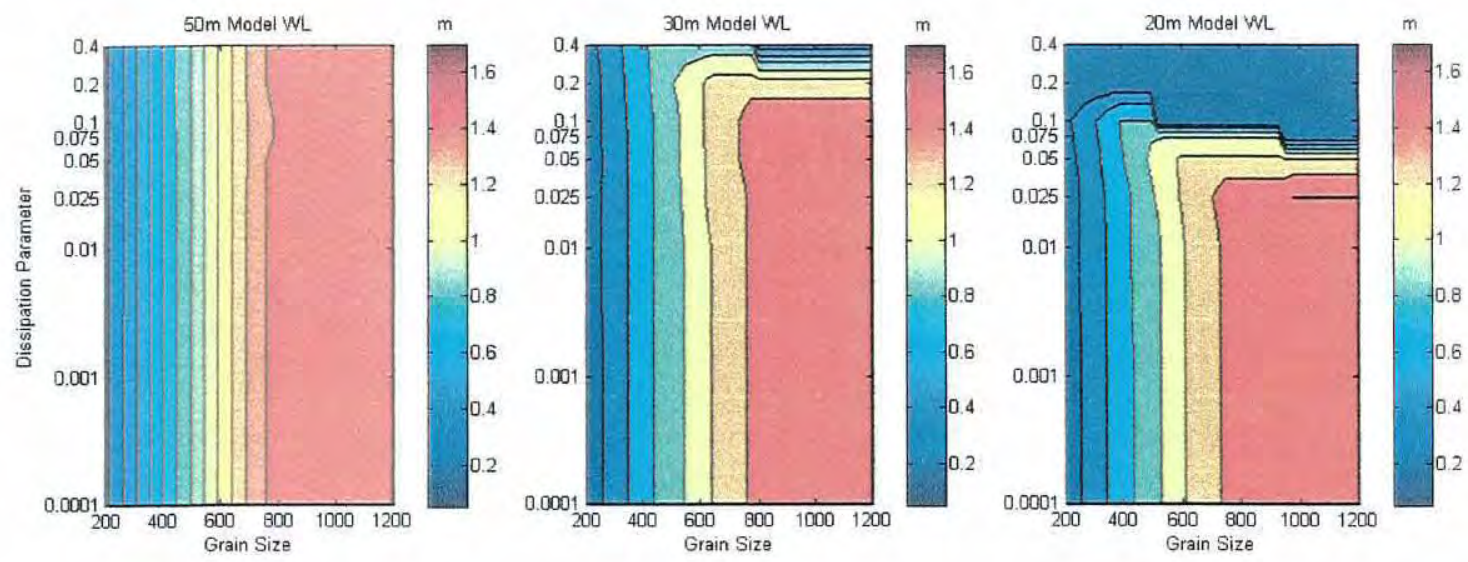

Figure 5-2: Model outputs of ripple wavelength according to grain size and dissipation parameters for $50 \mathrm{~m}, 30 \mathrm{~m}$, and $20 \mathrm{~m}$ depths.

Predicted ripple wavelengths range from 0 to about $1.5 \mathrm{~m}$ and remain relatively constant with respect to dissipation. However, grain size has a large influence on predicted wavelength, especially in deeper water. In order to determine if this trend corresponds with environmental conditions, model outputs must be compared with the ripple wavelengths calculated in Chapter 2.

The following figure plots the difference between model and measured wavelengths for every grain size and dissipation value, similar to the plot above. However, in Figure 5-3, the color bar represents the logarithmic comparison of the observed and model wavelengths according to:

$$
\delta=\log _{10}\left(\lambda_{\text {obs }}-\lambda_{\text {pred }}\right)^{2} .
$$



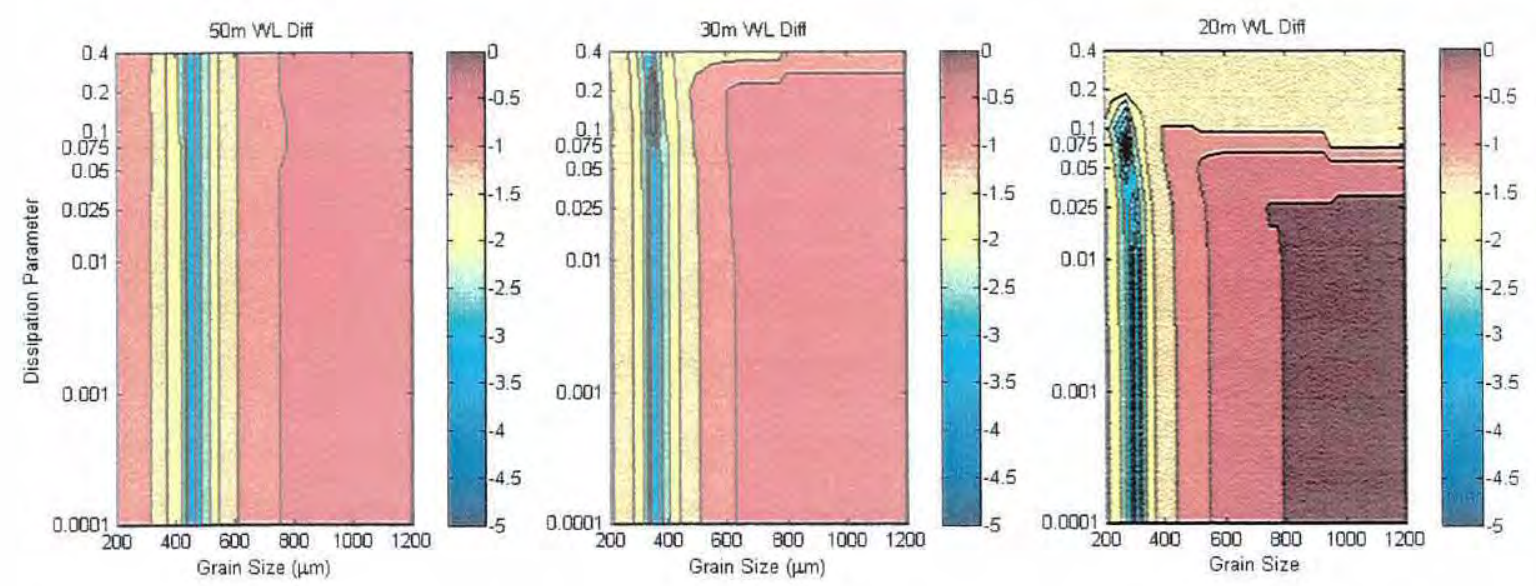

Figure 5-3: Difference in ripple wavelength according to grain size and dissipation parameters for $50 \mathrm{~m}, 30 \mathrm{~m}$, and $20 \mathrm{~m}$ depths.

Wavelength difference remains almost constant as dissipation parameter is varied, despite the large range of values $(0.0001$ to 0.4$)$. On the other hand, small changes in grain size result in large deviations between the observed and model wavelengths. Thus, wavelength is much more sensitive to grain size than dissipation. This conclusion allows the ripple model to be applied in two ways. It can be used to solve for either ripple wavelength or sediment grain size if one of these variables and the surface wave field is known.

For example, in this experiment, ripple wavelength was measured and a reliable wave field was created. In order to match the measured wavelengths, assuming smaller, more realistic dissipation values, grain sizes of $300 \pm 25,350 \pm 25$, and $475 \pm 35 \mu \mathrm{m}$ are required in 20, 30 and 50m water depth respectively. The error estimates on the grains sizes are estimated from \pm one standard deviation in the ripple wavelength measurement 
for each depth. Figure 5-4 plots the results with measured grain sizes recorded near the experiment site from three data sets (SAX04, EXT, and PRS). All points are within 15 $\mathrm{km}$ of an on-offshore transect through the middle of the ripple measurement locations.

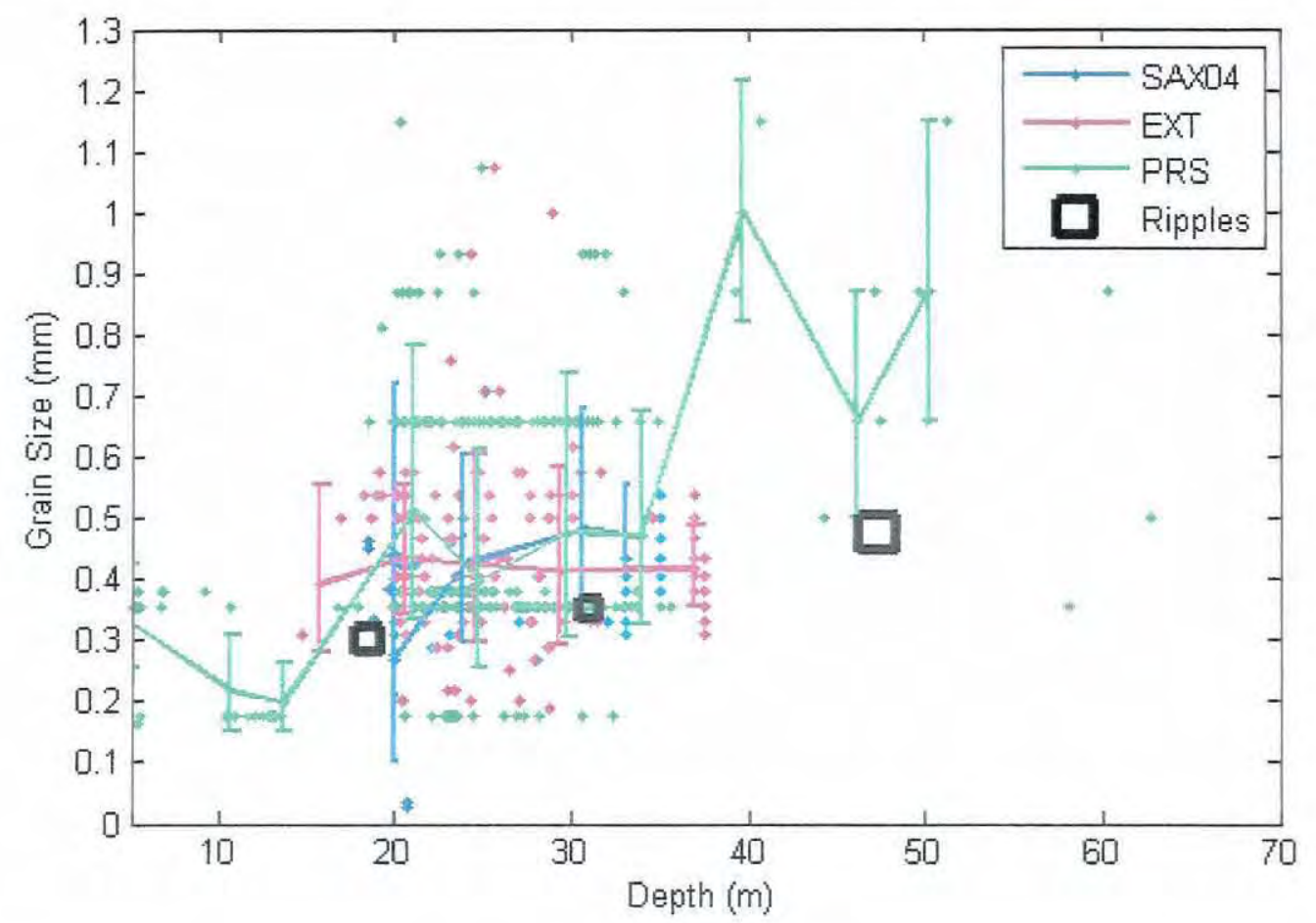

Figure 5-4: Measured grain sizes from 3 databases and grain sizes inferred with ripple model.

Grain sizes labeled "SAX04" were collected by the USGS research group during the experiment. The "EXT" and "PRS" records represent extracted and parsed data from the USGS USSEABED Sediment Database (USSEABED, 2006). Extracted data is numerical analytical data, and is much more precise than the parsed word-based data. Parsed data calculates mean grain size from textual descriptions of the data. Blue magenta and green points with error bars are based on binning the grain size data into 5 
$m$ depth bins and calculating the mean and standard deviation. The inferred grain sizes, marked with black boxes, correspond fairly well with the grain sizes measured near the experiment site, although they tend to be in the lower range of values. The size of the black boxes is equal to error estimates from the ripple measurement standard deviations. It is difficult to compare grain sizes in deeper water because of sparse measurements, but the inferred grain sizes are within the range of measured grain sizes. It can thus be inferred that Traykovski's time dependent ripple model can be applied to solve for either ripple wavelength or grain size, depending on which is known a priori.

\subsection{Conclusions}

\subsubsection{Discussion}

Sand ripples on the west Florida coast were measured with sidescan sonar during the Ripples DRI and SAX04 experiments. The ripple wavelengths calculated from these data are reliable. Agreement with the USGS research group's results increases confidence in the original measurements. The ripples measured in September were created by Hurricane Ivan and were the focus of this study. The second part of this thesis describes the steps taken to obtain the best possible inputs for a ripple model. First, a offshore wave field was obtained from combining Wavewatch III model outputs with wind measurements. There is some directional uncertainty with this wave field because 
Hurricane Ivan's strong winds tampered with buoy measurements, thus the model could not be compared to measurements of direction. However the model should be able to predict fairly realistic directional spectra. The offshore wave field was then inputted into Delft3D, which ran SWAN to solve for waves near the experiment site. The nearshore waves were then used to calculate orbital diameter, velocity, and period at the seabed. When these variables were inputted into the time dependent ripple model, the influence of dissipation and grain size on wavelength could be determined. The results reveal that ripple wavelength is most dependent on grain size.

Because the combined wave and ripple error analysis can solve for either ripple wavelength or grain size depending on which is inputted, the model can be applied in different ways. For example, it might be more cost effective to measure sand ripples with sidescan sonar than to measure grain size with sediment grabs. If wavelength is measured and a reliable surface wave field is available, then a proxy for grain size can be determined. After average grain size is determined for an area, ripple wavelength can easily be calculated at any time as long as wave information is available as well. Because a REMUS carrying a sidescan sonar system is autonomous and relatively easy to transport and launch, ripple wavelength measurements may be less complicated to collect than time intensive sediment grabs. Most importantly, a REMUS can cover a larger amount of area than sediment grabs. However, some concerns are associated with this method. First of all, grain size calculated by the ripple model only gives information about the grain size that controls ripple geometry. This may or may not be the mean 
grain size. Also, a significant amount of analysis is required to achieve a reliable wind field and to calculate ripple wavelength to input into the model.

\subsubsection{Further research}

Further research could be conducted in a couple areas. First, the wave field input into Delft3D can be improved by varying the wave field along the model run's southern boundary. The sensitivity of the predicted ripple wavelength to the input wave field should also be examined. The effect of dissipation on wavelength should be studied more extensively as well. For example, dissipation may be more or less significant on shelves with varying slopes. Flat slopes are expected to have more sensitivity than steep slopes however. As the continental shelf is fairly flat off the west coast of Florida, the conclusion that ripple wavelength is relatively unaffected by dissipation will most likely hold true for most shelves, despite their slopes. Finally, dissipation should be examined as a function of frequency because the ripple model is most sensitive to wave frequencies during a storm's decay. 


\section{Bibliography}

Ardhuin, F., T. G. Drake, et al. (2002). "Observations of wave-generated vortex ripples on the North Carolina continental shelf." Journal of Geophysical Research, C, Oceans 107(10): 14.

Ardhuin, F., W. C. O'Reilly, et al. (2003). "Swell Transformation across the Continental Shelf. Part I: Attenuation and Directional Broadening." Journal of Physical Oceanography 33(9): 1921-1939.

Booij, N., R. C. Ris, et al. (1999). "A third-generation wave model for coastal regions, Part I, Model description and valication." Journal of Geophysical Research, C, Oceans 104(4): 7649-7666.

Briggs, K. B., K. L. Williams, et al. (2002). "Fine-scale sedimentary structure; implications for acoustic remote sensing." Marine Geology 182(1-2): 141-159.

Buczkowski, B. J., J. A. Reid, et al. (2006). "usSEABED: Gulf of Mexico and Caribbean (Puerto Rico and U.S. Virgin Islands) Offshore Surficial Sediment Data Release 2006, Version 1.0." U.S. Geological Survey Data Series 146.

Chotiros, N. P., D. E. Smith, et al. ( 2002). "Refraction and Scattering Into a Sandy Ocean Sediment in the 30-40-kHz Band." IEEE Journal of Oceanic Engineering 27(3): 362-375.

Clifton, H. E. and J. R. Dingler (1984). "Wave-formed structures and paleoenvironmental reconstruction." Marine Geology 60(1-4): 165-198.

Dean, R. G. and R. A. Dalrymple (1991). Water Wave Mechanics for Engineers and Scientists. Singapore, World Dcientific Publishing Company, Inc.

Divins, D. L. and D. Metzger, NGDC Coastal Relief Model, April 25, 2006, http://www.ngdc.noaa.gov/mgg/coastal/coastal.html.

Grant, W. D. and O. S. Madsen (1986). "The Continental-Shelf Bottom Boundary Layer." Annual Review of Fluid Mechanics 18: 265-305.

Hanes, D. M., V. Alymov, et al. (2001). "Wave-formed sand ripples at Duck, North Carolina." Journal of Geophysical Research, C, Oceans 106(10): 22,575-22,592.

Herbers, T. H. C., E. J. Hendrickson, et al. (2000). "Propagation of swell across a wide continental shelf." Journal of Geophysical Research 105(19): 729-737. 
Naval Office of Information, (2005). Statement of Rear Admiral Jay M. Cohen, Chief of Naval Research before the Terrorism, Unconventional Threats and Capabilities Subcommittee of the House Armed Services Committee on Defense Science and Technology in support of the War on Terrorism, Transformation, and Beyond.

Jackson, D. R., K. L. Williams, et al. (2002). "High-frequency subcritical acoustic penetration into a sandy sediment." Ieee Journal of Oceanic Engineering 27(3): 346-361.

Jetté, C. D. and D. M. Hanes (1997). "High-resolution sea-bed imaging: an acoustic multiple transducer array." Measurement Science \& Technology 8: 787-792.

Kundu, P. K. and I. M. Cohen (2004). Fluid Mechanics. Oxford, Elsevier Academic Press.

Madsen, O. S., Y.-K. Poon, et al. (1988). Spectral Wave Attenuation by Bottom Friction: Theory. Proceedings of the 21st International Conference on Coastal Engineering, Am. Soc. of Civ. Eng., New York.

Newman, J. N. (1977). Marine Hydrodynamics. Cambridge, The MIT Press.

Nielsen, P. (1981). "Dynamics and geometry of wave-generated ripples." Journal of Geophysical Research, C, Oceans 86: 6467-6472.

Pond, S. and G. L. Pickard (1983). Introductory Dynamical Oceanography. Oxford, Butterworth-Heinemann.

Schmidt, H. and J. Lee (1999). "Physics of 3-D scattering from rippled seabeds and buried targets in shallow water." Journal of the Acoustical Society of America 105(3): 1605-1617.

Swart, D. H. (1974). Offshore sediment transport and equilibrium beach profiles. Delft Hydraulics Laboratory Publ. No. 131: 302.

Open University Course Team, (1999). Waves, Tides, and Shallow-Water Processes. Oxford, Butterworth-Heinemann Ltd.

Traykovski, P., A. E. Hay, et al. (1999). "Geometry, migration, and evolution of wave orbital ripples at LEO-15." Journal of Geophysical Research, C, Oceans 104(1): 1505 1524.

Traykovski, P., M. D. Richardson, et al. (In Press, 2006). "Mine Burial Experiments at the Martha's Vineyard Coastal Observatory." IEEE Journal of Oceanic Engineering. 
Wiberg, P. L. and C. K. Harris (1994). "Ripple geometry in wave-dominated environments." Journal of Geophysical Research, C, Oceans 99(1): 775-789.

Young, I. R. (1999). Wind Generated Ocean Waves. Amsterdam, Elsevier. 